INSTITUTO DE PESQUISAS ENERGÉTICAS E NUCLEARES

Autarquia Associada à Universidade de São Paulo

ESTUDOS DE REMOÇÃO DE ELEMENTOS INORGÂNICOS E DEGRADAÇÃO

DE COMPOSTOS ORGÂNICOS POR RADIAÇÃO GAMA EM

ÓLEOS LUBRIFICANTES USADOS

MARCOS ANTONIO SCAPIN

Tese apresentada como parte dos requisitos para a obtenção do Grau de Doutor em Ciências na Área de Tecnologia Nuclear - Materiais.

Orientadora:

Profa. Dra. Ivone Mulako Sato

SÃO PAULO

2008 
Dedico este trabalho aos meus pais, Odila e Wilson, aos meus sogros, Irene e Ortis que com bastante carinho e compreensão me apoiaram em tudo. 
A minha esposa Valdirene e minha filha Mariane por todo seu amor, companheirismo e abnegação. 


\section{Agradecimentos}

Primeiramente agradeço a Deus por tudo.

À Dra. Ivone Mulako Sato, que acreditou na minha capacidade de desenvolver este trabalho e ajudou a torná-lo realidade. Agradeço ainda pelas críticas e opiniões sempre muito valiosas para o meu crescimento profissional.

À Dra. Vera Lucia Ribeiro Salvador, pela imensa ajuda em todos os aspectos, amizade e carinho.

À Dra. Maria Aparecida Faustino Pires, Gerente do Centro de Química e Meio Ambiente (CQMA) pelo apoio e incentivo para a realização deste trabalho.

À Dra. Celina Lopes Duarte pela confiança, amizade e apoio irrestrito.

Ao Instituto de Pesquisas Energéticas e Nucleares pela oportunidade

À Eng ${ }^{a}$ Elizabeth Somessari e ao Eng ${ }^{\circ}$ Carlos Gaia, responsáveis pelo irradiador gama de Cobalto-60, pela realização das irradiações e o carinho que sempre me receberam.

Ao Dr. José Oscar Willian V. Bustillos pela realização das análises orgânicas por CG/MS, pelas valiosas trocas de idéias e pela amizade.

À Dra. Denise Alves Fungaro, pela especial gentileza em permitir a utilização do espectrofotômetro para a realização de análises.

$E$ a todos os amigos que direta ou indiretamente se fizeram presente durante a realização deste trabalho. 


\title{
ESTUDOS DE REMOÇÃO DE ELEMENTOS INORGÂNICOS E DEGRADAÇÃO DE COMPOSTOS ORGÂNICOS POR RADIAÇÃO GAMA EM
}

\author{
ÓLEOS LUBRIFICANTES USADOS
}

\author{
Marcos Antonio Scapin
}

\section{RESUMO}

Os óleos lubrificantes automotivos durante o seu uso sofrem degradação parcial de compostos orgânicos e incorporam elementos inorgânicos indesejáveis. Estas substâncias tornam o óleo lubrificante usado classificado como perigoso e altamente tóxico. Assim, no que diz respeito à conservação ambiental, o consenso mundial é que a melhor solução para os óleos lubrificantes usados objetive no tratamento para a sua reutilização. Dentro deste contexto e visando o uso de uma tecnologia alternativa, neste trabalho foi proposto um estudo sobre a eficiência e a viabilidade técnica do processo de oxidação avançada (POA) por radiação gama para o tratamento de óleo lubrificante automotivo usado. Amostras de óleo lubrificante usado foram diluídas em concentrações variadas com peróxido de hidrogênio e água Milli-Q. Estas amostras foram submetida a um irradiador de Cobalto-60, tipo Gammacell, com as doses absorvidas de 100, 200 e 500 kGy. Os resultados das análises inorgânicas por fluorescência de raios $X$ (WDXRF) mostraram que o tratamento proposto permite a remoção de elementos inorgânicos, principalmente enxofre, cálcio, ferro e níquel em níveis aceitáveis pela legislação ambiental para reuso destes óleos. Os resultados por cromatografia gasosa (CG/MS) mostraram que este tratamento, também, promove a degradação dos compostos orgânicos, formando principalmente, os compostos tridecano, 2-metil-naftaleno, trietilamina e uréia-tetrametil, os quais são de grande aplicação industrial. A análise multivariada, análise de Cluster (CA), confirmou que a aplicação POA é um tratamento promissor e viável para o reuso de óleo lubrificante usado. 


\title{
INORGANIC ELEMENTS AND ORGANIC COMPOUNDS DEGRADATION STUDIES BY GAMMA IRRADIATION IN
}

\author{
USED LUBRICATING OILS
}

\author{
Marcos Antonio Scapin
}

\begin{abstract}
The automotive lubricating oils have partial degradation of organic compounds and addition of undesirable inorganic elements, during its use. These substances classify the used lubricating oils as dangerous and highly toxic. According to global consensus, concerning the environmental conservation, the best is to perform a reuse treatment of these lubricating oils. For this purpose, the uses of an alternative and effective technology have been sought. In this work, the efficacy and technical feasibility of the advanced oxidation process (AOP), by gamma radiation, for used automotive lubricating oil treatment has been studied. Different quantities of hydrogen peroxide and water Miilli-Q were added to oil samples. They were submitted to the Cobalt-60 irradiator, type Gammacell, with 100, 200 and 500 kGy absorbed doses. The inorganic analysis by X-ray fluorescence (WDXRF) showed inorganic elements removal, mainly to sulphur, calcium, iron and nickel elements at acceptable levels by environmental protection law for oils reusing. The gas chromatography (GC/MS) analysis showed that the advanced oxidation process promotes the organic compounds degradation. The main identified compounds were tridecane, 2-methyl-naphthalene, and trietilamina-tetramethyl urea, which have important industrial applications. The multivariate analysis, Cluster Analysis (CA), showed that advanced oxidation process application is a viable and promising treatment for used lubricating oil reusing.
\end{abstract}




\section{SUMÁRIO}

1. INTRODUÇÃO

1.1 Conceituando reciclagem e reutilização...................................................3

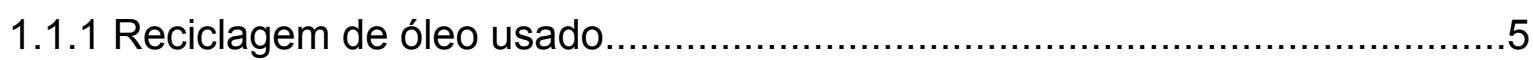

1.1.2 Descrição do processo corrente de re-refino de óleo usado.......................8

1.1.3 O mercado do óleo lubrificante e o re-refino.........................................13

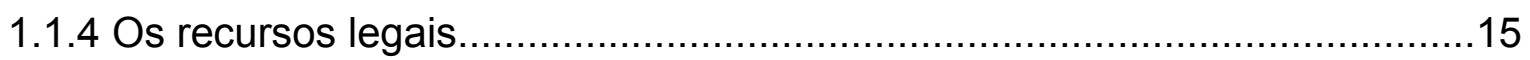

1.1.5 Panorama da utilização de óleo usado no Brasil....................................17

1.1.6 Principais empresas de re-refino de óleo usado no Brasil.........................18

1.1.7 Processos avançados para o tratamento e recuperação de óleo usado......20

1.1.8 Processos de oxidação avançada e suas aplicações ambientais................22

1.2 Fundamentos sobre interação da radiação ionizante com a matéria..............26

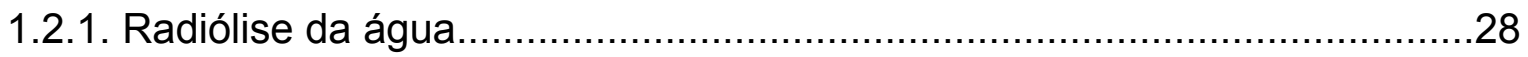

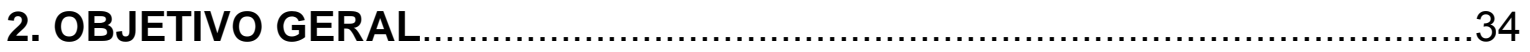

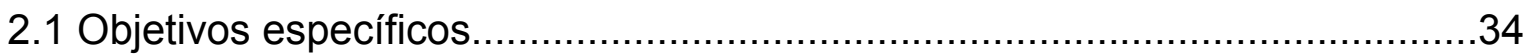

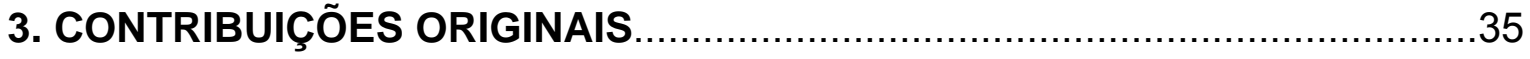

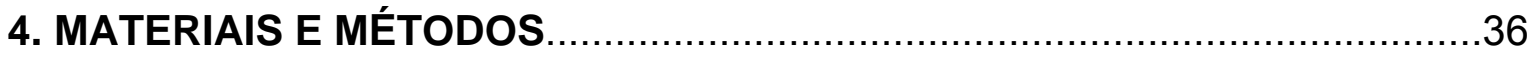

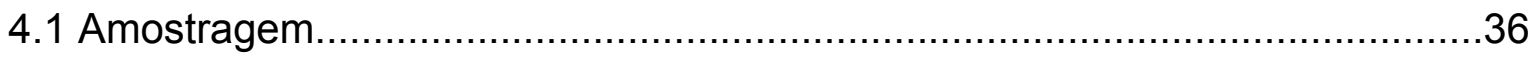

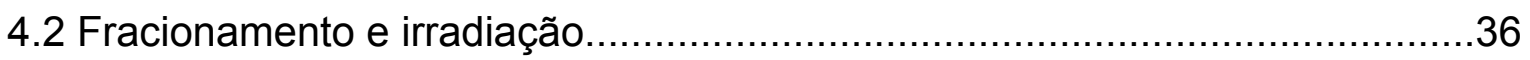

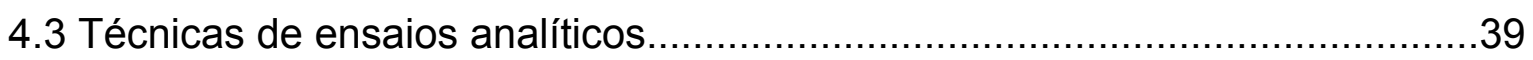

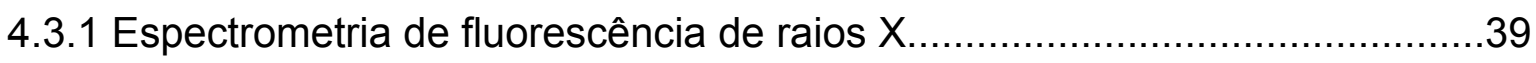

4.3.2 Método de parâmetros fundamentais (FP) .....................................40 
4.3.3 Preparação de amostras para análises por WDXRF.

4.3.4. Cromatografia gasosa associada à espectrometria de massa (GC/MS).....47

4.3.5. Cromatografia gasosa com detector por ionização de chama (GC/FID).....48

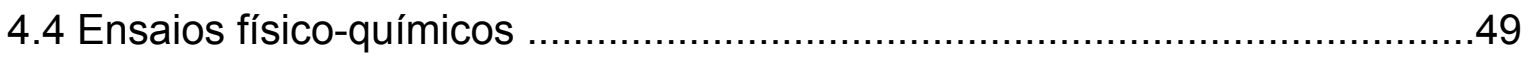

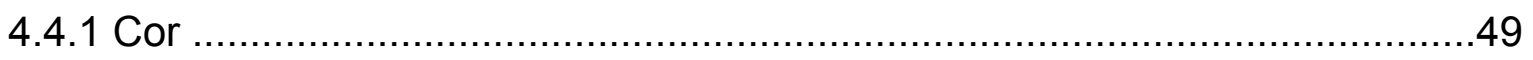

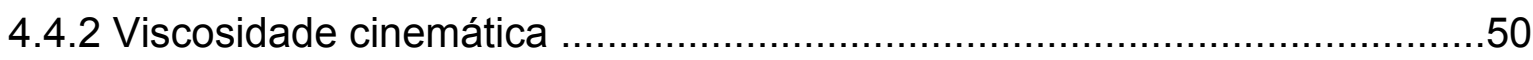

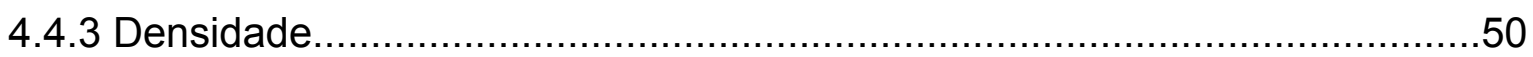

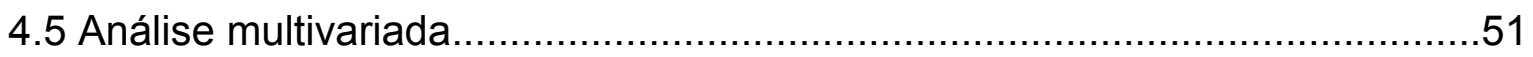

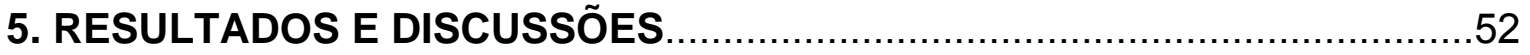

5.1 Validação da metodologia para amostras na fase orgânica.............................52

5.2 Validação da metodologia para amostras na fase aquosa.................................54

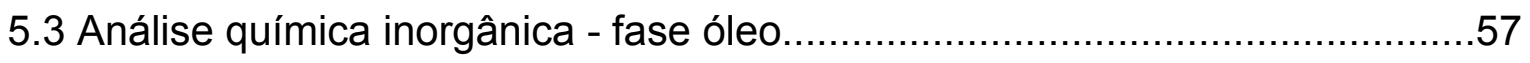

5.3.1 Determinação do nível de remoção dos elementos inorgânicos...................57

5.4 Análise química inorgânica - fase aquosa..................................................64

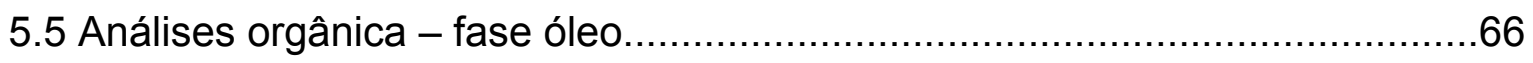

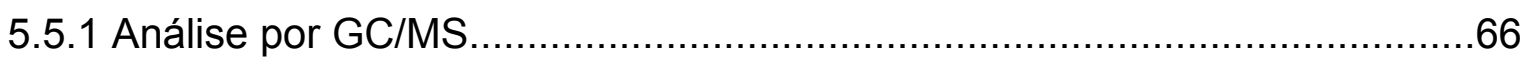

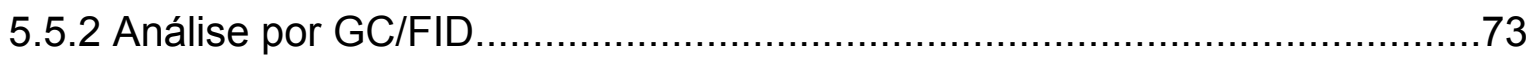

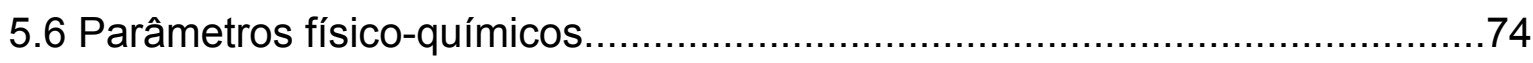

5.6.1 Cor

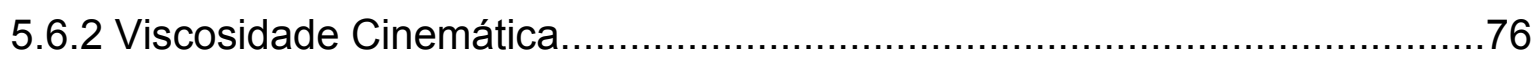

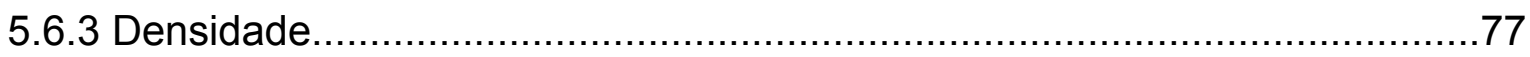

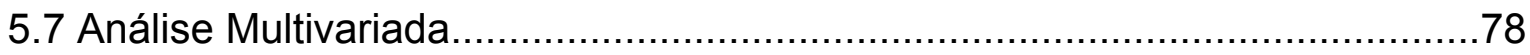

6. CONCLUSÕES

APENDICE A 
APENDICE B

APENDICE C

APENDICE D

APENDICE E

APENDICE F

APENDICE G

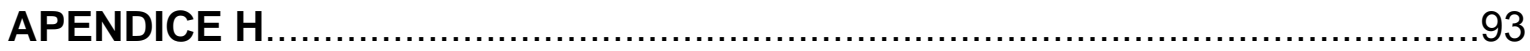

ANEXO A

ANEXO B

ANEXO C

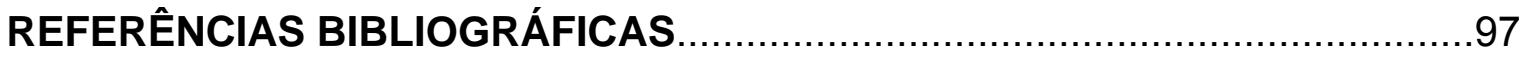

\section{LISTAS DE FIGURAS}

FIGURA 1 - Esquema do processo de desidratação do óleo usado. 10

FIGURA 2 - Esquema do processo de destilação flash.

FIGURA 3 - Esquema do processo de desasfaltamento...................................11

FIGURA 4 - Esquema do processo desulfonação..............................................12

FIGURA 5 - Esquema do processo de clarificação e neutralização.......................12

FIGURA 6 - Principais reações primárias formada pela ação da radiação ionizante na molécula de água....................................................30

FIGURA 7 - Etapas de fracionamento e irradiação.................................................38

FIGURA 8 - Etapas de preparação de amostras na fase óleo...............................44

FIGURA 9 - Etapas de preparação de amostras na fase aquosa.........................47 
FIGURA 10 - Valores de Z-score calculados para o SRM 1084

FIGURA 11 - Valores de Z-score calculados para o SRM ALFA AESAR (stock

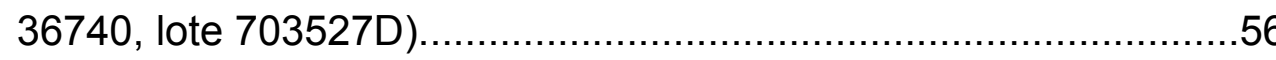

FIGURA 12 - Nível de remoção percentual para as amostras do Grupo A..........60

FIGURA 13 - Nível de remoção percentual para as amostras do Grupo B..........61

FIGURA 14 - Nível de remoção percentual para as amostras do Grupo C..........62

FIGURA 15 - Nível de remoção percentual para as amostras do Grupo D..........64

FIGURA 16 - Cromatograma GC/MS para as amostras PRC, A1, C4 e D4.........67

FIGURA 17 - Cromatograma GC/MS no tempo de retenção de 6,3 a 8,5 min.....68

FIGURA 18 - Cromatograma GC/MS no tempo de retenção de 8,1 a 10,3 min...69

FIGURA 19 - Cromatograma GC/MS no tempo de retenção de 10,0 a 12,0 min.70

FIGURA 20 - Cromatograma GC/MS no tempo de retenção de 12,7 a 14,7 min.71

FIGURA 21 - Cromatograma GC/MS no tempo de retenção de 14,8 a 30,0 min.72

FIGURA 22 - Intensidade de sinal relativa (\%) dos compostos orgânicos determinados por GC/FID......................................................

FIGURA 23 - Espectro de absorção UV próximo para as amostras PRC, A1,

B4, C4 e D4 .75

FIGURA 24 - Variação da viscosidade cinemática para as amostras PRC, A1,

$\mathrm{B} 4, \mathrm{C} 4$ e D4 .76

FIGURA 25 - Variação da densidade para as amostras PRC, A1, B4, C4 e D4.

FIGURA 26 - Diagrama de variáveis, método de Ward, distância Euclidiana .....79 


\section{LISTAS DE TABELAS}

TABELA 1 Panorama sobre consumo e destino de volumes de óleos (milhões de

litros/ano) de alguns países latino-americanos.

TABELA 2 - Litros de Óleo lubrificante, participação pelo uso e frota de veículos em cinco países (2001)

TABELA 3 - Potencial de oxidação de alguns elementos, compostos e radicais livres

TABELA 4 - Valores determinados e certificados, DPR\%, ER\% e LQ para o material de referência certificado SRM 1084.

TABELA 5 - Valores determinados e certificados, DPR\%, ER\% e LQ para o material de referência ALFA AESAR (stock 36740, lote 703527D),

TABELA 6 - Concentração elementar $\left(\mu \mathrm{g} \mathrm{g}^{-1}\right)$ e NR\% para as amostras do grupo

A, B, C, D e PRC para diferentes doses de irradiação. .58

TABELA 7 - Valores calculados (amostras C-D1 e C-D4) e determinados (amostras E-D1 e E-D4) dos elementos químicos na fase aquosa....65 


\section{INTRODUÇÃO}

Os óleos lubrificantes representam cerca de $2 \%$ dos derivados do petróleo e são utilizados em fins automotivos e industriais. De acordo com as suas aplicações, eles recebem aditivos (compostos orgânicos e/ou inorgânicos) em sua formulação de modo a atender aos requisitos necessários às diferentes aplicações a que se destinam (ANP, 1999; CEMPRE, 2007).

Os lubrificantes automotivos representam $75 \%$ do consumo nacional e requerem aditivos que tenham a função antioxidante, dispersante e detergente. Os mais utilizados são compostos organometálicos sulfonados, dietilcarbamatos, dietilfosfato de $\mathrm{Fe}, \mathrm{Zn}, \mathrm{Cd}$ e/ou $\mathrm{Bi}$, acetilcetonato de $\mathrm{Ti}, \mathrm{Mn}$, $\mathrm{Fe}$, Co e/ou $\mathrm{Ni}$ e alquil aril dietilfosfato de $\mathrm{Ca}, \mathrm{Fe}, \mathrm{Ni}, \mathrm{Zn}, \mathrm{Ag}, \mathrm{Cd}$, Sb, Pb e/ou Bi (Sychra, et al., 1981; CEMPRE, 2007).

Segundo o Conselho Nacional do Meio Ambiente (CONAMA, 2005), os óleos lubrificantes automotivos durante o seu uso são parcialmente degradados e apresentam em sua composição, compostos oxigenados (ácidos orgânicos e cetonas), compostos aromáticos polinucleares de viscosidade elevada (potencialmente carcinogênicos), resinas, vernizes, aditivos não consumidos totalmente, metais do desgaste dos motores, poeira e outras impurezas.

Os produtos de degradação e as impurezas inorgânicas classificam os óleos lubrificantes usados como perigosos e altamente tóxicos. Assim, é proibido qualquer descarte de óleo usado em solos, águas superficiais e subterrâneas, sistemas de esgoto e evacuação de águas residuais ou qualquer forma de eliminação que cause a contaminação atmosférica superior ao nível estabelecido na legislação de proteção ambiental (ABNT, 1987; CETESB, 2003; CONAMA, 2005). 
Os estudos mais recentes mostram que apenas um litro de óleo lubrificante usado pode contaminar a potabilidade de aproximadamente um milhão de litros de água e criar uma película que impede a aeração de aproximadamente mil metros quadrados de superfície de um corpo d'água, causando sérios danos à fauna e à flora aquática (Viveiros, 2000; Magalhães et al.,2007).

Dentro deste contexto, o remanejo de óleos usados, assim como de outros resíduos perigosos, deve partir do pressuposto de que é imperativo reciclar tudo o que seja possível e, somente em instância de impossibilidades, o resíduo deve ser eliminado por queima ou incineração (Magalhães et al.,2007).

Considerando este pressuposto, as diretrizes de remanejo de óleos usados devem estar fundamentadas, prioritariamente, nas seguintes diretrizes (Azevedo, 2002; Medina \& Gomes, 2001; Ross et al., 2003; Magalhães et al.,2007):

- $\quad$ Prevenção: redução do volume de resíduos produzidos na fonte, utilizando produtos alternativos de menor impacto ambiental;

- $\quad$ Revalorização dos resíduos: priorização para sua utilização por meio da reciclagem ou reutilização e

- Tratamento: utilização de processo físico, químico ou biológico dos resíduos, visando sua eliminação, se possível com o aproveitamento de energia.

Inserida na perspectiva de interesse político, social, comunitário e ambiental, a reciclagem é a alternativa adequada para o processamento de resíduos de óleos não consumidos. Essa atividade demonstra possuir uma viabilidade econômica, conforme os seguintes objetivos (Azevedo, 2002; CEMPRE, 2007; Magalhães et al.,2007): 
- $\quad$ Reduzir a contaminação ambiental;

- $\quad$ Aumentar a vida útil das reservas naturais de petróleo com a conseguinte economia de matérias prima não renováveis;

- Reduzir o consumo de energia (no processo de reciclagem, o consumo de energia é cerca de $20 \%$ da energia na produção primária);

- $\quad$ Trazer economia de divisas com a diminuição das importações;

- Gerar impostos e empregos com o manejo de materiais aparentemente inadequados.

\subsection{Conceituando reciclagem e reutilização}

A palavra reciclar significa separar ou extrair materiais do fluxo de dejetos de um processo e acondicioná-los para sua comercialização, de modo que possam ser usados como matérias primas em substituição a materiais virgens (Magalhães et al.,2007).

A reciclagem é considerada como uma opção a ser incentivada amplamente devido aos seus benefícios ambientais na mitigação da escassez de recursos naturais virgens e alteração de ecossistemas, na redução da demanda de disposição de resíduos e na diminuição de consumo de energia (Craighill et al., 1996; Magalhães et al.,2007). 
As formas de reciclagem mais utilizadas são: a energética, a química, a mecânica e a reutilização industrial (Medina \& Gomes, 2001; Magalhães et al.,2007).

A reciclagem energética tem estreita relação com a incineração, é realizada a partir de uma instalação de combustão de resíduos; contudo se difere da usina de incineração convencional por produzir energia (eletricidade e calefação), que pode ser vendida ou reutilizada para abastecer processos. O uso deste tipo de reciclagem pode ser bastante vantajoso, por prover certo grau de auto-suficiência energética. Porém, tem como desvantagem a emissão de poluentes na atmosfera. Essa desvantagem pode ser minimizada com medidas previamente calculadas para o tratamento do resíduo específico. Um exemplo bem sucedido deste processo é a reciclagem de pneus.

A reciclagem química visa recuperar compostos químicos, que deram origem aos materiais plásticos ou seus compósitos. Isso é possível com a quebra parcial ou total das moléculas dos resíduos plásticos, selecionados e limpos, por meio de reações químicas. Os materiais obtidos exigem tratamento dispendioso na purificação final. No Brasil, a reciclagem química é feita para polimetilmetacrilato (PMMA), politereftalato de etila (PET), pára-choques de automóveis (PPE, PA, PC), sistemas de freios (ABS) e tanques de combustível (PE). O objetivo da recuperação dos compostos e substâncias químicas é reutilizá-los como matéria prima secundária na produção de novos plásticos (Medina et al., 2001; Magalhães et al.,2007).

A reciclagem mecânica, segundo Medina \& Gomes (2001), consiste na redução de tamanho e re-processamento dos materiais, transformando-os em matéria prima secundária. Esse tipo de reciclagem finaliza o ciclo de reciclagem de um produto, onde ele pode voltar a ser utilizado como matéria prima para gerar o mesmo produto ou um novo produto (Magalhães et al.,2007). 
A reutilização industrial ou de materiais, no sentido amplo, corresponde à retirada de partes, ou peças de um produto, com nenhuma ou pouca alteração para um novo uso, conforme Medina \& Gomes (2001). Exemplo de reutilização são os pneus, que podem ser recauchutados algumas vezes antes de serem considerados inadequados para rodagem. Ainda assim, estes pneus podem ser utilizados nos outros tipos de reciclagem, como por exemplo, constituinte de asfalto para a pavimentação de ruas e rodovias. Peças de automóveis sinistrados não danificadas podem ser recolocadas em outros veículos, outro exemplo de reutilização industrial (Magalhães et al.,2007).

Um ponto importante a ser citado é o conceito sobre a dimensão do ciclo de vida (LCA - life cycle assessment) para a eleição do método mais apropriado de tratamento e reciclagem de resíduos sólidos, já que as soluções para um tratamento diferem dependendo das características requeridas para 0 subproduto (Ekvall, 1999; Magalhães et al.,2007).

A fim de evitar desperdícios e aliviar o impacto decorrente do consumo intensivo de matérias primas, as autoridades têm encorajado a prática de atividades para a reciclagem e reutilização de resíduos. No entanto, ultimamente estas políticas têm sido criticadas por suas implicações e impactos ambientais. Por exemplo, os benefícios da reciclagem de papel têm sido questionados em face aos estudos que mostram aumento no consumo de combustíveis fósseis no processo, este tipo de reciclagem contribui com o aumento da emissão de gases e conseqüentemente com o efeito estufa (Ross et al., 2003; Magalhães et al.,2007).

\subsubsection{Reciclagem de óleo usado}

É de conhecimento que os óleos lubrificantes usados podem ser reciclados, mas quando são filtrados para reuso pelo seu proprietário não podem ser destinados a qualquer forma de comercialização. Ainda podem ser rerefinados, neste processo, são removidos os contaminantes, os produtos de degradação e os aditivos não consumidos; e conferindo as mesmas 
características de óleo lubrificante básico, gerando matérias primas para novas formulações (Azevedo, 2002; Magalhães et al.,2007).

Especificamente, "processo de reciclagem" é um termo genérico que considera os óleos re-processados, re-filtrados e re-refinados. No reprocessamento, o óleo usado é submetido a diferentes operações destinadas a remover contaminantes insolúveis e produtos da oxidação por meio de tratamento térmico a altas temperaturas, filtragem, sedimentação ou decantação, desidratação e centrifugação. Segundo a qualidade disponível, o óleo assim obtido será utilizado para novas misturas ou cortes (blending), com ou sem inclusão de aditivos para novos lubrificantes. Mediante este processo obtêm-se produtos com qualidade similar ou equivalente ao original. Em geral, este processo implica em obter um produto destinado ao uso original (Azevedo, 2002; DEP, 2005; Magalhães et al.,2007).

O processo re-filtrado realiza a separação de sólidos e água por meio de aquecimento, filtração, desidratação e centrifugação. O óleo re-filtrado é usado para combustível (fuel e fuel misturado) já que ao longo do tratamento podem permanecer vários contaminantes como metais pesados, sustâncias aditivas (inibidores da corrosão) e outros. Seu uso está limitado à motores com menores requerimentos que os recomendados para óleos originais (Azevedo, 2002; Magalhães et al.,2007).

A re-refinação implica na remoção de contaminantes (em geral elementos inorgânicos), produto da oxidação e aditivos. Com este procedimento obtêm-se óleos bases para a produção de novos lubrificantes. O processo é utilizado em refinarias e trata-se em rigor, de uma pré-destilação, tratamento ácido, extração por solventes, separação em evaporadores de película, passagem por carvão ou argila ativada e desidratação. É um procedimento muito mais completo e controlado do que as categorias anteriores. Usualmente obtêm-se produtos secundários, como resíduos da destilação, utilizados em derivados do asfalto e filtros desmetalizados, ainda, referente à derivados para fração de asfalto, pode ser empregada para a fabricação de membranas e outros produtos asfálticos (pinturas, seladores, e outros). 
Por meio destes procedimentos se obtêm muitos subprodutos, o principal encontra-se na construção civil, (membranas asfálticas, pinturas asfálticas e outros) e na construção e conservação de estradas. Como material secundário pode ser utilizado em processos de separação por flutuação oleosa, lubrificantes secundários, carrier para pesticidas e tratamento fitossanitários (herbicidas), limpadores industriais para todo propósito, vernizes para barcos e construções lacustres ou marinas, proteção de embarcadouros e outros (Azevedo, 2002; KING COUNTRY, 2005; Magalhães et al.,2007).

No processo de reciclagem de óleo usado, o produto chega à rerefinaria por meio das seguintes etapas (Azevedo, 2002; CCI, 2005; LWART, 2005; LWART PROASFAR, 2005; Magalhães et al.,2007):

- $\quad$ Coleta: Efetuada nos pontos de coleta, principalmente postos de serviço e abastecimento de veículos e indústrias, em geral com o emprego de caminhõestanque dotados de bombas de sucção. Na medida do possível são identificadas as características do produto e as fontes geradoras;

- Transporte: Realizado por meio de caminhões-tanque autorizados pela Agência Nacional de Petróleo (ANP) para o transporte de resíduos;

- Estocagem: Realizada em tanques dispostos nos centros de estocagem, localizados em pontos próximos dos mais importantes centros de coleta. Antes da disposição, nos tanques é efetuada a análise química do material coletado para definir a sua classificação;

- $\quad$ Classificação: Tem por objetivo definir o processo ao qual o material será submetido e os produtos que serão obtidos. O óleo reciclável será utilizado como óleo base no processo de reciclagem; o produto derivado apresentará 
características similares ao produto original. O óleo para combustão será utilizado como combustível alternativo ao chamado fuel oil em caldeiras e outros processos industriais que utilizam fornalhas alimentadas com combustíveis líquidos. O resíduo, sem as características para reciclagem ou de queima por conter componentes inadequados aos demais usos é classificado como óleo para destruição, e é incinerado sob estritas normas de segurança quanto à emissão de contaminantes.

\subsubsection{Descrição do processo corrente de re-refino de óleo usado}

A seguir, as etapas que compõem o processo de re-refino de óleo usado são apresentadas resumidamente (Azevedo, 2002; LWART, 2005; Magalhães et al.,2007):

- Desidratação - Após o descarregamento do óleo numa caixa receptadora, este passa por uma filtração para retenção de partículas grossas. A desidratação inicia-se com um pré-aquecimento do óleo até $80^{\circ} \mathrm{C}$ nos desidratadores, a temperatura é elevada a $180^{\circ} \mathrm{C}$ para a vaporização de água e outras substâncias voláteis. A água e os solventes evaporados são separados em um separador de fases. Os solventes são aproveitados como combustível para os fornos e a água é encaminhada para tratamento numa estação de tratamento de efluentes. $\mathrm{Na}$ FIG. 1, é mostrado um esquema do processo de desidratação do óleo usado.

- Destilação Flash - Após o processo de desidratação, o óleo é bombeado para dois fornos e é aquecido até uma temperatura de $280^{\circ} \mathrm{C}$. Em seguida, ele é conduzido para o sistema de vasos de "flasheamento" a autovácuo (a 20 mmbar). Nesta fase, ocorre a separação de frações leves do óleo usado (óleo neutro leve, óleo spindle e óleo diesel). O óleo neutro leve entra na formulação de óleo com média viscosidade. O óleo spindle é usado em formulações diversas, e o óleo diesel é destinado ao uso da empresa. Na FIG. 2, é mostrado um esquema do processo de destilação flash. 
- Desasfaltamento - O óleo destilado é bombeado para dois fornos, e é aquecido a uma temperatura de $380^{\circ} \mathrm{C}$ e enviado para os evaporadores de película em vácuo (1mmBar). Nesta etapa, é separada a borra neutra do óleo, que é composta de fração degradada do óleo lubrificante usado. A sua composição é constituída principalmente, de polímeros, metais, resinas, aditivos e compostos de carbono. A borra neutra é empregada na fabricação de mantas e produtos asfálticos em geral (FIG. 3).

- $\quad$ Tratamento Químico - O óleo proveniente do desasfaltamento ainda possui alguma quantidade de componentes oxidados. A extração destes componentes é realizada com ácido sulfúrico que promove a aglomeração dos contaminantes, gerando a borra ácida. A borra ácida é um resíduo altamente poluente se lançado ao meio ambiente, requerendo um tratamento adequado. Usualmente, ela é lavada com água, neutralizada e desidratada transformando-se em combustível. $A$ água ácida gerada na lavagem é neutralizada com argila ativada e cal virgem, transformando-se em gesso, que é usado como corretivo de solo. A água neutralizada é enviada para tratamento (FIG. 4).

- Clarificação e Neutralização - Após o tratamento químico, o óleo é bombeado para os reatores de clarificação e neutralização onde é adicionada a terra fuller. A mistura óleo/terra é aquecida para promover a adsorção de compostos indesejáveis. Na fase final, é adicionada a cal para neutralização (FIG. $5)$.

- $\quad$ Filtragem - A mistura óleo/terra/cal passa por filtros prensa que separam a terra e a cal. A terra usada pode ser empregada em indústrias cerâmicas e do cimento. O óleo ainda passa por filtros especiais para eliminar os particulados remanescentes. No final do processo é obtido o óleo básico mineral re-refinado. As especificações de viscosidade, cor, ponto de fulgor, acidez, corrosão e outros 
são analisadas num processo de controle de qualidade que garante as características originais do produto.

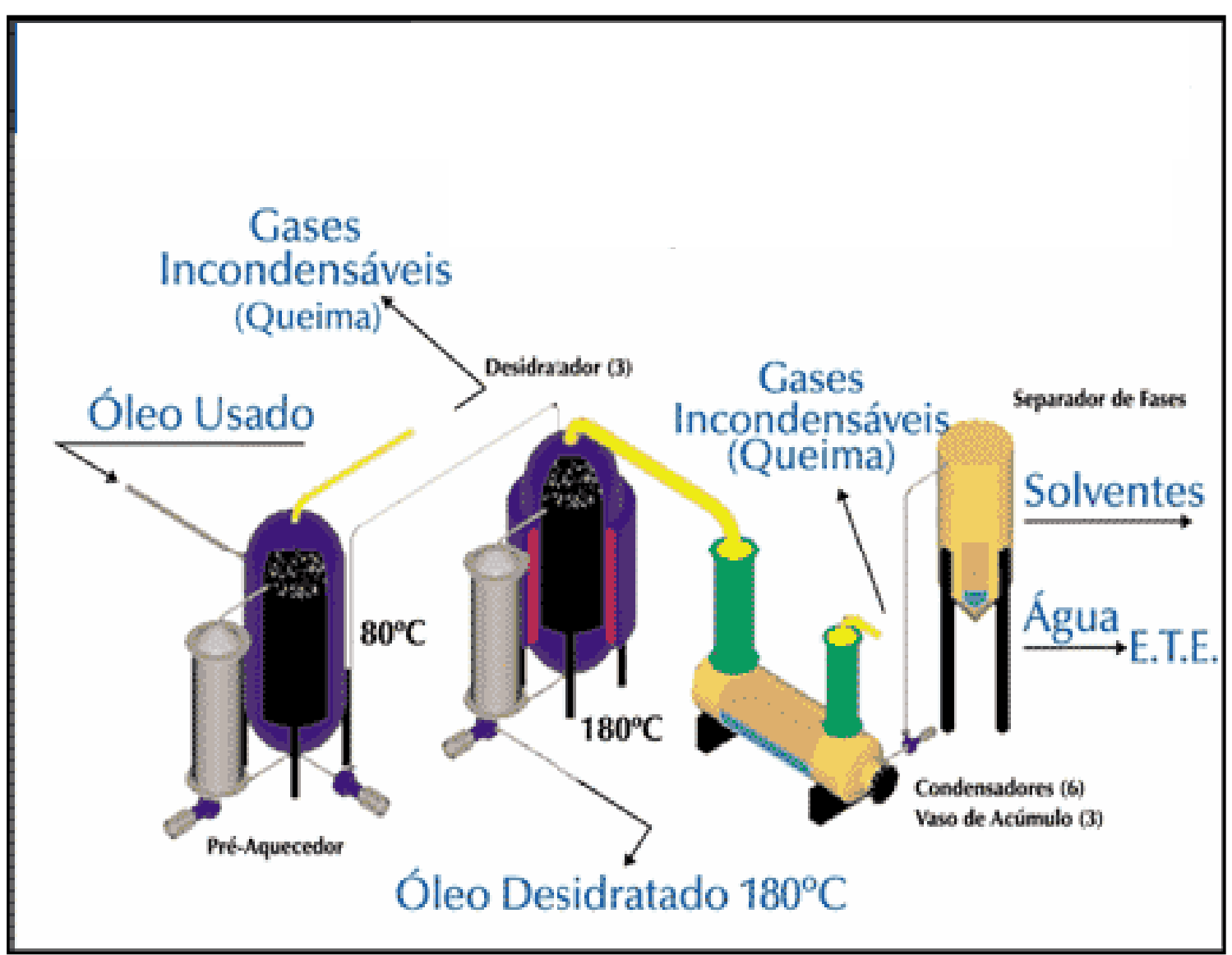

Fonte: Lwart (2005)

FIGURA 1 - Esquema do processo de desidratação do óleo usado. 


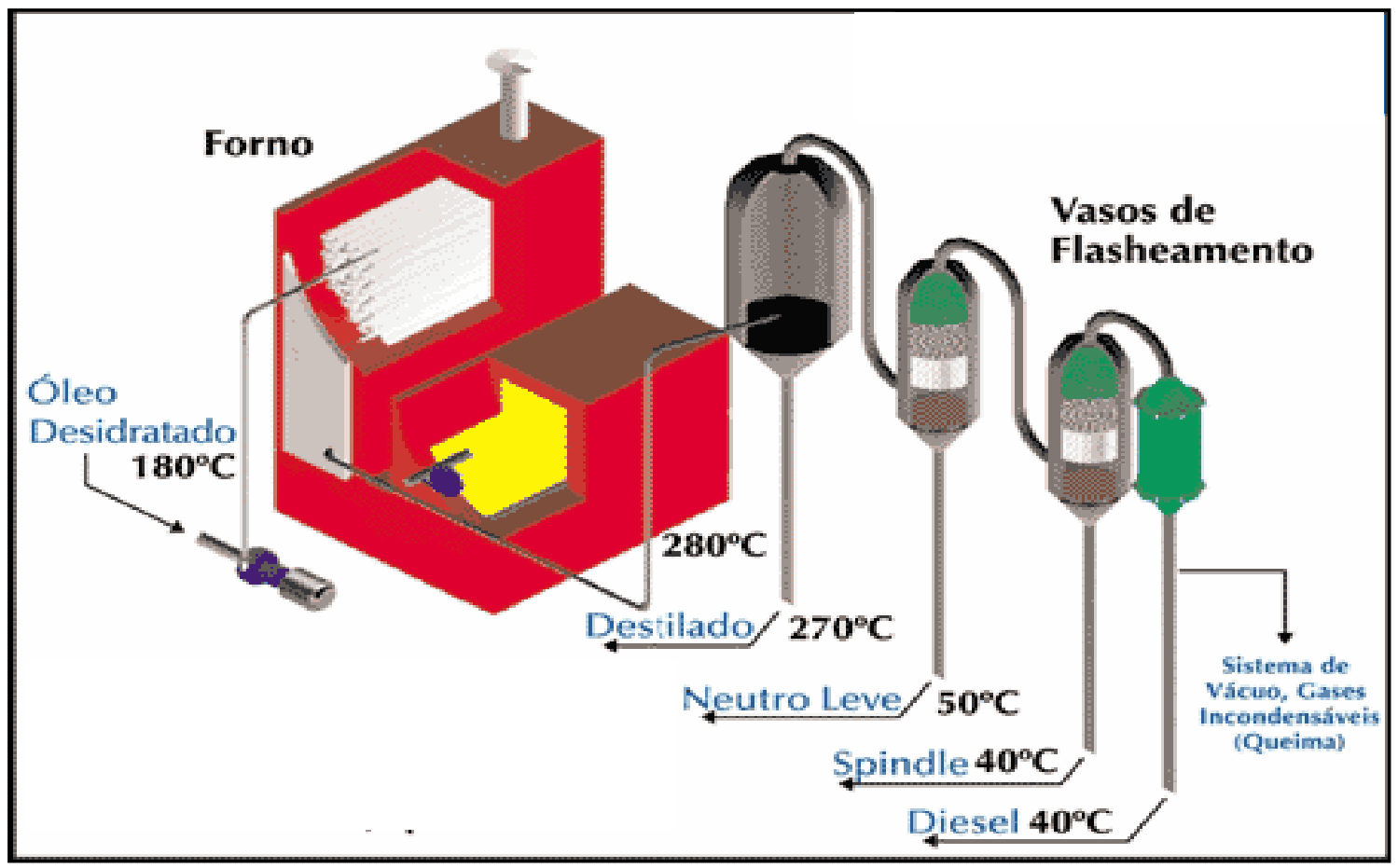

Fonte: Lwart (2005)

FIGURA 2 - Esquema do processo de destilação flash.

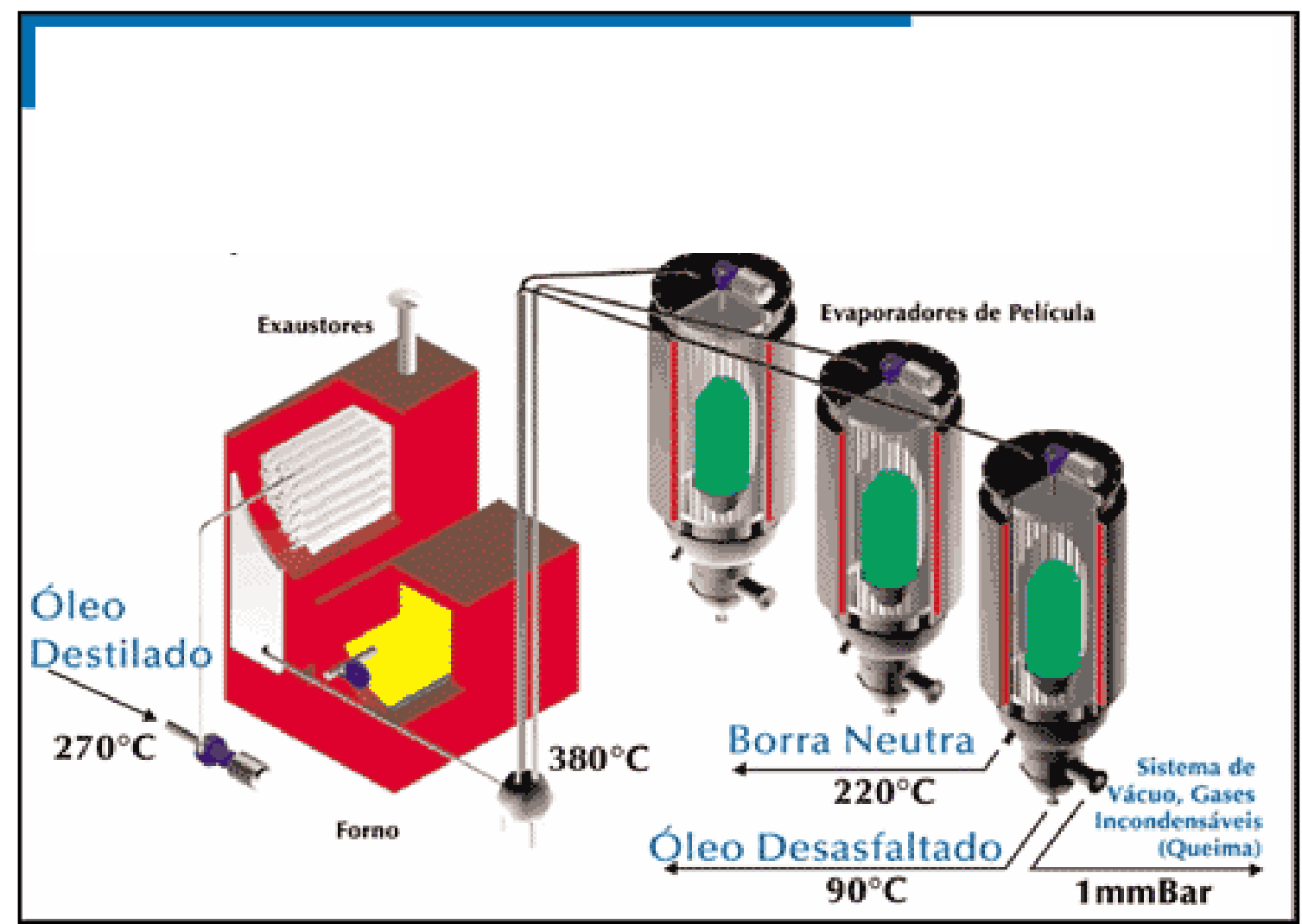

Fonte: Lwart (2005)

FIGURA 3 - Esquema do processo de desasfaltamento. 


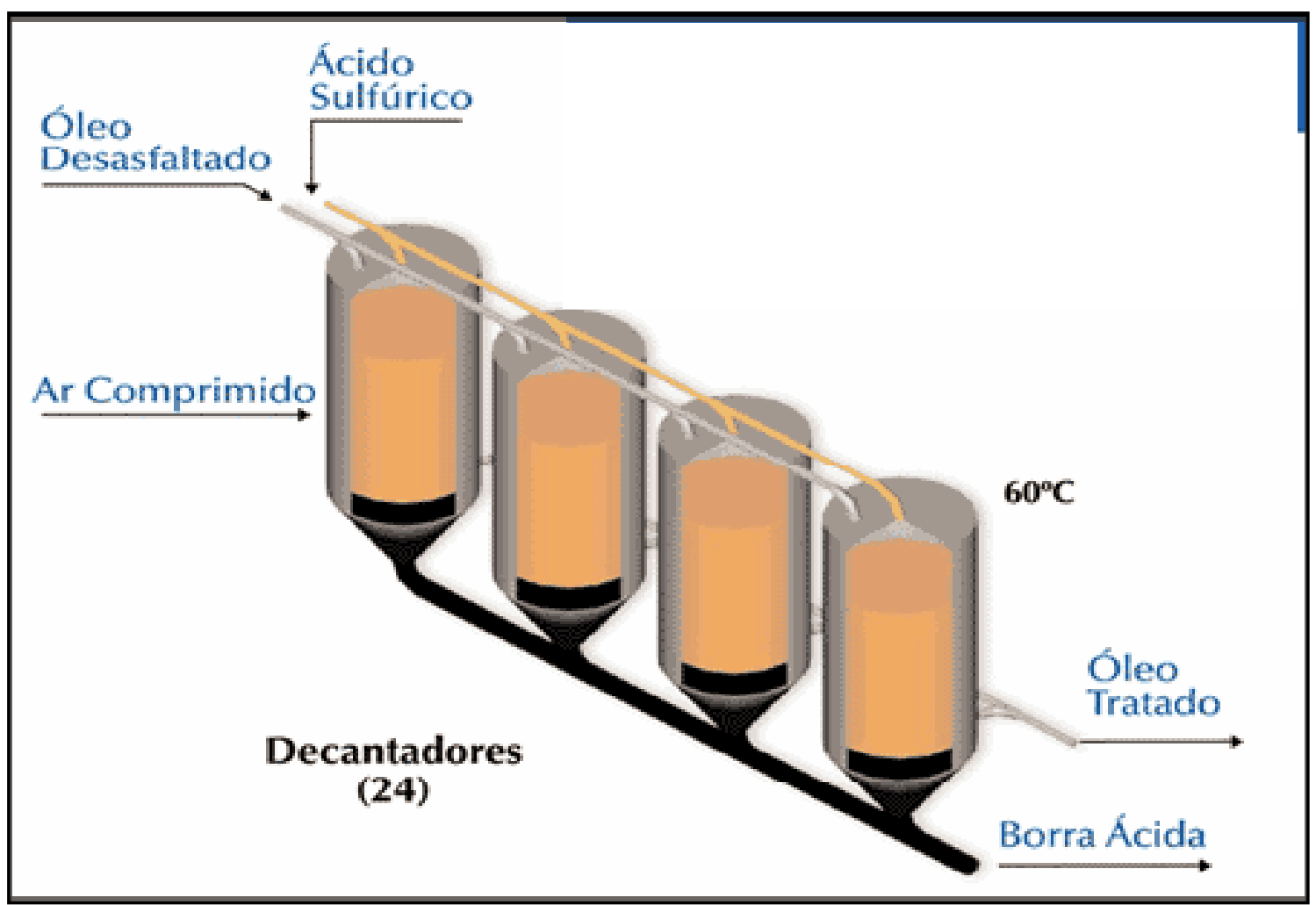

Fonte: Lwart (2005)

FIGURA 4 - Esquema do processo desulfonação.

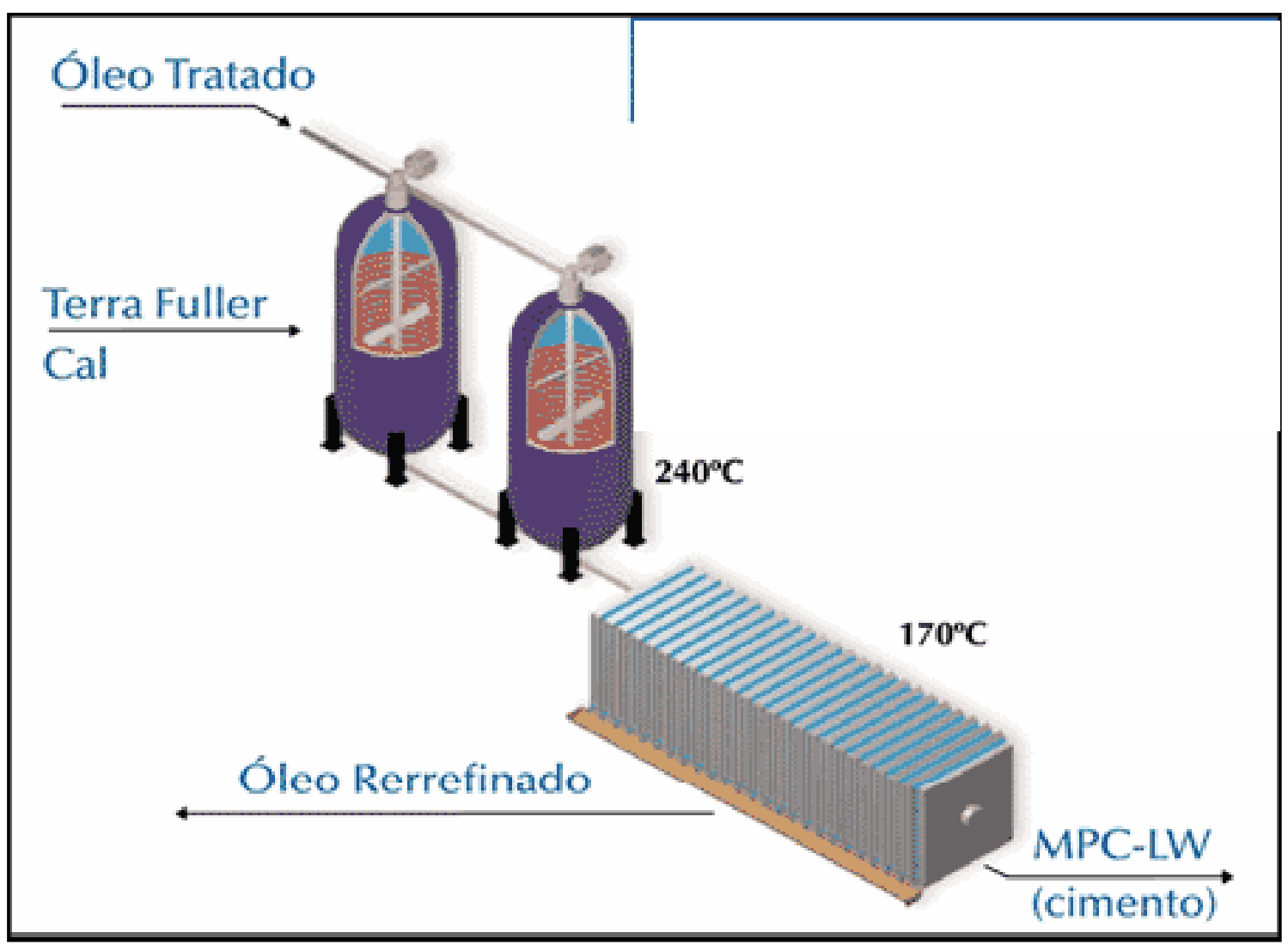

Fonte: Lwart (2005)

FIGURA 5 - Esquema do processo de clarificação e neutralização 


\subsubsection{O mercado do óleo lubrificante e o re-refino}

A produção de óleos lubrificantes no Brasil é de aproximadamente um bilhão de litros/ano (CONSELHO EM REVISTA, 2005; Magalhães et al.,2007). Deste volume cerca de 650 milhões de litros/ano são consumidos por motores ou outros usos, ou seja, não são passíveis de recuperação. Dos restantes, 350 milhões de litros/ano usados, que não são consumidos totalmente nos processos, $69,2 \%$ são reciclados via re-refino, ou seja, cerca 240 milhões de litros/ano. Dados de 2004 revelam que nesse ano foram coletados aproximadamente 240 milhões de litros, isto é, em torno de $24,0 \%$ de óleo lubrificante comercializado no país. O volume de óleo usado coletado, em 2004, possibilitou o processamento de cerca 170 milhões de litros de óleo básico re-refinado (Magalhães et al. 2007; CEMPRE, 2007).

Na TAB. 1 é apresentado um panorama sobre os volumes em milhões de litro/ano de óleo novo (ON), óleo consumido pelo uso (OU), resíduo de óleo usado (ROU), óleo recuperado por meio do processo de reciclagem (RPR), óleo recuperado por meio de processo desconhecido (RPD), a relação percentual entre o volume de resíduo de óleo usado sobre o volume de óleo novo (ROU/ON \%) e a relação percentual entre o volume de óleo recuperado pelo processo de reciclagem sobre o volume de resíduo de óleo usado (RPR/ROU - \%), para cinco países latino-americanos, referente ao ano de 2001 (Azevedo, 2002; Magalhães et al. 2007). 
TABELA 1 - Panorama sobre consumo e destino de volumes de óleos (milhões de litros/ano) de alguns países latino-americanos

\begin{tabular}{cccccccc}
\hline & ON & OU & ROU & RPR & RPD & $\begin{array}{c}\text { ROU/ON } \\
(\%)\end{array}$ & $\begin{array}{c}\text { RPR/ROU } \\
(\%)\end{array}$ \\
\hline Argentina & 238 & 119 & 130 & 50 & 80 & 55 & 38 \\
Brasil & 900 & 510 & 390 & 270 & 120 & 43 & 69 \\
Colômbia & 150 & 60 & 90 & 56 & 34 & 60 & 62 \\
Equador & 56 & 22 & 34 & 14 & 20 & 61 & 41 \\
México & 880 & 570 & 310 & 102 & 208 & 35 & 33 \\
\hline
\end{tabular}

Fonte - Azevedo, 2002

ON - óleo novo; OU - óleo consumido pelo uso; ROU - resíduo de óleo usado; RPR - óleo recuperado por meio do processo de reciclagem; RPD - óleo recuperado por meio de processo desconhecido; ROU/ON - \% - relação percentual entre o volume de resíduo de óleo usado sobre o volume de óleo novo; RPR/ROU - \% - relação percentual entre o volume de óleo recuperado pelo processo de reciclagem sobre o volume de resíduo de óleo usado.

$\mathrm{Na}$ TAB. 1 pode ser observado que o Brasil apresenta o maior índice percentual da relação entre o volume de óleo recuperado pelo processo de reciclagem sobre o volume de resíduo de óleo usado, RPR/ROU $=69 \%$. Este resultado demonstra que entre os países latino-americanos citados, o Brasil em 2001, reciclou o maior volume de resíduo de óleo usado, porém ainda apresenta um volume consideravelmente alto (120 milhões litro/ano) de resíduo de óleo usado recuperado por processo desconhecido (RPD). Provavelmente, a RPD está associada à queima inadequada destes resíduos.

Na TAB. 2 é apresentado o volume consumido de óleo em países latino-americanos, onde o Brasil possui o maior volume de consumo, seguido pelo México. Destes países, o Brasil é um dos que possui menor volume de óleo utilizado por veículo ao ano, tendo destaque neste quesito a Colômbia com 61,2 litros/ano. O óleo residual dos veículos no Brasil perfez um volume de 292.500 litros em 2002, constatando uma média de somente 15 litros por veículo, inferior a de países como Colômbia e Equador, porém semelhante a da Argentina e do México. 
TABELA 2 - Litros de Óleo lubrificante, participação pelo uso e frota de veículos em cinco países latino-americanos (2001).

\begin{tabular}{lccccccc}
\hline & $\begin{array}{c}\text { Óleo } \\
\text { novo } \\
\left(\mathrm{m}^{3} / \mathrm{ano}\right)\end{array}$ & $\begin{array}{c}\text { Uso } \\
\text { Automotriz } \\
(\%)\end{array}$ & $\begin{array}{c}\text { Uso } \\
\text { Automotriz } \\
\left(\mathrm{m}^{3} / \mathrm{ano}\right)\end{array}$ & $\begin{array}{c}\text { Frota de } \\
\text { veículos } \\
\text { (unidade })\end{array}$ & $\begin{array}{c}\text { Litros de } \\
\text { óleo por } \\
\text { veíc./ano }\end{array}$ & $\begin{array}{c}\text { Resíduo de } \\
\text { automotivos } \\
\left(\mathrm{m}^{3} / \mathrm{ano}\right)\end{array}$ & $\begin{array}{c}\text { Litros de } \\
\text { úleo } \\
\text { veíc./ano por }\end{array}$ \\
\hline Argentina & 238.000 & 75,00 & 178.500 & 6.607 .000 & 27,02 & 97.500 & 15 \\
Brasil & 900.000 & 75,00 & 675.000 & 19.310 .000 & 34,96 & 292.500 & 15 \\
Colômbia & 150.000 & 72,70 & 109.050 & 1.782 .000 & 61,20 & 65.430 & 37 \\
Equador & 56.000 & 80,00 & 44.800 & 793.000 & 56,49 & 27.200 & 34 \\
México & 880.000 & 71,50 & 629.200 & 15.347 .000 & 41,00 & 221.650 & 14 \\
\hline
\end{tabular}

Fonte - Azevedo, 2002

\subsubsection{Os recursos legais}

O controle da produção de óleos lubrificantes é realizado pela Agência Nacional de Petróleo (ANP), uma autarquia federal ligada ao Ministério de Minas e Energia, onde empresas produtoras, distribuidoras, coletoras e re-refinadoras são cadastradas. Segundo dados da ANP, há 26 empresas coletoras de óleos lubrificantes e 14 empresas re-refinadoras de óleo lubrificante, em todo o território nacional (Azevedo, 2002; Magalhães et al. 2007).

No Brasil, o conjunto de leis e normas que regulam a atividade de produção de óleos lubrificantes, em geral, é bastante eficaz no estabelecimento claro das obrigações do agente participante em cada etapa (MINISTÉRIO DO MEIO-AMBIENTE, 2005; Magalhães et al. 2007). As normas são: 
- $\quad$ Estabelecer parâmetros para os diversos graus de viscosidade dos óleos básicos produzidos pelo re-refino;

- $\quad$ Criar a figura do coletor com obrigações claras e definidas;

- Criar documentos de certificação de coleta e recepção, o primeiro com eficácia de documento fiscal e;

- Despertar consciência nas autoridades para as ações de repressão as atividades ilegais de queima em caldeiras e olarias.

Não obstante, preconiza-se melhorar aspectos referentes ao controle dos agentes formados pelos setores, como oficinas mecânicas, oficinas de troca, supermercados, postos de gasolina entre outros que se encontra em fase de adequação à legislação. A legislação obriga por meio da Resolução do CONAMA N ${ }^{\circ} 362$ de 23 de Junho de 2005, que todo o óleo utilizado seja reciclado, onde não, a incineração deve ser usada como uma medida excepcional, somente se demonstrada à impossibilidade de re-refino e sob condições severas de controle de queima e emissões de gases. Além disso, a Portaria Interministerial $N^{\circ} 1$, de 29 de Julho de 1999, do Ministro de Minas e Energia estabelece a responsabilidade conjunta do produtor, do importador, do revendedor e do consumidor de óleo lubrificante pela sua coleta. O produtor ou importador é responsável pela estocagem e destino final. A Agência Nacional de Petróleo (ANP) pelas Portarias ANP 125, 126, 127, 128, 130 e 131 regulam todo o processo de distribuição, coleta, estocagem e reciclagem dos óleos lubrificantes (Azevedo, 2002; MINISTÉRIO DO MEIO-AMBIENTE, 2005). As metas estabelecidas, pela ANP, vigoram a partir de outubro de 2000 , com o objetivo de coletar e reciclar $25 \%$ de óleo e a partir de outubro de 2001, atingir a meta de 30\%, índice comparável aos da Alemanha, França e Itália. Essa meta ainda não foi atingida conforme CEMPRE, 2005 e Azevedo, 2002. Existe uma crescente consciência sobre a necessidade de proteção ao meio ambiente e a sociedade, em geral, aprova a atividade de reciclagem de óleo lubrificante. (Azevedo, 2002; MINISTÉRIO DO MEIO-AMBIENTE, 2005; Magalhães et al. 2007). 


\subsubsection{Panorama da utilização de óleo usado no Brasil}

Nos últimos anos, a indústria de re-refino no Brasil se preparou para reciclar todo o óleo lubrificante usado disponível no país. Desde outubro de 2001, a meta de reciclagem, estabelecida em lei, é de $30 \%$ do volume produzido, ou seja, 300 milhões de litros ao ano devem ser re-refinados. Estes são indicadores muito similares aos de países da Europa e dos Estados Unidos (Azevedo, 2002; Magalhães et al. 2007).

Uma das diretrizes políticas da reutilização de óleos lubrificantes no Brasil está associada à qualidade do petróleo, já que, o petróleo brasileiro é mais rico na fração asfáltica, assim o óleo lubrificante usado é um material valioso, que endossa a política de recuperação (Azevedo, 2002, Magalhães et al. 2007).

Atualmente, observa-se uma quantidade relativamente baixa de uso de óleos lubrificantes no Brasil (34,9 litros/veículo/ano, TAB. 2) em conseqüência às novas tecnologias que permitem um maior tempo de uso de óleos lubrificantes em veículos automotores. Apesar disso, o número de litros de óleo usado gerado (após quilometragem limite) por veículo/ano está entre 15 e 20 litros/veículo/ano, apresentando um panorama bastante favorável para a indústria de reciclagem de óleo lubrificante (Azevedo, 2002; PETROQUIMICASUL, 2005; Magalhães et al. 2007).

Embora, este cenário apresentar aspectos positivos, na realidade, não existe dados confiáveis sobre o destino final atribuído aos óleos lubrificantes usados, aqueles não destinados ao re-refino. Estima-se que uma fração seja utilizada para mistura com combustíveis em caldeiras e olarias. Outra pequena fração, especialmente na zona rural, é utilizada para o tratamento de madeiras.

Segundo o Sindicato Nacional da Indústria do Re-refino de Óleos Minerais (SINDIRREFINO), na área específica de re-refino, a tecnologia foi desenvolvida através de vários anos pelos próprios re-refinadores sem colaboração oficial. Atualmente, o sindicato considera que o Brasil detém uma 
tecnologia eficiente e adaptada às necessidades do país, sem subsídios ou ajudas governamentais. Não existem, entretanto, dados confiáveis sobre os custos do processo de re-refino, pois cada empresa possui seus próprios perfis, e a atividade é considerada privada com controle estatal no processo e não no mercado (Azevedo, 2002; PETROQUIMICA DO SUL, 2005; LWART, 2005, Magalhães et al. 2007).

É importante destacar ainda que, apesar de ter solucionado o problema nos aspectos tecnológico e jurídico, no país existe um passivo ambiental relativamente grande, estimado em 120 milhões litros/ano de óleo usado em que desconhece o destino final de descarte, apresentado na TAB. 1.

Em geral, a experiência de reciclagem de óleo lubrificante no Brasil tem sido uma réplica do empirismo do setor de re-refino que, não obstante, alcançou bons resultados. Importante destacar que esse setor ainda não tem apoio governamental em fomento para inovações tecnológicas.

\subsubsection{Principais empresas de re-refino de óleo usado no Brasil}

Em 1987 o Brasil possuía cerca de 50 pequenas usinas de re-refino de óleo usado. Nessa época incidiam impostos sobre o preço do óleo básico que atingiu um valor de US $\$ 1.000 / \mathrm{m}^{3}$, utilizado no subsidio da coleta dos óleos usados. Desde 1987, com a queda do imposto único e aumento de custos para o atendimento das leis ambientais, ocorreu o fechamento de quase todas as rerefinadoras de pequeno porte e com problemas ambientais. Hoje, existem aproximadamente 10 empresas de re-refino em operação, reunidas no SINDIRREFINO (Sindicato Nacional da Indústria do Re-refino de Óleos Minerais), autorizadas a realizarem a coleta, estocagem e processamento. Elas estão localizadas principalmente nas regiões Sul, Sudeste, Centro Oeste e algumas cidades do Nordeste e nas capitais dos Estados que compõem a região Norte. A coleta é realizada junto aos postos de serviços, oficinas, empresas concessionárias e garagens de grandes frotas (CEMPRE, 2005; Magalhães et al. 2007). 
A maior empresa de reciclagem de óleo lubrificante do país é a LWART - Lubrificantes Ltda., localizada no Estado de São Paulo, município de Lençóis Paulista (300 km da capital). Esta empresa é responsável por quase metade de todo o re-refino no Brasil. Possui centros de coleta e estocagem em quase todo o país e duas plantas re-refinadoras, em Lençóis (SP) e Duque de Caxias (RJ) (Azevedo, 2002; CEMPRE, 2005; LWART, 2005). O óleo lubrificante usado inicial, na fábrica em Lençóis Paulista, é transformado em seguintes proporções (LWART, 2005; LWART PROASFAR, 2005; Magalhães et al. 2007):

- $\quad 67 \%$ - óleo básico re-refinado;

- $27 \%$ - subprodutos (asfalto, combustível, tinta, manta, impermeabilizante e outros) e

- $\quad 6 \%$ - percentual de água que se perde no processo.

Na região sul do Brasil, a Indústria Petroquímica do Sul Ltda. é uma das maiores coletoras e re-refinadoras de óleos lubrificantes do Brasil e da América do Sul. Além de produzir o óleo re-refinado também são produzidos óleos acabados e graxas. A sua capacidade de reciclagem é de 30 milhões de litros/ano. A empresa está instalada no Parque Industrial de Alvorada, RS, e possui uma capacidade de armazenamento superior a 4 milhões de litros (PETROQUIMICA DO SUL, 2005; Magalhães et al. 2007). 


\subsubsection{Processos avançados para o tratamento e recuperação de óleo usado}

O desenvolvimento mundial tem contribuído para o crescimento do consumo dos derivados do petróleo, principalmente no setor automobilístico, conseqüentemente ocorrendo o aumento do volume de óleo lubrificante usado. $\mathrm{O}$ fato de o óleo usado ser classificado como um resíduo perigoso e o petróleo ser obtido de uma fonte não renovável, as pesquisas nacionais e internacionais têm demonstrado melhoria de processos de tratamento de recuperação e reuso, com maior eficiência e menor custo.

O Instituto Mexicano de Petróleo (2007) patenteou um processo que permite regenerar óleo lubrificante usado por meio de filtração, juntamente com um tratamento por solventes supercríticos, variando a temperatura e a pressão. De acordo com os autores, a grande vantagem é que o processo permite uma extração seletiva de hidrocarbonetos e a utilização dos subprodutos (solventes) no próprio processo.

Cherednichenko e colaboradores (2006) patentearam um processo para a recuperação de óleo usado utilizando agentes coagulantes em meio aquoso. Estes são incorporados ao óleo usado sob agitação na presença de ar, posteriormente, após um período de repouso, a fase aquosa contendo os resíduos é separada da fase orgânica (óleo). Este óleo é seco a vácuo, filtrado e submetido à destilação a vácuo. Os gases liberados durante a destilação são utilizados para concentrar os efluentes alcalinos e as frações leves como combustível dos fornos. O produto final obtido é um óleo básico com as características do óleo base de origem das refinarias de petróleo. Segundo os autores, a principal vantagem é que o processo permite a utilização dos resíduos perigosos ambientais, além de ser economicamente viável e de tecnologia simples.

Hamad e colaboradores (2005) propuseram um tratamento utilizando gás liquefeito de petróleo (GLP) condensado e estabilizado. Segundo os autores, o processo é capaz de reduzir o teor de asfalteno em $0,106 \%$, as cinzas para $0,108 \%$ e os resíduos de carbono para $0,315 \%$ e ainda apresentando níveis de 
metais contaminantes muito baixos. O processo permite produzir $79 \%$ de óleo básico e a desvantagem consiste na necessidade de altas temperaturas de operação durante o processo.

Fakhri (2004) patenteou um processo para o tratamento de resíduos de petróleo cujos produtos são óleo lubrificante e óleo base para lubrificantes automotivos. O processo inclui a etapa de desidratação e destilação fracionada em coluna. Segundo o autor, o processo permite a produção de petróleo refinado livre de metais pesados e contaminantes.

Beaupied (2004) patenteou um processo para a recuperação de óleo usado utilizando processos de decantação e centrifugação. O óleo decantado é aquecido e água e outros contaminantes, como metais são separados pela centrifugação. A vantagem do processo, segundo o autor, são os módulos de tratamento compactos e de baixo custo, adequados para países pouco industrializados.

Deutsch (2001) patenteou um processo para a descontaminação de óleo mineral sintético e semi-sintético que permite remover compostos de enxofre, fósforo e metais pesados. O processo utiliza cinco etapas e os reagentes utilizados são glicol e hidróxido de sódio e de bário. O tratamento permite realizar a destilação fracionada em uma temperatura significativamente menor. Segundo o autor, uma grande vantagem é evitar o craqueamente de polímeros, possíveis de estarem presentes.

Ciora e Liu (2000) patentearam um processo que permite remover cinzas, odor e cor de óleo lubrificante usado. Este processo utiliza uma combinação de membranas, baseado no processo de absorção. A primeira etapa consiste na passagem do óleo usado através de uma membrana porosa inorgânica a alta pressão, retendo os resíduos como cinzas. Posteriormente, o óleo é filtrado por várias membranas como alumina ativada, zeólita, sílica gel, argila catiônica e aniônica a uma temperatura de $25-120{ }^{\circ} \mathrm{C}$, eliminando a cor e odor do óleo usado. O processo pode ser aplicado para óleos hidráulicos, de 
transmissão e especialmente automotivo. Segundo os autores a vantagem é a utilização do óleo recuperado como lubrificante ou combustível.

Merchaoui e colaboradores (1994) patentearam um processo de regeneração de óleo lubrificante usado utilizando um tratamento com uma base forte. O óleo é pré-aquecido a $120-250{ }^{\circ} \mathrm{C}$ e misturado com uma base forte na proporção de 1-3 \% em massa. A desidratação flash permite a remoção de hidrocarbonetos leves. A separação dos resíduos é realizada por meio de destilação fracionada a vácuo. Segundo os autores, as vantagens do processo estão relacionadas com a alta taxa de recuperação, baixo custo e pouca produção de resíduos.

Minana e colaboradores (1994) patentearam um processo de re-refino de óleo lubrificante usado, cujas etapas são destilação flash para a eliminação de água e frações voláteis, tratamento com uma base forte e posterior destilação fracionada para a remoção de polímeros e metais pesados. Segundo os autores, as vantagens são o alto rendimento, o baixo nível de resíduo gerado e o produto obtido comparável ao óleo refinado.

\subsubsection{Processos de oxidação avançada e suas aplicações ambientais}

Os processos de oxidação avançada (POA) utilizam o alto poder de oxidação do radical hidroxila, $\mathrm{OH}$, para reagir indistintamente com os compostos orgânicos.

Esses processos têm sido utilizados em vários estudos com o propósito de serem aplicados nos tratamentos de resíduos, principalmente aqueles que apresentam compostos orgânicos tóxicos.

O POA tem sido considerado como uma alternativa para substituir outros processos de tratamento como o de incineração, que libera dioxina para o ambiente, tratamento convencional para resíduos sólidos, aonde estes são depositados em aterros e o de tratamento biológico que requer um tempo longo 
de digestão dos efluentes para atingir quantidades mínimas de contaminantes, permitido por lei para descarga no ambiente.

Entre os POA destacam-se o processo oxidativo fenton (Lange et al., 2006), onde a geração de radical hidroxila é feita pela reação de um sal ferroso com peróxido de hidrogênio; processo sonólise (Borges, et al., 2002), onde o radical hidroxila é produzido por meio da interação de uma onda sonora de freqüência extremamente alta sobre água líquida e radiólise, que produzem os radicais hidroxila por meio da interação da radiação ionizante com água.

$\mathrm{Na}$ TAB. 3 são apresentados os potenciais de oxidação de alguns agentes oxidantes utilizados no tratamento de águas de abastecimento $\mathrm{e}$ oxidação de compostos tóxicos (Nogueira, et al., 1998).

TABELA 3 - Potencial de oxidação de alguns elementos, compostos e radicais livres

\begin{tabular}{lc}
\hline \multicolumn{1}{c}{ Espécie } & Potencial de oxidação (V) \\
\hline Flúor & 3,03 \\
Radical hidroxila & 2,80 \\
Ozônio & 2,07 \\
Peróxido de hidrogênio & 1,78 \\
Permanganato & 1,68 \\
Ácido hipobromoso & 1,59 \\
Dióxido de cloro & 1,57 \\
Ácido hipocloroso & 1,49 \\
Cloro & 1,36 \\
Bromo & 1,09 \\
lodo & 0,54 \\
\hline
\end{tabular}

Fonte - Nogueira, et al., 1998 
Os processos de oxidação avançada têm sido usados na proteção e conservação do meio ambiente, seu emprego tem sido aplicado na destruição de compostos orgânicos tóxicos presentes em amostras ambientais, água potável, remediação de solos e efluentes industriais, estas áreas tem sido objeto de estudo de pesquisas nacionais e internacionais.

O processo de transferência de energia das partículas carregadas para os átomos das moléculas se dá por um grande número de colisões. Um fóton de raios gama ao atravessar a matéria pode ser absorvido por um átomo ou ser desviado de sua trajetória.

As principais fontes industriais de raios gama são as de cobalto-60 e as de césio-137. Ambas são produzidas artificialmente, o cobalto 60 é obtido quando o cobalto 59 é bombardeado com nêutrons em um reator nuclear pela reação (n, $\gamma)$. O césio 137 é obtido na forma de cloreto de césio extraído no reprocessamento de combustível queimado em reatores nucleares. O cobalto 60 ao desintegrar emite dois raios gama com as energias de 1,17 Mev e 1,33 Mev. Sua meia vida é de 5,27 anos.

A literatura, nos últimos anos, tem reportado o uso do processo de oxidação avançada por feixe de elétrons e radiação gama em diversos tipos de tratamentos como, remoção, degradação, desinfecção e esterilização de compostos orgânicos, inorgânicos e microbiológicos presentes em efluentes industriais, domésticos e rejeitos aquosos [Sakamoto, et al., (1984); Pikaev, et al., 1984; Waite et al., 1992; Nickelsen et al., 1992; Lin et al., 1995; Pikaev, 1995; Podzorova, 1995; Mincher, et al., 1996; Duarte, 1999; Borely et al., 2000; Solpan, et al., 2002; Taixing, et al., (2002); Chitose et al., 2003; Almeida et al., 2004; Duarte et al., 2004; Zang et al., (2004); Popov, et al., 2005; Mori, M. N., 2006; Almeida, 2006 e Wasiewicz, et al., (2006)].

Com relação aos tratamentos de petróleo, seus derivados e resíduos, os trabalhos mais recentes são apresentados a seguir:

Qu e colaboradores (2007) estudaram a aplicação da radiação gama para a degradação radiolítica de DBT (dibenzothiophene) em amostras simuladas de petróleo, utilizando catalisadores. Os autores verificaram que entre os catalisadores testados, o de alumina $\left(\mathrm{Al}_{2} \mathrm{O}_{3}\right)$ impregnado com óxido de zircônio $\left(\mathrm{ZrO}_{2}\right)$ apresentou a maior atividade catalítica. Os resultados mostraram que na presença do catalisador $\mathrm{ZrO}_{2} / \mathrm{Al}_{2} \mathrm{O}_{3}$ e dose absorvida de $179 \mathrm{kGy}$, a eficiência de 
remoção de DBT foi de 98,9 \%; além disto, a estrutura do catalisador permaneceu estável sob a radiação gama, exceto a superfície coberta pelos compostos orgânicos oxidados.

Almeida e colaboradores (2006) estudaram os efeitos da radiação gama para a remoção de BTX (benzeno, tolueno e xileno) presentes na água do mar, contaminada devido à produção e o transporte de petróleo. Os autores concluíram que o tratamento proposto é eficiente para a degradação de BTX, mas o rendimento é muito inferior quando comparado aos resultados obtidos para amostras de água livre de salinidade.

Qu e colaboradores (2006) apresentaram um método para a remoção de compostos de enxofre presentes no petróleo utilizando a irradiação com raios gama. As amostras de petróleo foram simuladas utilizando DBT (dibenzothiophene) dissolvido em dodecano $\left(\mathrm{C}_{12} \mathrm{H}_{26}\right)$. Os resultados mostraram que a remoção de DBT foi de aproximadamente $33 \%$, com dose absorvida de 185 kGy. Outros procedimentos foram testados preliminarmente para melhorar a eficiência do processo, dentre eles; a adição de peróxido de hidrogênio, ácido acético e óxido de cobalto. A irradiação das amostras em temperatura ambiente com óxido de cobalto apresentou um resultado de $40 \%$ de remoção de DBT sob a mesma dose absorvida.

Tiburtius e colaboradores (2005) estudaram os efeitos do processo de oxidação avançada (processo foto-fenton) em soluções aquosas contaminadas por BTX e gasolina. Os resultados mostram que o tratamento permite degradação quase total de BTX e remoção de mais de $80 \%$ dos fenólicos intermediários em aproximadamente $30 \mathrm{~min}$. Segundo os autores, este processo sugere grande potencialidade para o tratamento de grandes volumes de água contaminados por derivados de petróleo.

Duarte e colaboradores (2004) estudaram os efeitos do processo de oxidação avançada por irradiação com feixe de elétrons para o tratamento de efluentes gerados na produção de petróleo de plataformas marinhas. Os resultados mostraram que a tecnologia do feixe de elétrons apresenta alta 
eficiência para a destruição de compostos orgânicos, mesmo na presença de alta salinidade.

Zaikina e colaboradores (2004) estudaram os efeitos da radiação ionizante para o pré-tratamento de petróleo e produtos petrolífero com concentração superior a $3 \%$ em massa de enxofre, em temperatura ambiente e altas temperaturas. Segundo os autores o tratamento proporciona dessulfurização eficiente das frações leves e considerável redução do teor de enxofre nas frações de maior peso molecular.

Mirkin e colaboradores (2003) utilizaram a irradiação por feixe de elétrons para a transformação de hidrocarbonetos pesados e/ou viscosos em leves. Segundo os autores, o processo proposto (hydrocarbon enhancement electron-beam technology - HEET) apresenta vantagens em relação a diferentes parâmetros como, faixas de temperatura, pressão, configuração das instalações entre outros.

Zaikina e colaboradores (2002) apresentaram um estudo sobre o uso da radiação ionizante para o tratamento de petróleo e óleo usado. Neste trabalho, eles concluem que para se tratar 70 mil toneladas/ano de óleo usado, um acelerador de elétrons de $20 \mathrm{~kW}$ é suficiente; para volumes menores ( $<2$ mil toneladas/ano), o uso de irradiadores industriais com fonte de Co-60 e Cs-137 mostram-se adequados.

\subsection{Fundamentos sobre interação da radiação ionizante com a matéria}

Todas as formas de radiação ionizante interagem com a matéria transferindo sua energia para átomos e moléculas presentes. Na primeira fase de interação, ocorre um efeito físico que consiste na ionização e excitação dos átomos, resultante da troca de energia entre a radiação e a matéria. Este efeito se processa num intervalo de tempo muito curto da ordem de $10^{-13}$ a $10^{-12} \mathrm{~s}$. Na segunda fase de interação, ocorrem os efeitos químicos, ou seja, ruptura de 
ligações nas moléculas e formação de radicais livres. Esta ação química processa-se num intervalo de tempo estimado em $10^{-9} \mathrm{~s}$ (Farhataziz e Rodgers, 1987; Spinks e Woods, 1990; Clough e Shalaby, 1991).

Os efeitos químicos de interação da radiação com a matéria ocorrem por dois mecanismos: direto, no qual a radiação interage diretamente na molécula em questão e indireto, no qual a radiação interage inicialmente com a molécula de água, gerando espécies químicas muito reativas e difusíveis que interagem com o material.

Os íons carregados positivamente, os elétrons e as espécies excitadas são os precursores das reações químicas observadas no material irradiado.

Os processos de transferência de energia para a matéria são diferentes para radiação eletromagnética $(\gamma$ e $X$ ) e partículas carregadas (feixe de elétrons e partículas carregadas positivamente). Os fótons com energia acima de $10 \mathrm{MeV}$ podem interagir no núcleo do átomo e ejetar um próton ou nêutron (reação nuclear) induzindo radiatividade no material absorvedor. Esta é a razão pela qual, aceleradores comerciais são limitados à energia de $10 \mathrm{MeV}$ e máquinas de raios $\mathrm{X}$ a $5 \mathrm{MeV}$.

A quantidade de energia transferida da radiação ionizante para a matéria num determinado volume, dividida pela massa contida neste volume é definida como dose absorvida. Esta grandeza, definida em 1953, abrange todos os tipos de radiação ionizante e é válida para qualquer tipo de material absorvedor. A unidade definida pelo Sistema Internacional de Unidades para dose absorvida é joule por quilograma $\left(\mathrm{J} \mathrm{kg}^{-1}\right)$, que é denominado gray (Gy), anteriormente chamado de $\mathrm{rad}\left(1 \mathrm{~Gy}=1 \mathrm{~J} \mathrm{~kg}^{-1}=100 \mathrm{rad}\right.$ ) (Spinks e Woods, 1990).

O rendimento de produtos químicos ou íons produzidos pela radiação é expresso como a razão da quantidade de produtos produzidos pela dose absorvida. Em química da radiação, este rendimento é denominado $G$, cuja unidade é mol $\mathrm{J}^{-1}$ e significa o número de radicais, moléculas ou íons que são 
formados (ou destruídos) em uma solução pela absorção de 100 eV de energia incidente (Farhataziz e Rodgers, 1987; Spinks e Woods, 1990; Clough e Shalaby, 1991; Duarte, 1999).

\subsubsection{Radiólise da água}

A água e sistemas aquosos têm sido muito estudados em química da radiação, assim, os mecanismos básicos de interação da radiação em moléculas estão bem estabelecidos. A exposição da água a radiação produz moléculas ionizadas, excitadas e elétrons livres. As moléculas ionizadas reagem rapidamente $\left(10^{-14}\right.$ a $\left.10^{-9} \mathrm{~s}\right)$ para formar radical hidroxila (Eq. 1) (Cooper et al., 1992; Lin et al., 1995; Duarte, 1999):

$$
\mathrm{H}_{2} \mathrm{O}^{+}+\mathrm{H}_{2} \mathrm{O} \rightarrow \mathrm{H}_{3} \mathrm{O}^{+}+\mathrm{OH}^{-}
$$

Enquanto os elétrons tornam-se hidratados (Eq. 2):

$$
\mathrm{e}^{-}+\mathrm{nH}_{2} \mathrm{O} \rightarrow \mathrm{e}_{\mathrm{aq}}^{-}
$$

Vários compostos intermediários e produtos moleculares são formados como conseqüência da interação entre a radiação ionizante e a água. Os principais transientes e produtos moleculares são formados nas seguintes proporções (Eq. 3):

$$
\mathrm{H}_{2} \mathrm{O} \rightarrow[2,6] \mathrm{e}_{\mathrm{aq}}^{-}+[0,6] \mathrm{H}^{\dot{2}}+[2,7] \mathrm{OH}^{\dot{2}}+[0,7] \mathrm{H}_{2} \mathrm{O}_{2}+[2,6] \mathrm{H}_{3} \mathrm{O}^{+}+[0,45] \mathrm{H}_{2}
$$

Os números em colchetes referem-se ao valor de $G$, valores estes que dependem do pH da solução aquosa:

- $\quad$ em meio ácido, o $e_{\text {aq }}^{-}$é convertido em átomos de hidrogênio (Eq. 4) 


$$
\mathrm{e}_{\mathrm{aq}}^{-}+\mathrm{H}_{\mathrm{aq}}^{+} \rightarrow \mathrm{H}^{\cdot} \quad\left(\mathrm{k}=2,3 \times 10^{7} \mathrm{M}^{-1} \mathrm{~s}^{-1}\right)
$$

- $\quad$ em meio básico, os átomos de hidrogênio são transformados em $e^{-}$aq $(E q$. 5)

$$
\mathrm{H}^{\cdot}+\mathrm{OH}_{\text {aq }}^{-} \rightarrow \mathrm{e}_{\text {aq }}^{-}\left({ }^{*} \mathrm{k}=2,5 \times 10^{7} \mathrm{M}^{-1} \mathrm{~s}^{-1}\right)
$$

Onde:

${ }^{*} \mathrm{k}=$ taxa de reação

e os radicais $\mathrm{OH}^{\circ}$ se dissociam em $\mathrm{O}_{\text {aq }}^{-} \mathrm{e} \mathrm{H}^{+}$aq (Eq. 6)

$$
\mathrm{OH}^{*} \rightarrow \mathrm{O}_{\mathrm{aq}}^{-}+\mathrm{H}^{+} \mathrm{aq}
$$

$\mathrm{Na}$ presença de ar, ambos radicais $\mathrm{H}^{*}$ e $\mathrm{e}_{\mathrm{aq}}^{-}$, são capturados pelo oxigênio, levando à formação de radical peróxido (Eq. 7)

$$
\mathrm{H}^{\cdot}+\mathrm{O}_{2} \rightarrow \mathrm{HO}_{2} \cdot\left({ }^{*} \mathrm{k}=2,0 \times 10^{10} \mathrm{M}^{-1} \mathrm{~s}^{-1}\right)
$$

e os radicais $\mathrm{OH}^{\prime}$ se dissociam em $\mathrm{O}_{2}^{-}{ }^{-}$e $\mathrm{H}^{+}$(Eq. 8 e 9)

$$
\mathrm{e}_{\mathrm{aq}}^{-}+\mathrm{O}_{2} \rightarrow \mathrm{O}_{2}^{-{ }^{-}}\left({ }^{*} \mathrm{k}=2,1 \times 10^{10} \mathrm{M}^{-1} \mathrm{~s}^{-1}\right)
$$




$$
\mathrm{HO}_{2} \leftrightarrow \mathrm{O}_{2}^{-}+\mathrm{H}^{+}
$$

Os radicais formados pela ação da radiação ionizante na molécula de água reagem entre si e essas reações são chamadas reações primárias, as principais são apresentadas na FIG. 6 (Farhataziz e Rodgers, 1987; Spinks e Woods, 1990; Clough e Shalaby, 1991; Duarte, 1999):

$$
\begin{aligned}
& \mathrm{H}^{-}+\mathrm{H}^{-} \rightarrow \mathrm{H}_{2} \\
& \mathrm{H}^{-}+\mathrm{OH}^{-} \rightarrow \mathrm{H}_{2} \mathrm{O} \\
& \mathrm{H}^{-}+\mathrm{e}_{\mathrm{aq}}^{-} \rightarrow \mathrm{H}_{2}+\mathrm{OH}_{\mathrm{aq}}^{-} \\
& \mathrm{OH}+\mathrm{OH}^{-} \mathrm{H}_{2} \mathrm{O}_{2} \\
& \mathrm{OH}+\mathrm{e}_{\mathrm{aq}}^{-} \rightarrow \mathrm{OH}_{\mathrm{aq}}^{-} \\
& \mathrm{e}_{\mathrm{aq}}^{-}+\mathrm{e}_{\mathrm{aq}}^{-} \rightarrow \mathrm{H}_{2}+2 \mathrm{OH}_{\mathrm{aq}}^{-} \\
& \mathrm{e}_{\mathrm{aq}}^{-}+\mathrm{H}_{\mathrm{aq}}^{+} \rightarrow \mathrm{H}^{-} \\
& \mathrm{H}^{-}+\mathrm{OH}_{\mathrm{aq}}^{-} \rightarrow \mathrm{e}_{\mathrm{aq}}^{-} \\
& \mathrm{OH}^{-} \leftrightarrow \mathrm{OH}^{+}{ }_{\mathrm{aq}}+\mathrm{O}^{-} \\
& \mathrm{H}_{2} \mathrm{O}_{2} \leftrightarrow \mathrm{OH}^{+}{ }_{\mathrm{aq}}+\mathrm{HO}_{2}^{-}
\end{aligned}
$$

FIGURA 6 - Principais reações primárias formada pela ação da radiação ionizante na molécula de água.

Estes radicais interagem com compostos orgânicos e inorgânicos e os produtos resultantes destas reações dependerão dos compostos presentes na solução (Getoff, 2002; Duarte, 1999). 
As reações químicas básicas dos compostos orgânicos com estas espécies são mostradas a seguir (Farhataziz e Rodgers, 1987; Spinks e Woods, 1990; Clough e Shalaby, 1991; Duarte, 1999):

- $\quad$ Elétron hidratado $\left(\mathrm{e}_{\mathrm{aq}}^{-}\right)$

$\mathrm{O} \mathrm{e}_{\mathrm{aq}}^{-}$é um potente redutor e atua na transferência de um elétron. As reações com compostos orgânicos são as típicas de um agente nucleofílico.

Os compostos alifáticos halogenados ( $\mathrm{RCl}, \mathrm{RBr}$ ou $\mathrm{RI})$ sofrem dehalogenação quantitativa, como é mostrado na Eq 10, de forma generalizada:

$$
\mathrm{e}_{\mathrm{aq}}^{-}+\mathrm{RCl} \rightarrow \mathrm{R}^{\cdot}+\mathrm{Cl}^{\circ}
$$

Os nitrocompostos são também altamente reativos, como são os policloro e polinitrometanos. Entre os compostos aromáticos, o benzeno, o fenol e a anilina reagem lentamente, mas o ácido benzóico e o benzeno halogenados e nitrosubstituídos reagem mais rapidamente.

\section{- $\quad$ Radical hidroxila ( $\mathrm{OH})$}

$\mathrm{O}^{\circ} \mathrm{OH}$ é o principal radical oxidante formado quando soluções aquosas são irradiadas. Ele pode reagir de várias formas com compostos orgânicos em soluções aquosas, os tipos mais comuns de reação são: adição, subtração de hidrogênio, transferência de elétrons e recombinação radical-radical. As reações de adição ocorrem prontamente com compostos aromáticos como, benzeno, tolueno e xileno (BTX) e compostos alifáticos insaturados (Eq. 11): 


$$
{ }^{\circ} \mathrm{OH}+\mathrm{CH}_{2}=\mathrm{CH}_{2} \rightarrow \mathrm{HOCH}_{2}-\mathrm{CH}_{2} \cdot
$$

As reações de subtração ocorrem com compostos orgânicos saturados, incluindo compostos contendo grupos carbonilas, como aldeídos e cetonas (Eq12):

$$
\mathrm{OH}+\mathrm{CH}_{3}-\mathrm{CO}-\mathrm{CH}_{3} \rightarrow \mathrm{CH}_{2} \mathrm{COCH}_{3}+\mathrm{H}_{2} \mathrm{O}
$$

As reações de transferência de elétrons são também comuns e ocorrem quando soluções aquosas são irradiadas com elétrons de alta energia, por exemplo, as reações envolvendo íons halogênios ( $\left.X^{-}\right)$(Eq. 13 e 14):

$$
\begin{aligned}
& \mathrm{OH}+\mathrm{X}^{-} \rightarrow \mathrm{X}+\mathrm{OH}^{-} \\
& \mathrm{X}^{\cdot}+\mathrm{X}^{-} \rightarrow \mathrm{X}_{2}^{-}
\end{aligned}
$$

$\mathrm{O} \mathrm{X}_{2}^{-}$pode reagir com moléculas orgânicas formando compostos orgânicos halogenados.

A vantagem adicional do radical hidroxila é que sua recombinação resulta na formação de peróxido de hidrogênio.

\section{- Peróxido de hidrogênio $\left(\mathrm{H}_{2} \mathrm{O}_{2}\right)$}

A principal reação para a formação de $\mathrm{H}_{2} \mathrm{O}_{2}$ é a recombinação radicalradical envolvendo $\mathrm{OH}$. $\mathrm{O}$ valor de $\mathrm{G}$ para a formação de $\mathrm{H}_{2} \mathrm{O}_{2}$ é $0,7 \mu \mathrm{mol} / \mathrm{J}$ e 
concentrações significantes permanecem em solução promovendo uma desinfecção residual (Eq. 15):

$$
{ }^{\circ} \mathrm{OH}+{ }^{\circ} \mathrm{OH} \rightarrow \mathrm{H}_{2} \mathrm{O}_{2}
$$

Pode ocorrer também a dissociação do peróxido de hidrogênio, fornecendo mais radicais oxidantes para o meio (Eq. 16):

$$
\mathrm{e}_{\mathrm{aq}}^{-}+\mathrm{H}_{2} \mathrm{O}_{2} \rightarrow{ }^{\circ} \mathrm{OH}+\mathrm{OH}^{\circ}
$$




\section{OBJETIVO GERAL}

O objetivo deste trabalho é estudar a eficácia e a viabilidade da utilização do processo de oxidação avançada (POA) por radiação gama, gerada por fonte de Cobalto-60, para o tratamento de óleo lubrificante usado, visando possibilitar a sua reutilização.

\subsection{Objetivos específicos}

- Desenvolvimento e validação de metodologia para a determinação de elementos inorgânicos em fase orgânica e aquosa, antes e após irradiação, por fluorescência de raios X (WDXRF);

- Otimização de metodologia para a identificação de compostos orgânicos presentes no óleo lubrificante, antes e após irradiação, por cromatografia gasosa associada à espectrometria de massa (GC/MS) e detector de ionização de chama (GC/FID);

- Otimização de metodologia para a avaliação de parâmetros físicoquímicos, antes e após a irradiação;

- Avaliação do nível de remoção de elementos inorgânicos, degradação ou formação de compostos orgânicos e alterações de parâmetros físico-químicos, após diferentes doses de radiação;

- Comparação do POA com o processo convencional por meio de ferramentas estatísticas. 


\section{CONTRIBUIÇÕES ORIGINAIS}

A literatura, nestes últimos anos, tem reportado a aplicação do processo de oxidação avançada por feixe de elétrons e radiação gama em diversos tipos de tratamentos já citados anteriormente (páginas 30, 31 e 32), mas um estudo sistemático visando à reutilização de óleos lubrificantes usados (automotivos ou industriais) é praticamente inexistente.

A contribuição inédita deste trabalho consiste na aplicação da radiação gama, gerada por fonte de Co-60, para promover a remoção de elementos inorgânicos como, Si, P, S, Cl Ca, V, Cr, Mn, Fe, Ni, Cu, Zn, Cd e outros e também verificar os possíveis compostos orgânicos produzidos e/ou degradados, em função das doses de radiação absorvidas em óleos lubrificantes usados.

Apesar de, o Brasil possuir uma legislação para o reuso de óleo usado, o setor de reaproveitamento apresenta-se ainda muito deficiente, onde somente cerca de $20 \%$ é reciclado, um indicativo da necessidade do uso de tecnologias modernas para ampliar o volume de reaproveitamento deste resíduo. Assim, este projeto de pesquisa tem um caráter inédito no estudo de aplicação de radiação ionizante para óleo mineral automotivo usado, visando à melhoria global deste, para o seu reuso. 


\section{MATERIAIS E MÉTODOS}

Os materiais e os métodos são apresentados a seguir em cinco itens: amostragem, fracionamento e irradiação, técnicas de ensaios analíticos, ensaios físico-químicos e análise multivariada.

\subsection{Amostragem}

A amostragem neste trabalho foi realizada na empresa Tasa Lubrificantes Ltda., localizada no Estado do Rio de Janeiro, em Nova Iguaçu e com filial em São Paulo (Pirituba). Ela possui registro na ANP e tem estabelecido os parâmetros de aceitação do óleo lubrificante usado. Rotineiramente, para cada lote recebido, uma amostragem é efetuada e direcionada ao laboratório de análises para verificar a qualidade, o grau de contaminação e subseqüente processo de recuperação.

As amostras de óleo usado $(1 \mathrm{~L})$ e óleo re-refinado $(1 \mathrm{~L})$ pelo seu processo, com especificações requeridas pela ANP e ASTM foram fornecidas pela empresa.

\subsection{Fracionamento e irradiação}

Após, estudos preliminares, foram determinados melhores parâmetros para os processos de fracionamento e irradiação; descritos a seguir:

A amostra de óleo lubrificante usado foi homogeneizada manualmente, e separada em quatro grupos e estes foram fracionados como descrito abaixo: 
- $\quad$ Grupo A: cada $5 \mathrm{~mL}$ da amostra inicial foram transferidos para 4 frascos de vidro de boro silicato de $5 \mathrm{~mL}$ e nomeadas $\mathrm{A} 1, \mathrm{~A} 2, \mathrm{~A} 3$ e $\mathrm{A} 4$;

- $\quad$ Grupo B: cada $4 \mathrm{~mL}$ da amostra inicial foram transferidos para 4 frascos de vidro de $5 \mathrm{~mL}$ e para cada frasco foi adicionado $1 \mathrm{~mL}$ de peróxido de hidrogênio $\left(\mathrm{H}_{2} \mathrm{O}_{2}-30 \%\right.$ - PA). Essas amostras foram homogeneizadas por 10 minutos em um homogeneizador mecânico (SPEX-MILL, CAT №ᅳ 761556) e nomeadas B1, B2, B3 e B4;

- $\quad$ Grupo C: cada $7 \mathrm{~mL}$ da amostra inicial foram transferidos para 4 frascos de vidro de $14 \mathrm{~mL}$ e cada frasco foi avolumado com água Milli-Q, estas foram homogeneizadas por 10 minutos no homogeneizador e nomeadas como $\mathrm{C} 1$, C2, C3 e C4;

- $\quad$ Grupo D: cada $4 \mathrm{~mL}$ da amostra inicial foram transferidos para 4 frascos de vidro de $14 \mathrm{~mL}$ e cada frasco foi avolumado com água Milli-Q, também homogeneizadas por 10 minutos e nomeadas como D1, D2, D3 e D4.

A irradiação das amostras foi realizada em temperatura ambiente usando o irradiador de Co-60, tipo Gammacell, modelo $220 \mathrm{~N}$, série 142 , com atividade de $11.000 \mathrm{Ci}\left(4.10^{14} \mathrm{~Bq}\right)$ e taxa de dose de 3,3 kGy/h no Centro de Tecnologia das Radiações (CTR) - IPEN/SP.

A dosimetria dessa fonte é realizada periodicamente pelo Laboratório de Dosimetria no CTR, utilizando dosímetros do tipo "Fricke" e "Pespex", para determinar a taxa de dose absorvida do sistema. 
As amostras A1, B1, C1 e D1 não foram irradiadas, constantes como amostras controle. As amostras A2, B2, C2 e D2 foram submetidas à dose de absorção de 100 kGy, as A3, B3, C3 e D3 a 200 kGy e as A4, B4, C4 e D4 a 500 kGy. Após a irradiação, as amostras foram centrifugadas (centrífuga Fanny, 3000 rpm por 2 minutos). Posteriormente, as fases óleo e água foram separadas por gravidade e armazenadas sob refrigeração até a realização dos ensaios analíticos. Na FIG 7 é mostrada as etapas de fracionamento e irradiação.

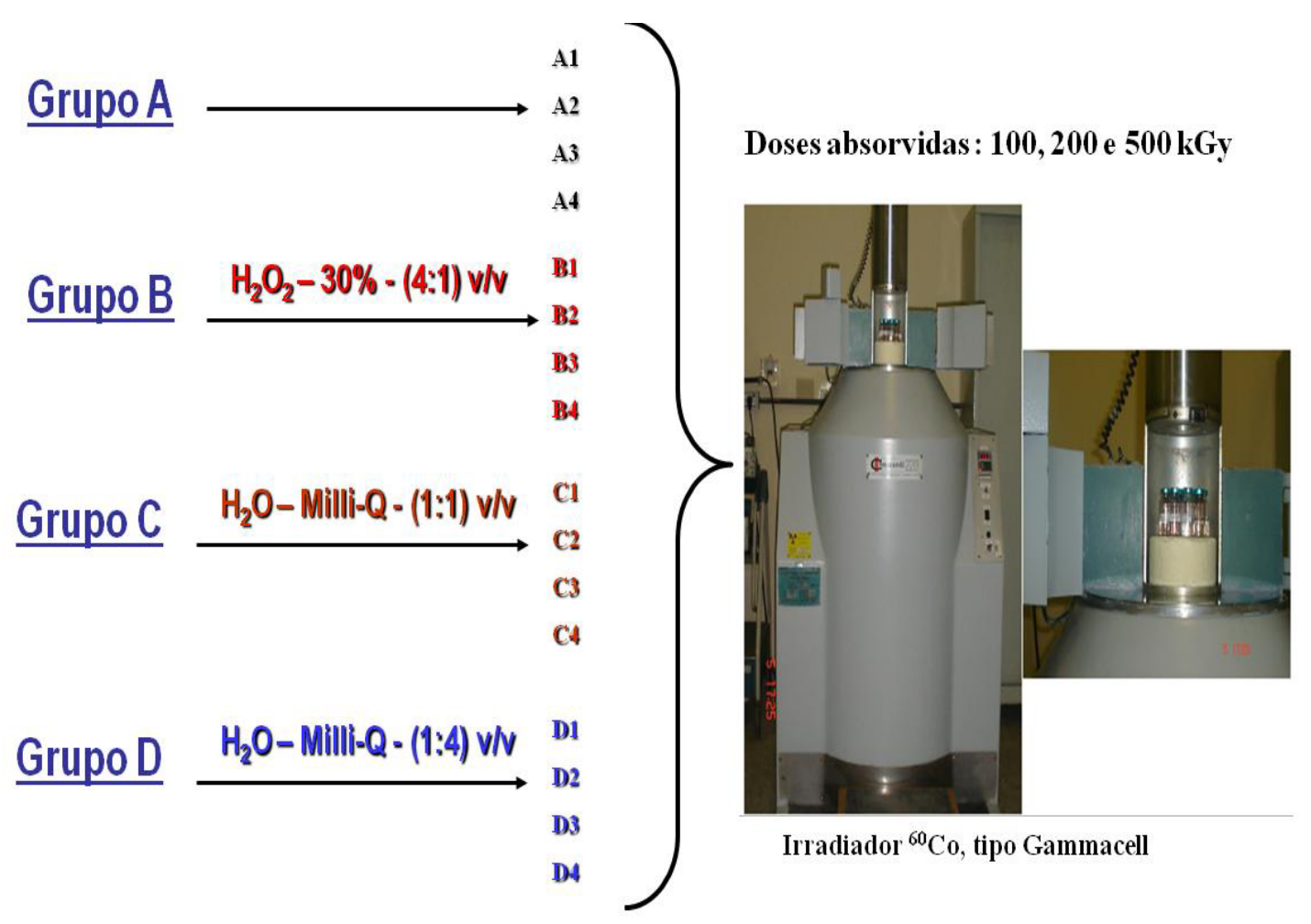

FIGURA 7 - Etapas de fracionamento e irradiação 


\subsection{Técnicas de ensaios analíticos}

A seguir são apresentadas as técnicas de análise/ensaio utilizadas para as analises inorgânicas [espectrometria de fluorescência de raios $X$ (WDXRF) e o método de parâmetros fundamentais (FP), preparação de amostras e validação da metodologia para as análises na fase óleo e aquosa], análises orgânicas [cromatografia gasosa associada à espectrometria de massa (GC/MS) e ao detector por ionização de chama (GC/FID)] e ensaios físico-químicos.

\subsubsection{Espectrometria de fluorescência de raios $X$}

A determinação dos elementos inorgânicos foi realizada por espectrometria de fluorescência de raios $X$ por dispersão de comprimento de onda (WDXRF), usando um espectrômetro RIGAKU Co., modelo RIX 3000, 1996.

A seguir são descritos os principais componentes e acessórios do equipamento:

- $\quad$ Tubo de raios $X$ de Rh com potência de 3,0 kW;

- $\quad$ Filtros de Al, Ti, Ni e Zr;

- $\quad$ Colimadores de 160, 460 e $580 \mu \mathrm{m}$;

- Detectores de cintilação (scintillation - SC) e proporcional de fluxo (flowproportional counters - FPC);

- Cristais analisadores de fluoreto de lítio (LiF-200), germânio (Ge-111), fosfato de tálio (TAP) e pentaerythritol (PET-002);

- $\quad$ Seis portas amostra e

- $\quad$ Sistema para a irradiação em atmosfera de ar, hélio ou vácuo.

As análises foram realizadas no Laboratório de Fluorescência de Raios X (LFX) do Centro de Química e Meio Ambientes (CQMA), IPEN/SP. 


\subsubsection{Método de parâmetros fundamentais (FP)}

A técnica de fluorescência de raios $X$ utiliza de várias metodologias para análises químicas quantitativas, como às de método de regressão linear, padrão interno, método Compton, quimiométricos e de algoritmos. Entre os métodos de algoritmos, o método de parâmetros fundamentais (FP) permite calcular a composição analítica de uma amostra, sem a utilização de padrões similares, a partir da medida da intensidade da linha de emissão do analito e dos valores tabelados dos principais parâmetros fundamentais como distribuição espectral primária (fonte), coeficiente de absorção (fotoelétrico e de massa), rendimento de fluorescência e outros, apresentados no ANEXO B (Scapin, 2003; Lachance, 1995).

O algoritmo envolve duas etapas fundamentais, previsão e calibração. Na primeira etapa, a equação de FP é utilizada para prever a intensidade das linhas características de um padrão de calibração (um material com concentração conhecida e certificada). Os cálculos são realizados especificamente para o espectrômetro em que as medidas estão sendo realizadas, uma vez que a equação de FP considera aspectos de geometria, fonte de excitação e condições instrumentais de medidas. As intensidades teoricamente calculadas são relacionadas com as intensidades medidas (experimentais) para cada linha característica e a sensibilidade instrumental (um fator de conversão) do equipamento é determinada para cada elemento analisado.

Na segunda etapa, o algoritmo estima inicialmente uma composição aproximada da amostra. O cálculo é realizado considerando a somatória de todas as intensidades relativas das linhas de emissão detectadas para cada elemento presente na matriz, assumindo uma composição total de $100 \% \mathrm{em}$ massa. 
A partir desta primeira aproximação, as intensidades fluorescentes esperadas são calculadas para uma composição mais predita, comparando-os com os valores medidos e uma nova composição é ajustada, recalculando um novo conjunto de intensidades esperadas. Este processo de iteração é repetido automaticamente até que a composição esperada forneça uma intensidade de raios $\mathrm{X}$ correspondente ao valor medido, dentro de um nível de significância de 0,05 (Nagata et. al, 2001).

A correlação entre a sensibilidade instrumental e o número atômico $(Z)$ do elemento fornece uma curva conhecida como curva de sensibilidade instrumental, que é armazenada em uma biblioteca. A sensibilidade para os elementos não medidos é determinada por interpolação nesta curva (Scapin, 2003). Por meio desta curva de sensibilidade é possível determinar os elementos de Z=5 (boro) a Z=92 (urânio), dentro de um intervalo de concentração desde porcentagem (\%) até micrograma por grama $\left(\mu \mathrm{g} \mathrm{g}^{-1}\right)$.

As condições de operação instrumental (posição do ângulo de Bragg para o pico e background, cristais analisadores, colimadores, detectores, potencia do tubo de raios $X$ ) utilizados para a obtenção da curva de sensibilidade são apresentadas no APÊNDICE A. No APÊNDICE B são apresentados os materiais utilizados, linhas de emissão características, intensidades experimentais $\left(\mathrm{I}_{\mathrm{EX}}\right)$ e teóricas $\left(\mathrm{I}_{T}\right)$ e a sensibilidade para os elementos de boro $(B=5)$ a urânio $(Z=92)$. No APÊNDICE $C$ é mostrada a curva de sensibilidade instrumental (relação entre sensibilidade instrumental e número atômico para as linhas de emissão $K$ e $L$ ) do espectrômetro de fluorescência de raios $X$ utilizado.

O limite de quantificação, para o método de parâmetros fundamentais, está relacionado com o limite de detecção instrumental, visto que o espectro contínuo, as linhas características emitidas pelos elementos são parâmetros de cálculo para a sensibilidade. 
Assim, cada pico da linha de emissão de um elemento é constituído por uma fração de intensidades fluorescentes de raios $X$ característicos (intensidade líquida) e outra proveniente do espectro contínuo, radiação de fundo, isto é background (BG).

O limite de quantificação $\left(\operatorname{LQ}_{\mu \mathrm{g} \mathrm{g}} \mathrm{g}^{-1}\right)$ para cada elemento $i$ está diretamente relacionado com a intensidade do $B G_{i}$ em contagens por segundo(cps) sob o pico desse elemento de acordo com Eq. 17 (Rousseau, 2001; Scapin, 2003):

$$
L Q_{\mu g g^{-1}}=\frac{3}{m} * \frac{\sqrt{I_{B G}}}{T_{B G}}
$$

Este limite pode ser expresso como uma concentração elementar $\left(\mu \mathrm{g} \mathrm{g}^{-1}\right)$, com um nível de confiança de 95\%, que resulta em uma intensidade líquida igual a três vezes a intensidade do $B G$ (cps):

Na qual,

$\mathrm{m} \equiv$ sensibilidade (quociente entre intensidade teórica/intensidade medida) extraída da curva de sensibilidade;

$I_{B G} \equiv$ intensidade de fundo na posição de pico expresso em contagem por segundo (cps) e

$T_{B G} \equiv$ tempo total (tempo fixo de contagem de $B G$ ).

A intensidade de $B G$ foi calculada por meio da Eq. 18

$$
I_{B G_{i}}=\frac{I_{1}\left(2 \theta_{3}-2 \theta_{2}\right)+I_{3}\left(2 \theta_{2}-2 \theta_{1}\right)}{2 \theta_{3}-2 \theta_{1}}
$$


Na qual,

$I_{1}, I_{3} \equiv$ intensidade de $B G$, à esquerda e à direita do pico, respectivamente.

$2 \theta_{2}, 2 \theta_{1}, 2 \theta_{3} \equiv$ posição de ângulo de Bragg $(2 \theta)$ no pico, à esquerda e à direita do pico, respectivamente.

No APÊNDICE D são apresentados os limites de quantificação calculados do oxigênio ao urânio, utilizando os materiais apresentados no APÊNDICE B.

\subsubsection{Preparação de amostras para análises por WDXRF}

Dois procedimentos foram utilizados para a preparação de amostras, um para as amostras de fase óleo (fase orgânica) e o outro de fase aquosa, descritos abaixo.

As amostras de fase óleo foram preparadas conforme os seguintes passos. Em um molde de $\mathrm{Pt} / \mathrm{Au}$ de $50 \mathrm{~mL}$, previamente tarado, foram adicionados 2,00000 $\pm 0,00005 \mathrm{~g}$ de cera (wax C micro powder) e $1,00000 \pm 0,00005 \mathrm{~g}$ de amostra. Essa mistura foi aquecida em uma chapa elétrica a $60 \pm 5{ }^{\circ} \mathrm{C}$ até a fusão e homogeneizada manualmente. Posteriormente a amostra foi resfriada a temperatura ambiente e desmoldada, obtendo-se um disco de $25 \mathrm{~mm}$ de diâmetro e $10 \mathrm{~mm}$ de espessura, ilustrado na FIG. 8 (Scapin et al., 2006). 


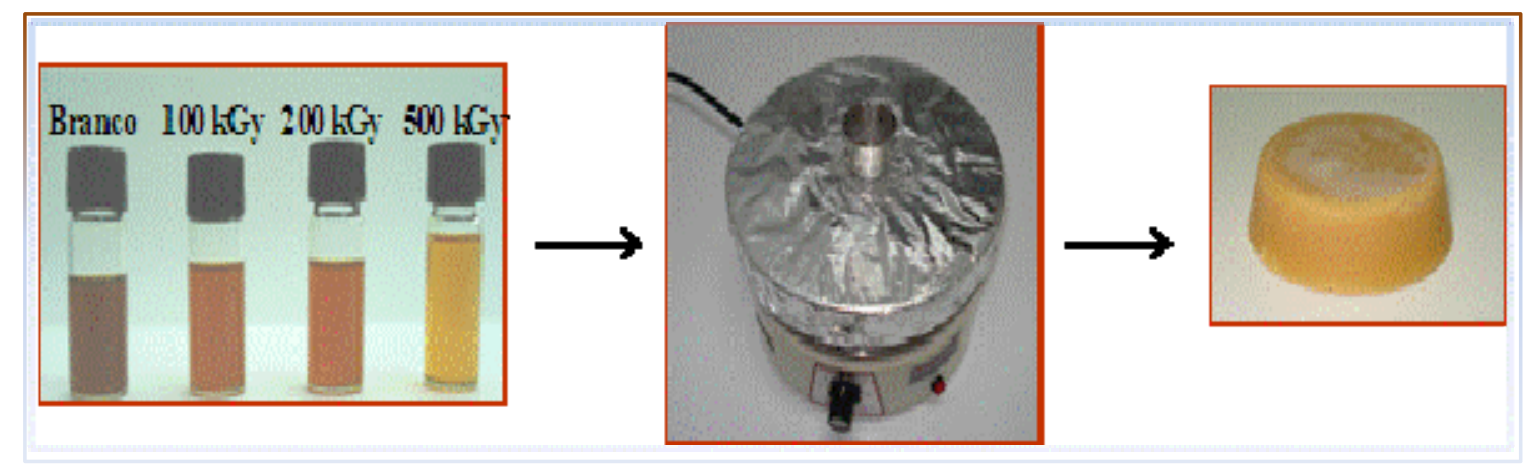

FIGURA 8 - Etapas de preparação de amostras na fase óleo

A metodologia foi avaliada utilizando o material de referência certificado 1084, Wear-metals in lubricating oil, da NIST. Foram preparadas seis amostras e obtidas duas medidas para cada elemento, totalizando um conjunto de 12 medidas por elemento. As intensidades fluorescentes experimentais foram interpoladas na curva de sensibilidade e as concentrações determinadas para os elementos $\mathrm{Mg}, \mathrm{Al}, \mathrm{Si}, \mathrm{S}, \mathrm{Ti}, \mathrm{Cr}, \mathrm{Fe}, \mathrm{Ni}$, $\mathrm{Cu}$ e Pb.

A avaliação da precisão, em termos de repetibilidade, e da exatidão, em termos de erro percentual relativo, foram realizadas por meio de testes estatísticos de acordo com o Guia para a expressão da incerteza de medição e as orientações sobre validação de métodos de ensaios químicos, ambos publicados pelo INMETRO (INMENTRO, 1998; INMETRO, 2003; Scapin, 2003), descritos a seguir:

Primeiramente foi aplicado o teste de Chauvenet, para a detecção dos valores outliers, de acordo com a Eq. 19

$$
\left|X_{i}-\bar{X}\right|>k_{n} . S
$$

Na qual, 
$X_{i} \equiv$ valor medido;

$\bar{X} \equiv$ valor médio;

$k_{n} \equiv$ Coeficiente de Chauvenet (ANEXO A);

$s \equiv$ desvio padrão.

Posteriormente foi aplicado o teste de incerteza para a avaliação da precisão, usando a Eq. 20

$$
U= \pm t_{n-1\left(\frac{\alpha}{2}\right)} * \frac{s}{\sqrt{n}}
$$

$\mathrm{Na}$ qual,

$\mathrm{n} \equiv$ número de repetições;

$\mathrm{s} \equiv$ desvio padrão;

$t_{n-1\left(\frac{\alpha}{2}\right)} \equiv$ valor tabelado teste $t$-Student.

A avaliação da exatidão foi realizada por meio do teste Z-score de acordo com a Eq. 21

$$
Z=\frac{\bar{x}_{\mathrm{det}}-x_{c e r t}}{\sqrt{\sigma_{\mathrm{det}}^{2}+\sigma_{c e r t}^{2}}}
$$

Na qual, 
$\bar{x}_{\text {det }} \equiv$ valor médio determinado;

$x_{\text {cert }} \equiv$ valor certificado;

$\sigma_{\text {det }}^{2} \equiv$ variância calculada;

$\sigma^{2}{ }_{c e r t} \equiv$ variância certificada.

As amostras de fase aquosa foram preparadas conforme seguintes passos:

a) Utilizando uma micropipeta automática, modelo Finnpipette, da ThermoLabsystems, $100 \mu \mathrm{L}$ de amostra foram depositados sobre um disco de papel de filtro (Whatman-42) de 2,0 cm de diâmetro, fixado sobre fita adesiva dupla face da $3 \mathrm{M}$.

b) Posteriormente, as amostras foram secas a temperatura entre $25-30{ }^{\circ} \mathrm{C}$;

c) Após a secagem as amostras foram recobertas com filme de polietileno (Mylar) (Sato, 1988);

d) Réplicas de três amostras foram assim preparadas e para cada uma foram obtidas três medidas no espectrômetro, utilizando o método de parâmetros fundamentais.

A metodologia foi validada usando o material de referência certificado "ALFA AESAR Ground \& Waste Water Pollution Standard Solution 1, Specpure ${ }^{\circledR}$, para os elementos Al, V, Cr, Mn, Fe, Ni, Cu, Zn e Pb, seguindo os mesmos procedimentos utilizados para a validação das amostras de fase óleo (INMETRO, 1998; INMETRO, 2003; Scapin ${ }^{\text {, }}$ et al., 2007) A FIG. 9 ilustra o procedimento de preparação de amostra. 


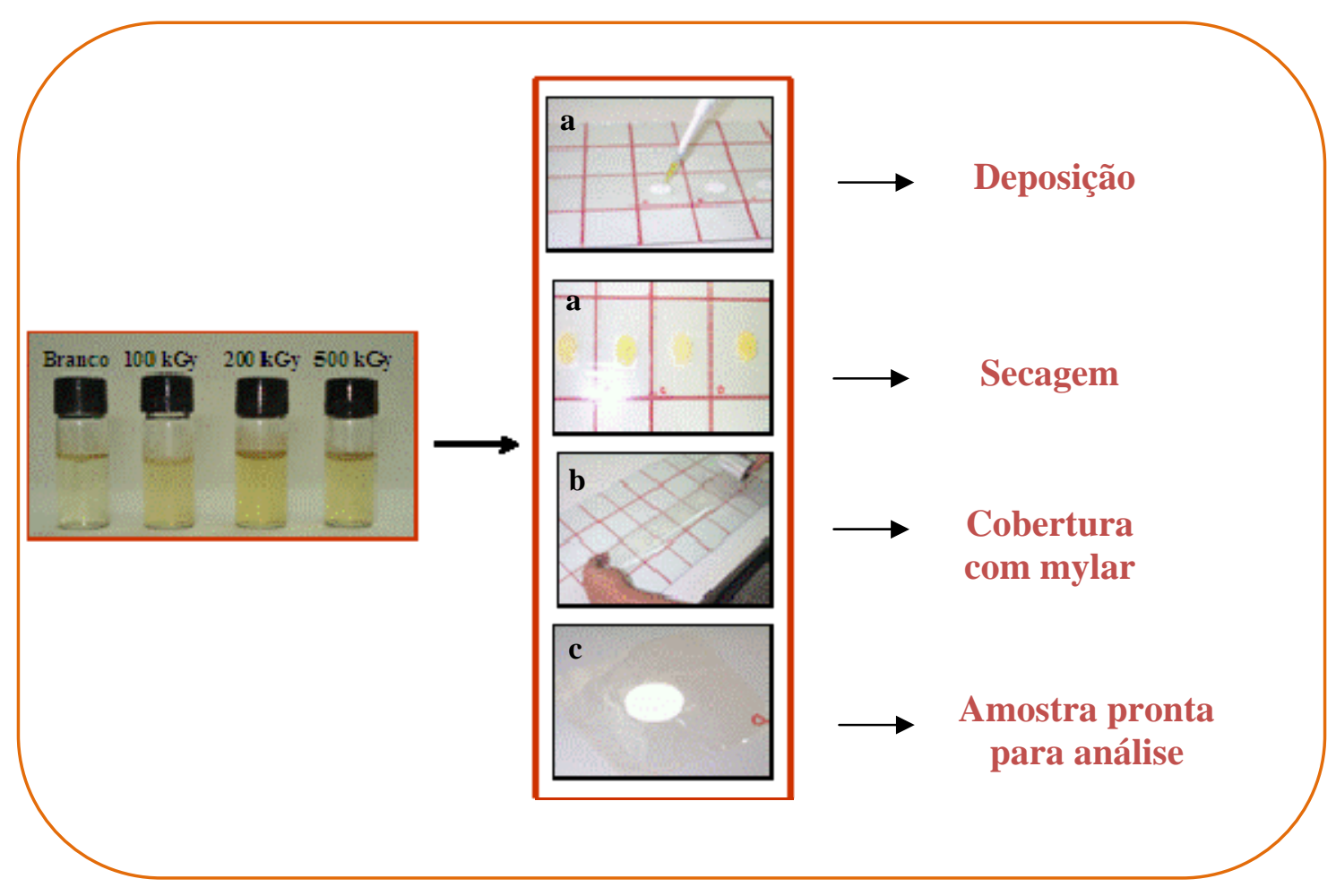

FIGURA 9 - Etapas de preparação de amostras na fase aquosa

\subsubsection{Cromatografia gasosa associada à espectrometria de massa (GC/MS)}

As análises para a identificação dos compostos orgânicos foi realizada no Laboratório de Química Ambiental do Centro de Química e Meio Ambiente (CQMA), IPEN/SP, utilizando o cromatógrafo a gás associado ao espectrômetro de massa, GC/MS da Shimadzu, modelo QP5000, equipado com uma coluna capilar revestida com DB-5ms da J\&W scientific, com $30 \mathrm{~m}$ de comprimento, 0,25 $\mathrm{mm}$ de diâmetro interno e 0,25 $\mu \mathrm{m}$ de espessura do filme da fase estacionária. O procedimento de preparação de amostra, assim como as condições de medida foi adaptado do método EPA 8260B (Volatile organic compounds by gas chromatography/mass spectrometry - GC/MS Environmental Protection Agency).

Cada alíquota de $1 \mu \mathrm{L}$ das amostras A1 (amostra controle), C4 e D4 (irradiadas com dose absorvida de 500 kGy, após adição de água Milli-Q, 50 e 
$70 \% \mathrm{v} / \mathrm{v}$, respectivamente) e PCR (amostra reciclada por processo convencional) foi diluída (1:10) em diclorometano e injetadas no modo splitless.

O gás hélio foi usado como gás de arraste, com fluxo de 1,3 $\mathrm{mL} / \mathrm{min}$. A coluna foi mantida a $75^{\circ} \mathrm{C}$ durante 1 minuto e aquecida em seguida até 200 ${ }^{\circ} \mathrm{C}$, a uma razão de $15{ }^{\circ} \mathrm{C} / \mathrm{min}$. A temperatura final foi mantida por 1 minuto a $250{ }^{\circ} \mathrm{C}$. O tempo total de análise foi de 35 minutos.

Os compostos orgânicos presentes foram identificados utilizando-se o banco de dados da biblioteca NIST (National Institute of Standards of Technology) por meio do software acoplado ao espectrômetro GC/MS.

\subsubsection{Cromatografia gasosa com detector por ionização de chama (GC/FID)}

As mesmas amostras A1, C4, D4 e PCR, utilizadas para análise por GC/MS, foram usadas para a análise semi-quantitativa dos compostos orgânicos, no Centro de Tecnologia das Radiações (CTR), IPEN/SP, utilizando o cromatógrafo a gás com detector por ionização de chama, DIC da Shimadzu, modelo 17A, seguindo o procedimento adaptado do método EPA 8260B.

Foram utilizadas as seguintes condições experimentais de medidas:

- $\quad$ Coluna capilar revestida com sílica fundida DB-5 (5\% fenil, 95\% dimetil polixiloxano) apolar da J\&W scientific, Folson, CA, USA, com $30 \mathrm{~m}$ de comprimento, $0,32 \mathrm{~mm}$ de diâmetro interno e $0,25 \mu \mathrm{m}$ de espessura do filme da fase estacionária;

- $\quad$ Temperatura do detector $180{ }^{\circ} \mathrm{C}$;

- $\quad$ Temperatura do injetor $150^{\circ} \mathrm{C}$;

- $\quad$ Rampa de subida da temperatura da coluna, $50{ }^{\circ} \mathrm{C}-200{ }^{\circ} \mathrm{C}\left(50^{\circ} \mathrm{C} / \mathrm{min}\right)$ por $5,0 \mathrm{~min} ; 200^{\circ} \mathrm{C}-300^{\circ} \mathrm{C}\left(50^{\circ} \mathrm{C} / \mathrm{min}\right)$ por $2,0 \mathrm{~min}$; 
- $\quad$ Tempo total de cada análise $32 \mathrm{~min}$;

- Volume de injeção de $1 \mu \mathrm{L}$ (amostra inicial diluída em 4 : 100 (v/v) em diclorometano).

\subsection{Ensaios físico-químicos}

Os ensaios físico-químicos realizados como testes complementares são descritos a seguir:

\subsubsection{Cor}

De acordo com a Agência Nacional do Petróleo - Portaria № 129 (ANP, 1999), a variação de cor do óleo lubrificante básico permite verificar possível contaminação e indícios de oxidação.

Assim, quanto mais claro for o óleo, menor será o nível de contaminação e oxidação. Os ensaios devem ser realizados de acordo com a Norma ASTM D 1500 (Test Method for ASTM Color of Petroleum Products, ASTM Color Scale).

As análises de cor foram realizadas por esctrofotometria na região do ultravioleta (UV próximo, 200 a 380nm) com um espectrofotômetro Cary 1E, da Varian, do Centro de Química e Meio Ambiente (CQMA), IPEN/SP.

Alíquotas de $100 \mu \mathrm{L}$ de amostra foram diluídas em $5 \mathrm{~mL}$ de tetracloreto de carbono PA, Merck. Os espectros das amostras foram obtidos utilizando-se uma cubeta de quartzo de $1 \mathrm{~cm}$ de caminho óptico, normalmente utilizados em análises espectrofotométricas. 


\subsubsection{Viscosidade cinemática}

A viscosidade cinemática do óleo lubrificante básico é um parâmetro que permite avaliar a resistência ao escoamento para uma determinada temperatura. Assim, quanto mais viscoso for um lubrificante, maior será a sua resistência ao escoamento, permitindo a melhor lubrificação das peças envolvidas. Este parâmetro é o de maior importância para a especificação de um óleo lubrificante.

As análises de viscosidade foram realizadas no LFX/CQMA, à temperatura de $25 \pm 3{ }^{\circ} \mathrm{C}$ utilizando o Método NBR 10441. A metodologia foi adaptada devido à quantidade pequena da amostra para a aplicação do método normalizado. A metodologia foi avaliada em função do valor obtido para a amostra de óleo lubrificante reciclada por processo convencional (PCR), a qual se encontra dentro das especificações estabelecidas pela ANP.

\subsubsection{Densidade}

A densidade de um óleo lubrificante básico é um parâmetro que permite avaliar prováveis níveis de contaminação e degradação.

As medidas de densidade foram realizadas em temperatura ambiente no LFX/CQMA. A metodologia foi avaliada em referência também a amostra PCR. 


\subsection{Análise multivariada}

A análise multivariada é uma ferramenta que permite a interpretação de uma base de dados com um número grande de variáveis por meio de tratamentos estatísticos. Os métodos de análises multivariadas, como Análise de Componentes Principais (PCA) e Análises de Clusters (AC) permitem aos resultados experimentais a avaliação de relações como: reduzir base de dados sem comprometer o valor da informação inicial, identificar grupos de objetos ou variáveis similares, identificar as relações entre as variáveis e o modo de relacionamento, permitir o conhecimento das relações entre as variáveis e realizar previsões de algumas variáveis em função das outras (Castanho, 1999; Morrison, 2003; Hair, 2005).

Neste trabalho foi aplicada a Análise de Cluster com método de Ward, que calcula a distância euclidiana. Os cálculos foram realizados por meio do software STATISTICA, versão 6. O objetivo desta análise foi avaliar todos os resultados obtidos (nas análises químicas e físico-químicas) em função dos tratamentos utilizados.

Foi construída uma matriz com 14 casos por 5 variáveis. Para os casos foram considerados os teores dos elementos S, P, Cl, Si, Ca, Zn e Ni, os valores de absorbância obtidos da análise de cor, os valores de viscosidade e densidade e os teores dos nove compostos orgânicos em maior concentração $\left(\mathrm{C}_{5} \mathrm{H}_{13} \mathrm{NO}, \mathrm{C}_{13} \mathrm{H}_{28}, \mathrm{C}_{16} \mathrm{H}_{34}, \mathrm{C}_{5} \mathrm{H}_{13} \mathrm{NO}_{3}, \mathrm{C}_{8} \mathrm{H}_{18} \mathrm{O}_{3}, \mathrm{C}_{10} \mathrm{H}_{22} \mathrm{~N}_{2}, \mathrm{C}_{10} \mathrm{H}_{18} \mathrm{O}, \mathrm{C}_{716} \mathrm{O}\right.$, $\mathrm{C}_{9} \mathrm{H}_{22} \mathrm{~N}_{2}$ ). Para as variáveis foram consideradas as amostras de controle $\mathrm{A} 1$, B4, C4, D4 e PCR descritas anteriormente (APÊNDICE G). Por meio do software Statistic, versão 6 , estes dados foram normalizados e agrupados (APÊNDICE H). 


\section{RESULTADOS E DISCUSSÕES}

Os resultados são apresentados em quatro tópicos:

- Determinação dos elementos inorgânicos, subdivididos nos itens:

- Resultados da validação das metodologias para análise quantitativa por WDXRF na fase óleo e aquosa;

- Resultados de análise dos elementos inorgânicos para as amostras na fase óleo e aquosa;

- Determinação do nível de remoção dos elementos inorgânicos para as diferentes doses de irradiação

- Análise dos compostos orgânicos por cromatografia gasosa GC/MS e por GC/FID;

- Resultados de parâmetros físico-químicos, cor, viscosidade cinemática e densidade e

- $\quad$ Análise multivariada.

\subsection{Validação da metodologia para amostras na fase óleo}

$\mathrm{Na}$ TAB 4, são apresentados os valores determinados e certificados (média e incerteza) do material de referência 1084 (Wear-metals in lubricating oil, da NIST), os valores de desvio padrão relativo percentual (DPR\%), de erro relativo percentual (ER\%) e limite de quantificação (LQ).

Os valores calculados para o DPR\% mostram que a metodologia proposta apresenta uma repetibilidade satisfatória, pois os elementos determinados (Mg, Al, Si, S, Ti, Cr, Fe, Ni, Cu e Pb) apresentaram valores entre 1,0 a $5,1 \%$, evidenciado que o procedimento de preparação de amostra é reprodutivo, já que são rejeitados valores superiores a 10\% (INMETRO, 2003). 
A exatidão, calculada como ER\%, apresentou para todos os elementos determinados valores menores que $3,3 \%$. Os resultados evidenciam que a metodologia proposta também apresenta exatidão satisfatória comprovada por meio dos valores obtidos pelo teste Z-score, recomendado pelo EURACHEM/CITAC Guide. Os valores de Z-score calculados para os elementos $\mathrm{Mg}, \mathrm{Al}, \mathrm{Ti}, \mathrm{Cr}$, Fe, Ni e Cu são mostrados na FIG. 10 , onde todos são menores que $|1|$. O teste Z-score aceita como satisfatório os valores entre $-1<Z<1$, questionáveis os entre $-2<Z<2$ e rejeita os valores $>|3|$. Assim, a acurácia da metodologia proposta foi validada para a determinação dos elementos $\mathrm{Mg}, \mathrm{Al}, \mathrm{Si}, \mathrm{S}, \mathrm{Ti}, \mathrm{Cr}, \mathrm{Fe}, \mathrm{Ni}, \mathrm{Cu}$ e Pb em amostras de óleo lubrificante.

O valores calculados para o limite de quantificação apresentou $5 \mu \mathrm{g}$ $\mathrm{g}^{-1}$ para os elementos $\mathrm{Mg}, \mathrm{Al}$, Si e S; $7 \mu \mathrm{g} \mathrm{g}^{-1}$ para $\mathrm{Cr}$ e Fe; 8 e $9 \mu \mathrm{g} \mathrm{g}^{-1}$ para $\mathrm{Ni}$ e $\mathrm{Cu} ; 12$ e $15 \mathrm{\mu g} \mathrm{g}^{-1}$ para $\mathrm{Pb}$ e Ti, respectivamente. Os resultados mostram que estes valores são suficientes para a avaliação de conteúdos de elementos químicos em amostras de óleo lubrificantes, conforme o objetivo deste trabalho, ainda o método demonstra a grande potencialidade da técnica de WDXRF para as análises multi-elementares destes tipos de materiais de forma rápida, precisa e exata, sem a necessidade de tratamentos químicos na preparação das amostras.

TABELA 4 - Valores determinados e certificados, DPR\%, ER\% e LQ para o material de referência certificado SRM 1084.

\begin{tabular}{lccccc}
\hline \multirow{2}{*}{ Elemento } & $\begin{array}{c}\text { Certificado } \\
\mu \mathrm{g} \mathrm{g}^{-1}\end{array}$ & $\begin{array}{c}\text { Determinado } \\
\mu \mathrm{g} \mathrm{g}^{-1}\end{array}$ & $\begin{array}{c}\text { DPR } \\
\%\end{array}$ & $\begin{array}{c}\text { ER } \\
\%\end{array}$ & $\begin{array}{c}\mathrm{LQ} \\
\mathrm{g} \mathrm{g}^{-1}\end{array}$ \\
\hline $\mathrm{Mg}$ & $94 \pm 4$ & $94 \pm 1$ & 2,0 & 0,4 & 5 \\
$\mathrm{Al}$ & $98 \pm 2$ & $98 \pm 3$ & 3,6 & $-0,3$ & 5 \\
$\mathrm{Si}$ & ${ }^{*} 102$ & $99 \pm 4$ & 5,0 & 3,3 & 5 \\
$\mathrm{~S}$ & ${ }^{*} 2237$ & $2195 \pm 81$ & 3,7 & 1,9 & 5 \\
$\mathrm{Ti}$ & $99 \pm 5$ & $99 \pm 4$ & 4,0 & 0,3 & 15 \\
$\mathrm{Cr}$ & $100 \pm 3$ & $98 \pm 5$ & 5,1 & 1,7 & 7 \\
$\mathrm{Fe}$ & $100 \pm 3$ & $98 \pm 1$ & 1,0 & 1,7 & 7 \\
$\mathrm{Ni}$ & $101 \pm 4$ & $100 \pm 3$ & 3,0 & 1,2 & 8 \\
$\mathrm{Cu}$ & $98 \pm 4$ & $99 \pm 1$ & 1,0 & $-0,5$ & 9 \\
$\mathrm{~Pb}$ & ${ }^{*} 101$ & $101 \pm 1$ & 1,0 & $-0,3$ & 12 \\
\hline Valor não certificado & & & &
\end{tabular}




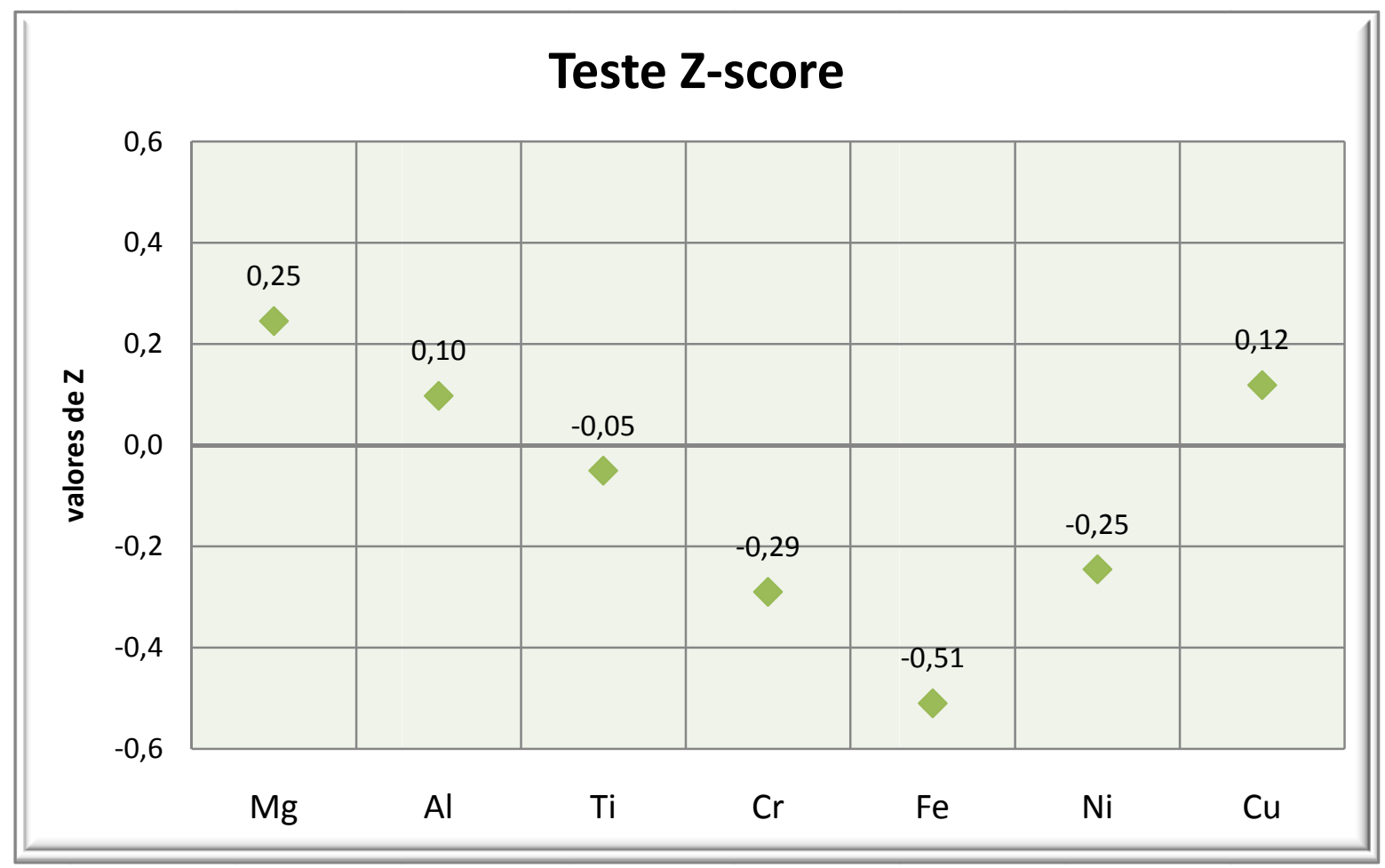

FIGURA 10 - Valores de Z-score calculados para o SRM 1084.

5.2 Validação da metodologia para amostras na fase aquosa

Na TAB. 5, são apresentados os valores determinados e certificados (média e incerteza) do material de referência ALFA AESAR Ground \& Waste Water Pollution Standard Solution 1, Specpure ${ }^{\circledR}$ (stock 36740, lote 703527D), os valores de desvio padrão relativo percentual (DPR\%), os de erro relativo percentual (ER\%) e os de limite de quantificação (LQ). 
TABELA 5 - Valores determinados e certificados, DPR\%, ER\% e LQ para o material de referência ALFA AESAR (stock 36740, lote 703527D),.

\begin{tabular}{cccccc}
\hline Elemento & $\begin{array}{c}\text { Certificado } \\
\mu \mathrm{gL}^{-1}\end{array}$ & $\begin{array}{c}\text { Determinado } \\
\mu \mathrm{g} \mathrm{mL}^{-1}\end{array}$ & $\begin{array}{c}\mathrm{DPR} \\
\%\end{array}$ & $\begin{array}{c}\mathrm{ER} \\
\%\end{array}$ & $\begin{array}{c}\mathrm{LQ} \\
\mu \mathrm{mL}^{-1}\end{array}$ \\
\hline $\mathrm{Al}$ & $500 \pm 1$ & $500 \pm 2$ & 0,4 & 0,1 & 5 \\
$\mathrm{~V}$ & $250 \pm 1$ & $251 \pm 6$ & 2,4 & 0,2 & 10 \\
$\mathrm{Cr}$ & $100 \pm 1$ & $102 \pm 2$ & 2,0 & 1,7 & 7 \\
$\mathrm{Mn}$ & $100 \pm 1$ & $103 \pm 2$ & 1,9 & 3,1 & 7 \\
$\mathrm{Fe}$ & $100 \pm 1$ & $103 \pm 2$ & 1,9 & 2,8 & 7 \\
$\mathrm{Ni}$ & $100 \pm 1$ & $101 \pm 3$ & 3,0 & 1,0 & 8 \\
$\mathrm{Cu}$ & $100 \pm 1$ & $103 \pm 3$ & 3,0 & 2,9 & 9 \\
$\mathrm{Zn}$ & $100 \pm 1$ & $102 \pm 3$ & 2,9 & 2,0 & 13 \\
$\mathrm{~Pb}$ & $100 \pm 1$ & $100 \pm 4$ & 4,0 & 0,2 & 12 \\
\hline
\end{tabular}

Os valores calculados de DPR\% para os elementos determinados (Al, V, Cr, Mn, Fe, Ni, Cu, Zn E Pb) estão entre 0,5 a 4,0 \%. Estes valores evidenciam a reprodutibilidade do método, já que são rejeitados valores superiores a $10 \%$ (INMETRO, 2003).

Em relação à exatidão, os valores de $\mathrm{ER} \%$, para todos os elementos determinados apresentaram-se entre 0,1 a 3,1\%, demonstrando que esta metodologia também apresenta exatidão satisfatória, comprovada pelos valores obtidos pelo teste Z-score. Os valores de Z-score, para os elementos $\mathrm{Al}, \mathrm{V}, \mathrm{Cr}, \mathrm{Mn}, \mathrm{Fe}, \mathrm{Ni}, \mathrm{Cu}, \mathrm{Zn}$ e Pb, são mostrados na FIG. 11 e situaram-se entre $-1,00$ a $+0,20$, portanto, também validando esta metodologia. 
O valores de limite de quantificação calculados, encontraram-se entre $5 \mu \mathrm{g} \mathrm{mL}^{-1}$ a $13 \mu \mathrm{g} \mathrm{mL}^{-1}$ para os elementos $\mathrm{Al}, \mathrm{V}, \mathrm{Cr}, \mathrm{Mn}, \mathrm{Fe}, \mathrm{Ni}, \mathrm{Cu}, \mathrm{Zn}$ e $\mathrm{Pb}$. Estes limites satisfazem a avaliação da determinação multi-elementar de elementos menores e traços em amostras de água residual, demonstrando a grande potencialidade da técnica de WDXRF para este tipo de análise.

\section{Teste Z-score}

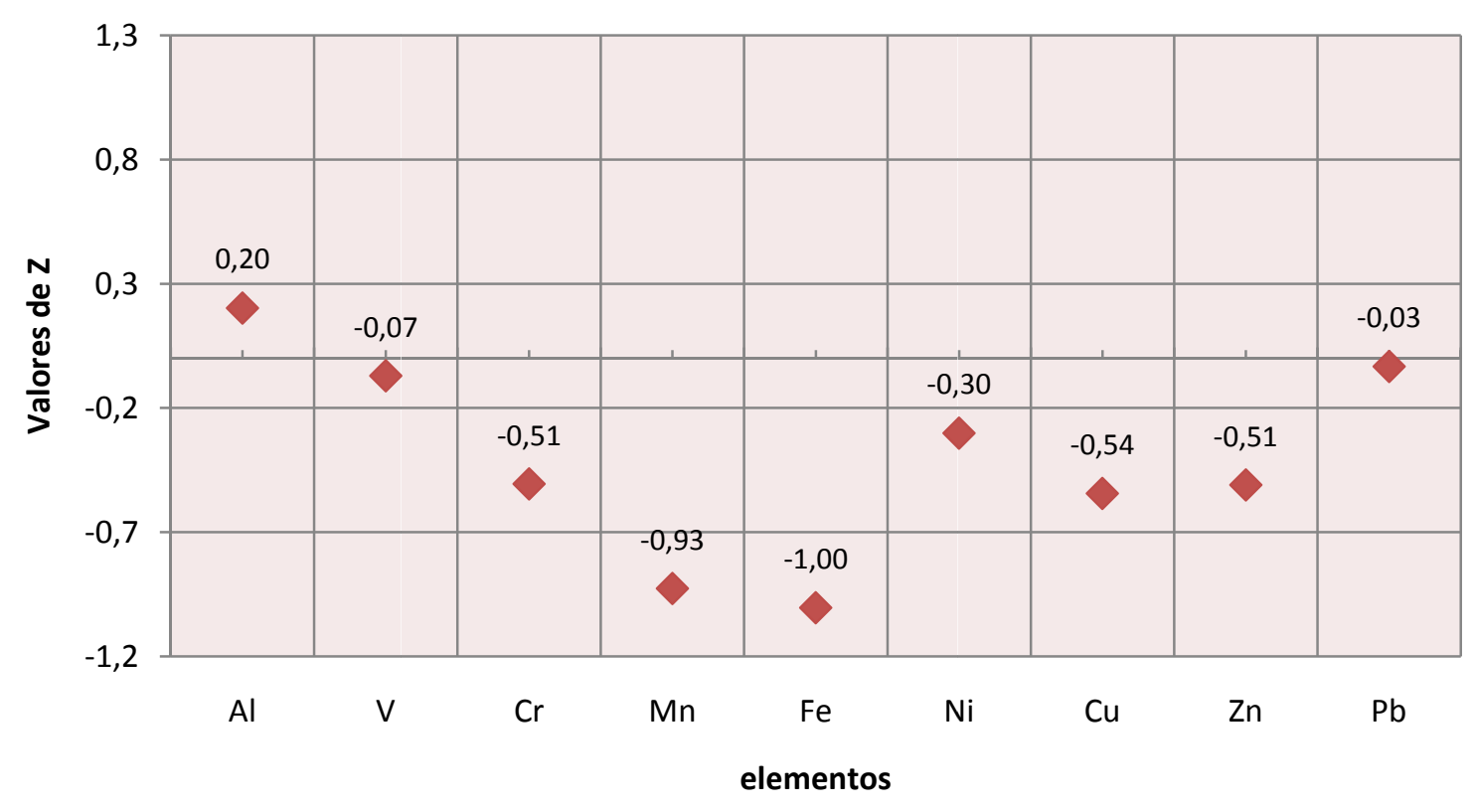

FIGURA 11 - Valores de Z-score calculados para o SRMALFA AESAR (stock 36740, lote 703527D) 


\subsection{Análise química inorgânica - fase óleo}

A seguir são apresentados os resultados obtidos para o nível de remoção de elementos inorgânicos em função das diferentes doses de irradiação.

\subsubsection{Determinação do nível de remoção dos elementos inorgânicos}

As analises quantitativas preliminares revelaram a presença dos elementos $\mathrm{Mg}, \mathrm{Al}, \mathrm{Si}, \mathrm{P}, \mathrm{S}, \mathrm{Cl}, \mathrm{Ca}, \mathrm{Cr}, \mathrm{Mn}, \mathrm{Fe}, \mathrm{Ni}, \mathrm{Zn}$, e Pb. Foi verificado que a remoção significativa destes elementos inicia-se a partir da dose absorvida de 100 kGy, comprovado pelas amostras de óleo usado submetidas às doses absorvidas de 10, 20, 50 e 100kGy (Scapin ${ }^{\text {b }}$ et al., 2007).

A avaliação do nível de remoção dos elementos inorgânicos, em função dos tratamentos e diferentes doses de radiação aplicadas foram realizadas para as amostras dos grupos A, B, C e D, fase óleo (descritos no item 4.2, pg. 36 a 38) e uma comparação da eficiência de remoção, foi realizada com a amostra de óleo lubrificante recuperada pelo processo da empresa Tasa, denominada processo de recuperação convencional (PRC).

$\mathrm{Na}$ TAB. 6 são apresentadas as concentrações determinadas em ordem crescente para os elementos maiores que $10 \mu \mathrm{g} \mathrm{g}^{-1}$ (S, P, Cl, Si, Ca, Fe, Zn e Ni) nas amostras A1, B1, C1 e D1 (amostras não irradiadas); A2, B2, C2, e D2 (irradiadas com dose absorvida de 100 kGy); A3, B3, C3, e D3 (irradiadas com dose absorvida de 200 kGy); A4, B4, C4, e D4 (irradiadas com dose absorvida de 500 kGy) e amostra PRC. Juntamente, estão relacionados os níveis de remoção percentual (NR\%). 
TABELA 6 - Concentração elementar $\left(\mu \mathrm{g} \mathrm{g}^{-1}\right)$ e NR\% para as amostras do grupo A, B, C, D e PRC para diferentes doses de irradiação.

\begin{tabular}{|c|c|c|c|c|c|c|c|c|}
\hline \multirow[b]{2}{*}{ Amostras } & \multicolumn{8}{|c|}{ Elementos } \\
\hline & $\mathrm{S}$ & $\mathrm{P}$ & $\mathrm{Cl}$ & $\mathrm{Si}$ & $\mathrm{Ca}$ & $\mathrm{Fe}$ & $\mathrm{Zn}$ & $\mathrm{Ni}$ \\
\hline $\begin{array}{c}\mathrm{A} 1 \\
{\left[\mu \mathrm{g} \mathrm{g}^{-1}\right]}\end{array}$ & $11896 \pm 237$ & $571 \pm 23$ & $571 \pm 23$ & $221 \pm 9$ & $84 \pm 3$ & $62 \pm 1$ & $55 \pm 1$ & $18 \pm 1$ \\
\hline $\begin{array}{c}\mathrm{NR} \% \\
\mathrm{~A} 2\end{array}$ & 0 & 0 & 0 & 0 & 0 & 0 & 0 & 0 \\
\hline$\left[\mu g^{-1}\right]$ & $10234 \pm 205$ & $529 \pm 21$ & $496 \pm 20$ & $176 \pm 7$ & $67 \pm 3$ & $56 \pm 1$ & $43 \pm 1$ & $15 \pm 1$ \\
\hline $\begin{array}{c}\text { NR\% } \\
\text { A3 }\end{array}$ & 14 & 7 & 13 & 20 & 20 & 10 & 22 & 17 \\
\hline$\left[\mu \mathrm{g} \mathrm{g}^{-1}\right]$ & $8119 \pm 162$ & $469 \pm 19$ & $443 \pm 18$ & $161 \pm 6$ & $59 \pm 3$ & $48 \pm 1$ & $38 \pm 1$ & $13 \pm 1$ \\
\hline $\begin{array}{c}\mathrm{NR} \% \\
\mathrm{~A} 4\end{array}$ & 32 & 18 & 22 & 27 & 30 & 23 & 31 & 28 \\
\hline$\left[\mu \mathrm{g} \mathrm{g}^{-1}\right]$ & $7568 \pm 151$ & $437 \pm 17$ & $390 \pm 16$ & $124 \pm 5$ & $51 \pm 2$ & $30 \pm 1$ & $28 \pm 1$ & 121 \\
\hline NR\% & 36 & 23 & 32 & 44 & 39 & 52 & 49 & 33 \\
\hline B1 & & & & & & & & \\
\hline$\left[\mu \mathrm{g} \mathrm{g}^{-1}\right]$ & $11449 \pm 229$ & $565 \pm 23$ & $565 \pm 23$ & $220 \pm 9$ & $75 \pm 3$ & $59 \pm 1$ & $53 \pm 1$ & $18 \pm 1$ \\
\hline $\begin{array}{c}\text { NR\% } \\
\text { B2 }\end{array}$ & 4 & 1 & 1 & 0 & 11 & 5 & 4 & 0 \\
\hline$\left[\mu \mathrm{g} \mathrm{g}^{-1}\right]$ & $9668 \pm 193$ & $524 \pm 21$ & $482 \pm 12$ & $174 \pm 7$ & $65 \pm 3$ & $55 \pm 1$ & $40 \pm 1$ & $15 \pm 1$ \\
\hline $\begin{array}{c}\text { NR\% } \\
\text { B3 }\end{array}$ & 19 & 8 & 16 & 21 & 23 & 11 & 27 & 17 \\
\hline$\left[\mu \mathrm{g} \mathrm{g}^{-1}\right]$ & $8016 \pm 160$ & $452 \pm 18$ & $437 \pm 17$ & $156 \pm 6$ & $56 \pm 2$ & $43 \pm 1$ & $38 \pm 1$ & $13 \pm 1$ \\
\hline $\begin{array}{c}\text { NR\% } \\
\text { B4 }\end{array}$ & 33 & 21 & 23 & 28 & 33 & 31 & 31 & 28 \\
\hline$\left[\mu \mathrm{g} \mathrm{g}^{-1}\right]$ & $7479 \pm 150$ & $426 \pm 17$ & $332 \pm 13$ & $122 \pm 5$ & $49 \pm 2$ & $29 \pm 1$ & $23 \pm 1$ & $11 \pm 1$ \\
\hline NR\% & 37 & 25 & 42 & 45 & 42 & 53 & 58 & 39 \\
\hline $\mathrm{C} 1$ & & & & & & & & \\
\hline$\left[\left[\mu g^{-1}\right]\right.$ & $10806 \pm 216$ & $549 \pm 22$ & $534 \pm 21$ & $177 \pm 7$ & $71 \pm 3$ & $57 \pm 1$ & $52 \pm 1$ & $16 \pm 1$ \\
\hline $\begin{array}{l}\text { NR\% } \\
\text { C2 }\end{array}$ & 9 & 4 & 6 & 20 & 15 & 8 & 5 & 11 \\
\hline$\left[\mu \mathrm{g} \mathrm{g}^{-1}\right]$ & $9173 \pm 183$ & $496 \pm 20$ & $469 \pm 19$ & $170 \pm 7$ & $64 \pm 3$ & $53 \pm 1$ & $40 \pm 1$ & $14 \pm 1$ \\
\hline $\begin{array}{c}\text { NR\% } \\
\text { C3 }\end{array}$ & 23 & 13 & 18 & 23 & 24 & 15 & 27 & 22 \\
\hline$\left[\mu \mathrm{g} \mathrm{g}^{-1}\right]$ & $7879 \pm 158$ & $451 \pm 18$ & $426 \pm 17$ & $155 \pm 6$ & $56 \pm 2$ & $40 \pm 1$ & $32 \pm 1$ & $13 \pm 1$ \\
\hline $\begin{array}{c}\mathrm{NR} \% \\
\mathrm{C} 4\end{array}$ & 34 & 21 & 25 & 30 & 33 & 35 & 42 & 28 \\
\hline$\left[\mu \mathrm{g} \mathrm{g}^{-1}\right]$ & $6890 \pm 138$ & $332 \pm 13$ & $306 \pm 12$ & $116 \pm 5$ & $45 \pm 2$ & $23 \pm 1$ & $22 \pm 1$ & $10 \pm 1$ \\
\hline $\mathrm{NR} \%$ & 42 & 42 & 46 & 48 & 46 & 63 & 60 & 44 \\
\hline D1 & & & & & & & & \\
\hline$\left[\mu \mathrm{g} \mathrm{g}^{-1}\right]$ & $10468 \pm 209$ & $541 \pm 22$ & $526 \pm 21$ & $176 \pm 7$ & $70 \pm 3$ & $56 \pm 1$ & $46 \pm 1$ & $15 \pm 1$ \\
\hline $\begin{array}{c}\text { NR\% } \\
\text { D2 }\end{array}$ & 12 & 5 & 7 & 20 & 17 & 10 & 16 & 17 \\
\hline$\left[\mu \mathrm{g} \mathrm{g}^{-1}\right]$ & $9008 \pm 180$ & $482 \pm 19$ & $451 \pm 18$ & $162 \pm 6$ & $62 \pm 3$ & $51 \pm 1$ & $39 \pm 1$ & $14 \pm 1$ \\
\hline $\begin{array}{c}\text { NR\% } \\
\text { D3 }\end{array}$ & 24 & 16 & 21 & 27 & 26 & 18 & 29 & 22 \\
\hline$\left[\mu \mathrm{g} \mathrm{g}^{-1}\right]$ & $7871 \pm 157$ & $443 \pm 18$ & $405 \pm 16$ & $131 \pm 5$ & $51 \pm 2$ & $40 \pm 1$ & $29 \pm 1$ & $13 \pm 1$ \\
\hline $\begin{array}{c}\text { NR\% } \\
\text { D4 }\end{array}$ & 34 & 22 & 29 & 41 & 39 & 35 & 47 & 28 \\
\hline$\left[\mu \mathrm{g} \mathrm{g}^{-1}\right]$ & $3809 \pm 76$ & $306 \pm 12$ & $283 \pm 11$ & $97 \pm 4$ & $42 \pm 2$ & $19 \pm 1$ & $19 \pm 1$ & $<10$ \\
\hline $\mathrm{NR} \%$ & 68 & 46 & 50 & 56 & 50 & 69 & 65 & 56 \\
\hline $\begin{array}{c}\text { PRC } \\
{\left[\mu \mathrm{g} \mathrm{g}^{-1}\right]}\end{array}$ & $4990 \pm 100$ & $13 \pm 1$ & $<10$ & $<10$ & $67 \pm 3$ & $21 \pm 1$ & $10 \pm 1$ & $<10$ \\
\hline
\end{tabular}


As amostras do Grupo A (A2, A3 e A4), óleo usado (amostra bruta), submetida às doses de absorção de 100, 200 e 500 kGy, demonstraram uma correlação entre as doses absorvidas e o nível de remoção percentual (NR\%), ou seja, quanto maior a dose, maior o nível de remoção.

$\mathrm{Na}$ FIG. 12, pode ser observado o aumento linear no nível de remoção percentual em função das doses absorvidas quando comparamos a amostra controle (A1) com as amostras irradiadas (A2, A3 e A4).

Os maiores valores para o NR\% foram obtidos para a amostra A4 (dose absorvida de $500 \mathrm{kGy}$ ), onde os metais de transição $\mathrm{Fe}$ e Zn, apresentaram valores de 52 e $49 \%$. O menor valor para o NR\% foi verificado para $\mathrm{P}(23 \%)$.

A comparação entre as amostras irradiadas (A2, A3 e A4) com a amostra PRC permite concluir que para se atingir as faixas de concentrações da amostra PRC, doses de irradiação maiores devem ser aplicadas ou scavengers adicionados para favorecer a remoção ou ainda realizar o procedimento com o aumento do volume de água na amostra de óleo, favorecendo a radiólise, conseqüentemente promovendo um aumento no nível de remoção de elementos químicos. 


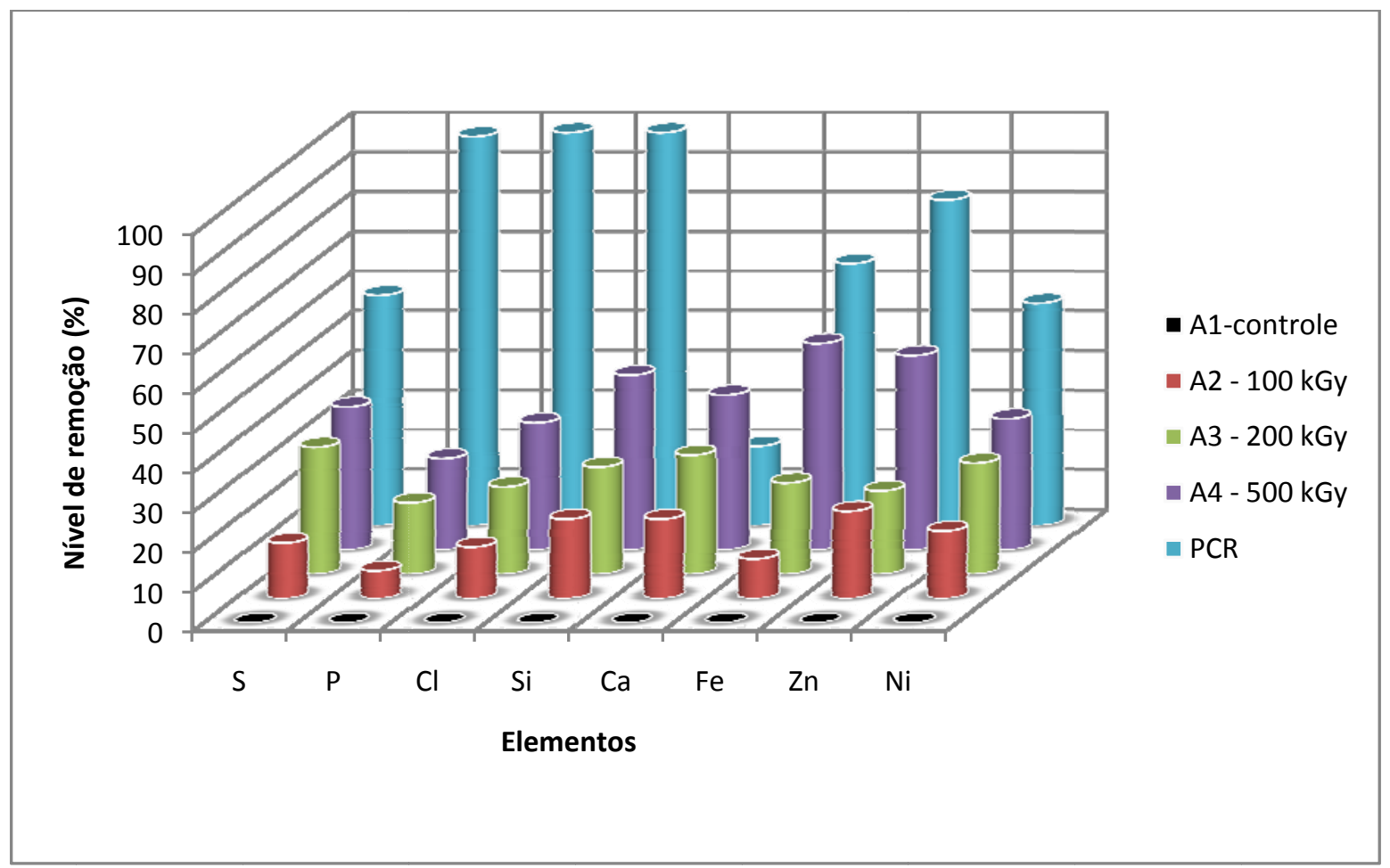

FIGURA 12 - Nível de remoção percentual para as amostras do Grupo A

As amostras do Grupo B (B1, B2, B3 e B4), com adição de $\mathrm{H}_{2} \mathrm{O}_{2}$ $30 \%(20 \%, v / v)$ mostraram que este procedimento, mesmo antes da irradiação, favorece a remoção dos elementos; demonstrando uma remoção para $\mathrm{Ca}$ (11\%), Fe (5\%), Zn (4\%) e S (4\%) (TAB. 6). Na FIG. 14, pode ser observado que após a irradiação os melhores resultados foram obtidos para a amostra com dose de 500 kGy (B4). Comparando os valores de NR\% entre a amostra A4 e B4 verifica-se o aumento do $\mathrm{NR} \%$ do $\mathrm{Cl}$ de 32 para $42 \%$, do Ca de 39 para $42 \%$, do $\mathrm{Zn}$ de 49 para $58 \%$ e do $\mathrm{Ni}$ de 28 para $39 \%$. Os resultados demonstraram que a adição de $\mathrm{H}_{2} \mathrm{O}_{2}-30 \%$ favorece as reações de radiólise nas condições do experimento, contribuindo consideravelmente para a remoção dos elementos acima mencionados. Em relação aos elementos S, P, Si e Fe, estes não apresentaram um aumento no NR\% muito significativo, o $\mathrm{S}$ de 36 para $37 \%$, o Si de 44 para 45\%; o P de 23 para 25\% e o Fe de 52 para 53\%, em relação às amostras do grupo $A$. 


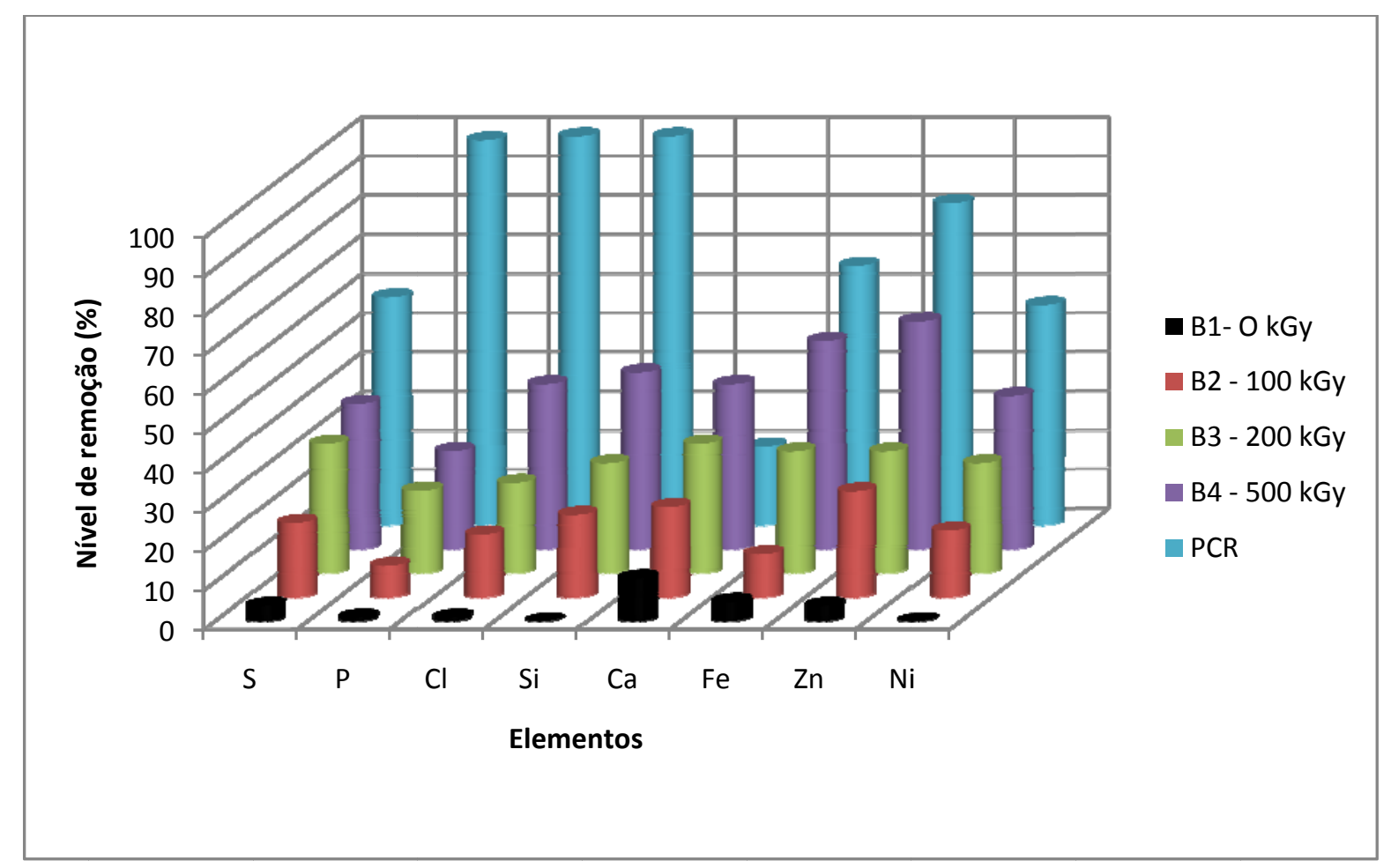

FIGURA 13 - Nível de remoção percentual para as amostras do Grupo B

As amostras do Grupo C, com $\mathrm{H}_{2} \mathrm{O}$ Milli-Q (adição de $50 \%$, v/v) para favorecer a radiólise, mostraram também que mesmo antes da irradiação ocorre aumento no NR\% (Si 20\%, Ca 15\%, Ni 11\%, S 9\%, Fe 8\%, Cl 6\%, Zn $5 \%$ e P 4\%), que são significativamente superiores daqueles obtidos com os experimentos anteriores (TAB. 6). Na FIG. 14, é observado que os melhores resultados foram obtidos para a amostra com dose absorvida de 500 kGy (C4). Os NR\% para os elementos Fe, Zn e Ni foram superiores a 50\%, (63, 60 e $56 \%$, respectivamente). Uma excelente remoção foi verificada para o elemento $\mathrm{P}(\mathrm{NR} \%=42 \%)$. Os resultados demonstraram que a adição da água na amostra de óleo usado, produz melhores resultados do que os obtidos com $\mathrm{H}_{2} \mathrm{O}_{2}-30 \%$. Assim, pode ser constatado o favorecimento das reações de radiólise nas condições do experimento. 
A comparação dos valores da amostra C4 com a PRC permite verificar que os NR\% são muito próximos para os elementos $\mathrm{S}, \mathrm{Fe}, \mathrm{Zn}$ e Ni. O $\mathrm{Ca}$, apresentou NR\% aproximadamente duas vezes maior na amostra C4, indicando que a aplicação de dose de 100 kGy é comparável ao processo convencional na remoção deste elemento. Nestas condições do experimento, $\mathrm{P}, \mathrm{Cl}$ e Si mostraram uma taxa de remoção de 40 a $50 \%$ do processo convencional.

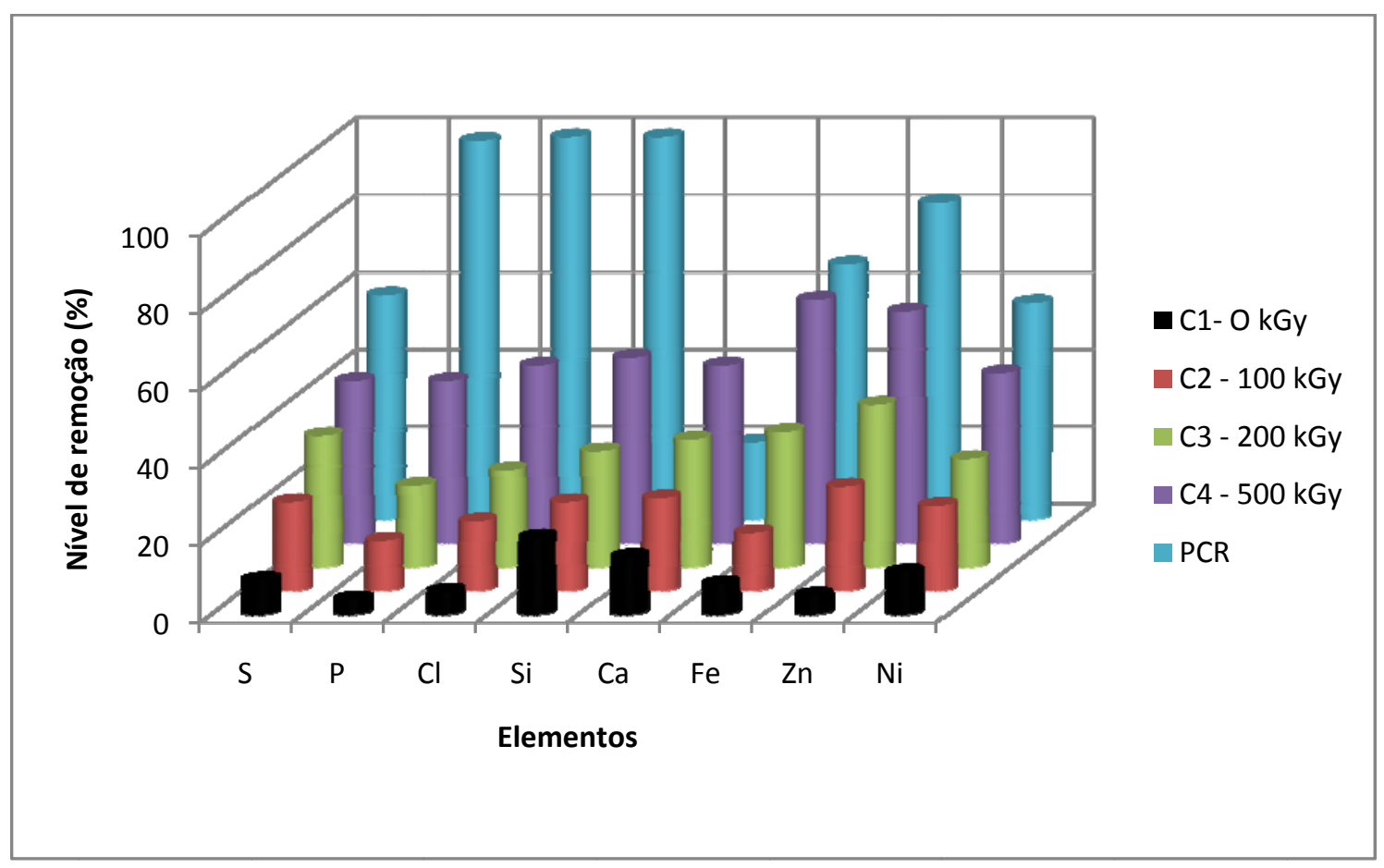

FIGURA 14 - Nível de remoção percentual para as amostras do Grupo C 
A amostra D1, com $\mathrm{H}_{2} \mathrm{O}$ Milli-Q, na proporção $70 \%(\mathrm{v} / \mathrm{v})$, não foi verificado uma remoção significativamente diferente da amostra $C 1$, apresentando valores de NR\% semelhantes (TAB. 6).

$\mathrm{Na}$ FIG. 15, é observado que após a irradiação, a amostra submetida a dose absorvida de 500 kGy (D4) apresentou os melhores resultados, ou seja, maior eficiência de remoção de metais dentre todos os experimentos realizados. O NR\% para o elemento $S$ foi de $68 \%, 10 \%$ maior ao valor da amostra PRC. Este resultado é muito importante, já que a presença deste elemento nos derivados de petróleo é indesejável. Os derivados de petróleo contaminados com enxofre, quando queimados produzem gases com compostos oxigenados de enxofre e quando lançados na atmosfera contribuem principalmente, para o aumento da acidez das chuvas (chuvas ácidas).

Em relação aos outros elementos, todos apresentaram NR\% $\geq 50 \%$, exceção para o P $(\mathrm{NR} \%=46 \%)$. Os resultados indicaram mais uma vez que o aumento de diluição com a água facilita as reações de radiólise, conseqüentemente promovendo melhores níveis de remoção para a mesma dose de absorção.

Nestas condições de experimento, $\mathrm{P}, \mathrm{Cl}$ e Si mostraram uma taxa de remoção menor (cerca de 50\%) da amostra PRC (FIG. 15 e TAB. 6), indicando que devem ser introduzidas variáveis diferentes como adição de scavengers ou aumento da taxa de dose, se objetivar em apresentar um processo alternativo ao convencional para a reciclagem de óleo lubrificante usado. 


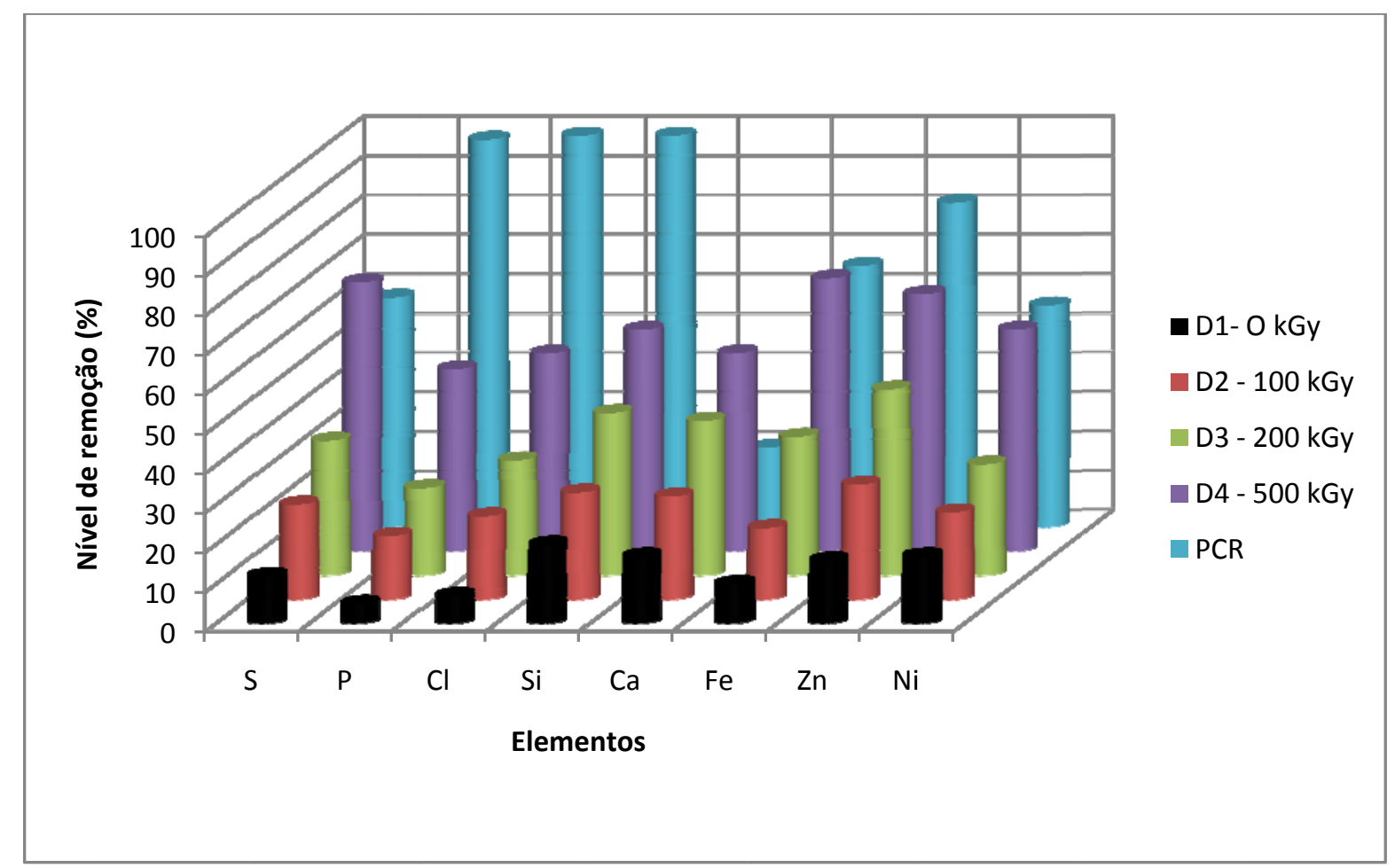

FIGURA 15- Nível de remoção percentual para as amostras do Grupo D

\subsection{Análise química inorgânica - fase aquosa}

Os ensaios foram realizados para as amostras com água Milli-Q, $70 \%$ (v/v), amostra controle D1, não irradiada e irradiada com 500 kGy - D4, por esta apresentar o melhor rendimento de nível de remoção dos elementos inorgânicos. O objetivo do ensaio foi verificar a presença dos elementos removidos da fase óleo e transferidos para a fase aquosa, para uma estimativa de balanço. $\mathrm{Na}$ TAB. 7, são apresentados os valores de concentrações calculadas em relação às concentrações determinadas na fase óleo (C-D1 e CD4) e os valores determinados experimentalmente, denominados E-D1 e E-D4, para a fase aquosa. 
TABELA 7. Valores calculados (amostras C-D1 e C-D4) e determinados (amostras E-D1 e E-D4) dos elementos químicos na fase aquosa

\begin{tabular}{ccccc}
\hline elementos & \multicolumn{2}{c}{ Valores calculados $\left(\mu \mathrm{mL}^{-1}\right)$} & \multicolumn{2}{c}{ Valores determinados $\left(\mu \mathrm{g} \mathrm{m}^{-1}\right)$} \\
\cline { 2 - 5 } & C-D1 & C-D4 & E-D1 & E-D4 \\
$\mathrm{S}$ & $143 \pm 3$ & $809 \pm 16$ & $170 \pm 30$ & $230 \pm 30$ \\
$\mathrm{P}$ & $3 \pm 1$ & $27 \pm 1$ & $7 \pm 3$ & $8 \pm 3$ \\
$\mathrm{Cl}$ & $5 \pm 1$ & $29 \pm 1$ & $14 \pm 4$ & $44 \pm 4$ \\
$\mathrm{Si}$ & $5 \pm 1$ & $12 \pm 1$ & $10 \pm 2$ & $80 \pm 10$ \\
$\mathrm{Ca}$ & $1 \pm 1$ & $4 \pm 1$ & $<1$ & $30 \pm 10$ \\
$\mathrm{Fe}$ & $1 \pm 1$ & $4 \pm 1$ & $<1$ & $1 \pm 1$ \\
$\mathrm{Zn}$ & $1 \pm 1$ & $4 \pm 1$ & $1 \pm 1$ & $2 \pm 1$ \\
$\mathrm{Ni}$ & $<1$ & $<1$ & $<1$ & $<1$ \\
\hline
\end{tabular}

Os resultados (TAB. 7) indicam uma correlação entre os valores calculados e determinados para a amostra controle D1. As diferenças observadas podem ser aceitas, pois estas se encontram na mesma ordem de grandeza, comprovando a migração dos elementos da fase óleo para a fase aquosa. As concentrações determinadas de S e P são aproximadamente $70 \%$ menores que as calculadas para a amostra D4. Um dos fatores para a diferença dos resultados, pode ser associado à ocorrência da degradação dos compostos orgânicos mais pesados pela ação da radiação gama, resultando na formação de compostos mais leves, os quais provavelmente volatilizam e carregam por arraste os elementos $\mathrm{S}$ e $\mathrm{P}$. Foi observado um aumento das concentrações em valores determinados para $\mathrm{Cl}$, Si e $\mathrm{Ca}$, quando comparados aos valores calculados. Uma das fontes pode ser atribuída à contaminação da amostra pelo frasco de vidro. Durante a radiólise, cujas reações, ainda hoje, não podem ser preditos exatamente, pode ocorrer reações secundárias promovendo a remoção destes elementos dos frascos e subseqüente migração para a fase aquosa. 


\subsection{Análise orgânica - fase óleo}

A seguir são apresentados os resultados obtidos para as análises dos compostos orgânicos por cromatografia gasosa.

\subsubsection{Análise por GC/MS}

As análises por GC/MS foram realizadas para as amostras PRC (recuperada por processo convencional), A1, (amostra de óleo usado) e C4 e D4 (amostras de óleo usado irradiadas com dose absorvida de 500 kGy e adição de $\mathrm{H}_{2} \mathrm{O}$ Milli-Q 50\% e 70\% - v/v, respectivamente) (Scapin et al., 2008).

Na FIG. 16, é mostrado o cromatograma das amostras PRC, A1, C4 e D4, na qual pode ser observada a presença de vários picos. Estes foram selecionados, para a identificação dos compostos orgânicos, de acordo com o tempo de retenção, área relativa percentual superior a 4,9\% e semelhança a 80\% em comparação ao banco de dados da biblioteca NIST. 


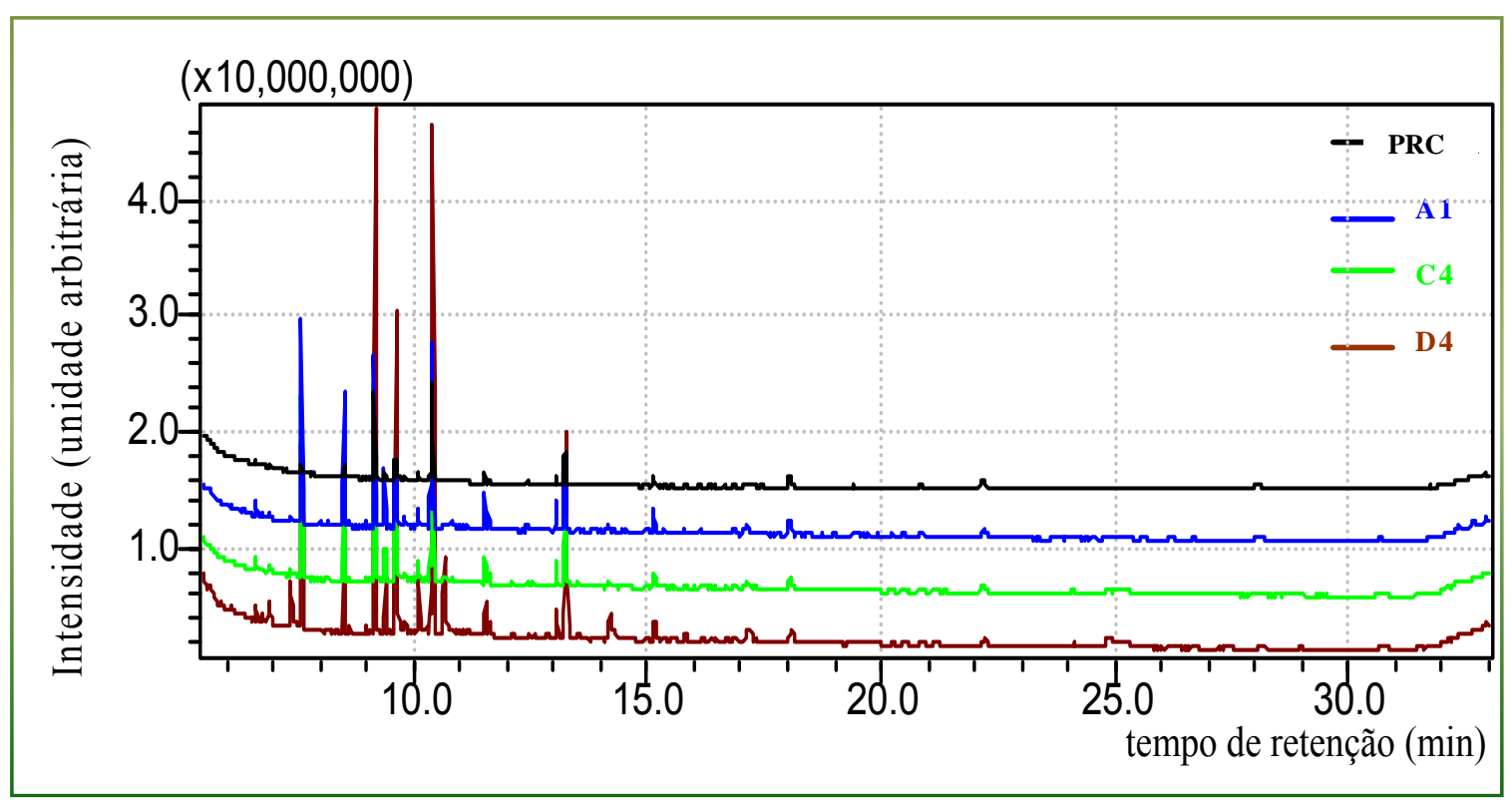

FIGURA 16 - Cromatograma GC/MS para as amostras PRC, A1, C4 e D4.

Os compostos identificados no tempo de retenção de 6,3 a 8,5 min foram: (1) tridecano $\left(\mathrm{C}_{13} \mathrm{H}_{28}\right)$, (2) 2-metil, naftaleno, $\left(\mathrm{C}_{11} \mathrm{H}_{10}\right)$, (3) trietilamina $\left(\mathrm{C}_{6} \mathrm{H}_{15} \mathrm{~N}\right)$, (4) uréia, tetrametil $\left(\mathrm{C}_{5} \mathrm{H}_{13} \mathrm{NO}\right)$ e (5) tridecano $\left(\mathrm{C}_{13} \mathrm{H}_{28}\right)$, mostrados nas FIG. 17.

Na FIG. 17a, pode ser observado a formação dos compostos 1, 2, 3 e 4, em relação à amostra PRC, cujas intensidades apresentam-se muito baixas. Estes compostos são provavelmente produtos de degradação do óleo usado (amostra A1).

O tratamento aplicado à amostra D4 e posterior irradiação com dose absorvida de 500 kGy proporcionaram um aumento nas intensidades dos compostos 1, 2, 3 e 4; uma diminuição não muito expressiva do composto 5 (FIG. 17b). Os quatro compostos orgânicos formados são classificados como inflamáveis, o que confere a amostra D4, um maior poder de inflamabilidade, acrescentando propriedades desejadas no óleo usado, quando este for utilizado como combustíveis. 


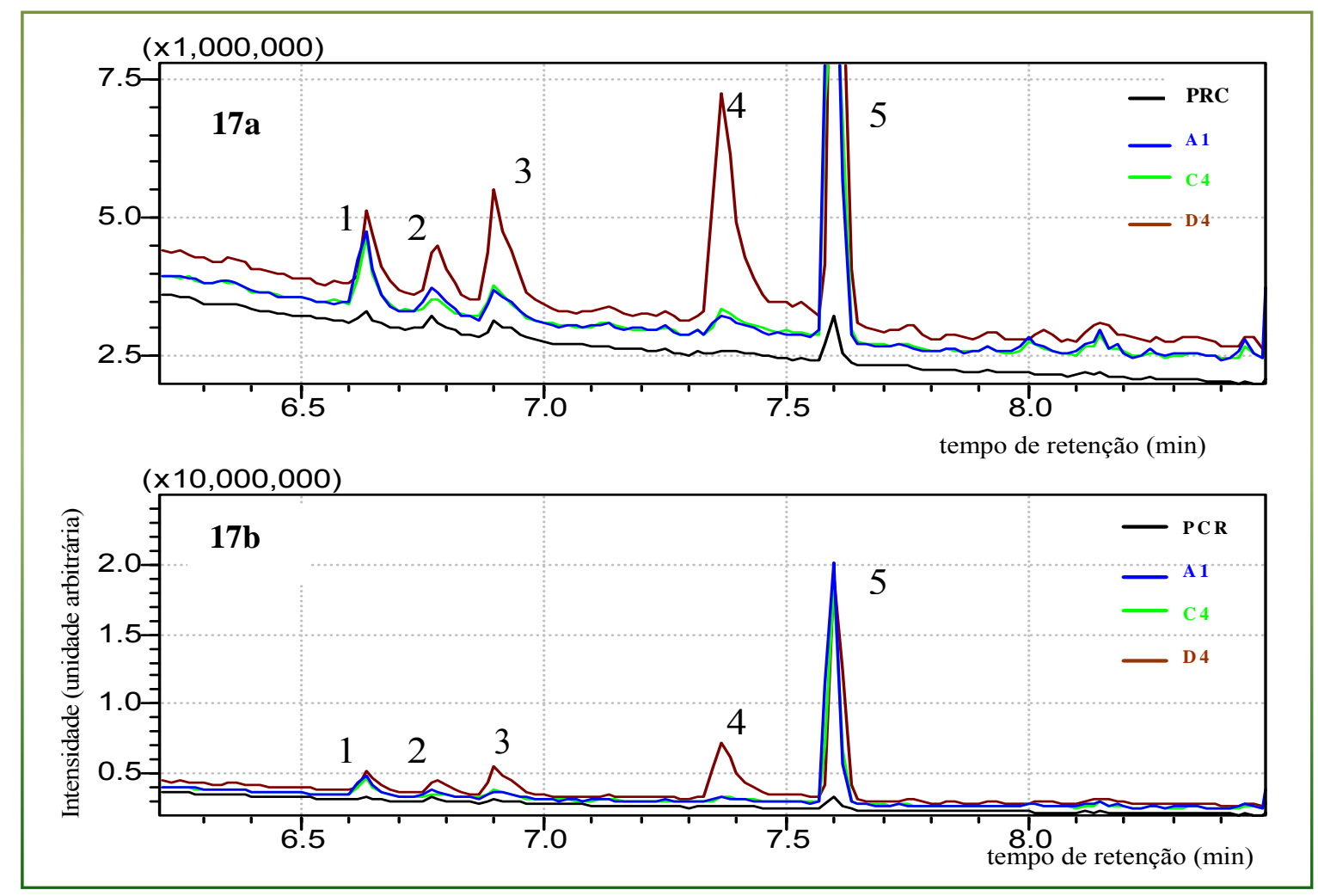

FIGURA 17 - Cromatograma GC/MS no tempo de retenção de 6,3 a 8,5 min.

No tempo de retenção de 8,1 a 10,3 min foram identificados os compostos: (6) hexadecano $\left(\mathrm{C}_{16} \mathrm{H}_{34}\right)$, (7) dietanometilamina $\left(\mathrm{C}_{5} \mathrm{H}_{13} \mathrm{NO}_{3}\right)$, (8) hexadecano $\left(\mathrm{C}_{16} \mathrm{H}_{34}\right)$, (9) dietiletilenoglicol $\left(\mathrm{C}_{8} \mathrm{H}_{18} \mathrm{O}_{3}\right)$ e (10) N,N-dietilciclohexano-1,4-diamina $\left(\mathrm{C}_{10} \mathrm{H}_{22} \mathrm{~N}_{2}\right)$, mostrados na FIG. 18. 


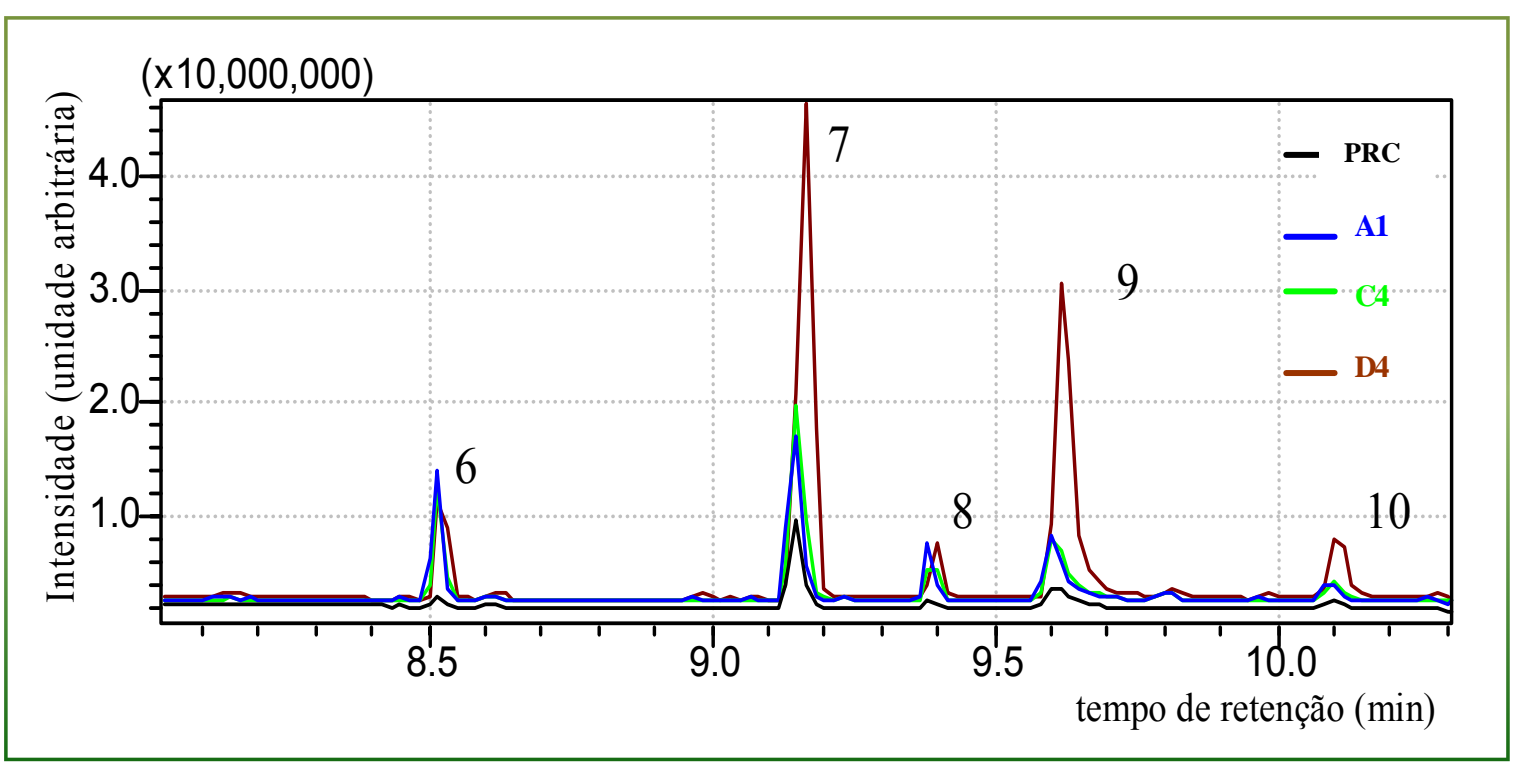

FIGURA 18 - Cromatograma GC/MS no tempo de retenção de 8,1 a 10,3 min.

Os compostos de maior abundância para a amostra D4 são o dietanometilamina (7) e o dietiletilenoglicol (9), apesar de ter sido verificado sua formação para as amostras C4, A1 e PRC. O composto 7 (dietanometilamina) é conhecido comercialmente como METHYLDIETHANOLAMINE (MDEA), sendo utilizado nos diversos setores industriais, na composição de catalisadores, poliuretano para a produção de espuma, inibidor de processo de corrosão e tratamento de efluentes gasosos para a remoção de sulfeto de hidrogênio e dióxido de carbono e outros. O composto 9 (dietiletilenoglicol) é conhecido comercialmente como BUTILDIGLICOL, um solvente, utilizado na composição de uma grande variedade de resinas sintéticas e em formulações de tintas e vernizes; é também utilizado como agente para clareamento e aumento de brilho e viscosidade. É utilizado também, como aditivo para diversos fluidos hidráulicos; por exemplo, fluídos para freios de veículos automotivos. Em relação ao composto 10 (N,N-dietil-ciclohexano-1,4-diamina), o levantamento bibliográfico revelou que na conjuntura atual, o composto não oferece ainda aplicações industriais.

No tempo de retenção de 9,9 a 12,1 min foram identificados os compostos: (11) N,N-dietil-ciclohexano-1,4-diamina $\left(\mathrm{C}_{10} \mathrm{H}_{22} \mathrm{~N}_{2}\right)$, (12) etil,octanol 
$\left(\mathrm{C}_{10} \mathrm{H}_{18} \mathrm{O}\right)$, (13) 3-metil, 2-Hexanol $\left(\mathrm{C}_{7} \mathrm{H}_{16} \mathrm{O}\right)$ e (14) Heptadecano $\left(\mathrm{C}_{17} \mathrm{H}_{36}\right)$, mostrados na FIG. 19.

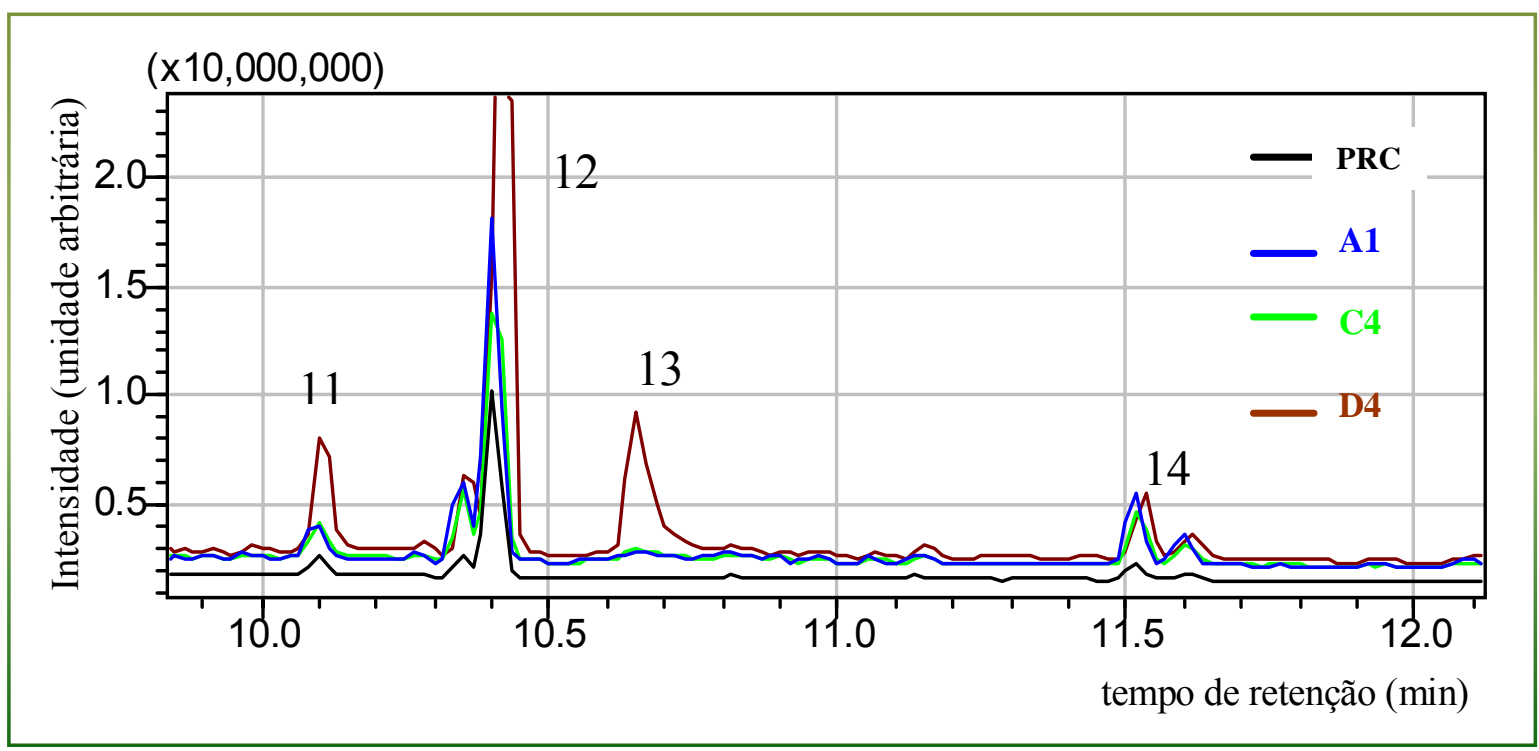

FIGURA 19 - Cromatograma GC/MS no tempo de retenção de 10,0 a 12,0 min

O composto mais abundante, neste intervalo de tempo é o 12 (etil,octanol), que é um álcool, utilizado industrialmente como inibidor de corrosão. Em relação aos compostos 11 (N,N-dietil-ciclohexano-1,4-diamina) e 13 (3-metil, 2-Hexanol), atualmente, também ainda não oferecem aplicações industriais; mas de acordo com a IUPAC (International Union Pure Applied Chemistry) integram os grupos funcionais das aminas e álcoois.

No tempo de retenção de 12,7 a 14,7 min foram identificados os compostos: (15) ecosano $\left(\mathrm{C}_{20} \mathrm{H}_{42}\right), \quad$ (16) N-butylpentamethylenediamine $\left(\mathrm{C}_{9} \mathrm{H}_{22} \mathrm{~N}_{2}\right)$ e (17) Ethylene glycol monovinyl ether $\left(\mathrm{C}_{4} \mathrm{H}_{8} \mathrm{O}_{2}\right)$, mostrados na FIG. 20. 


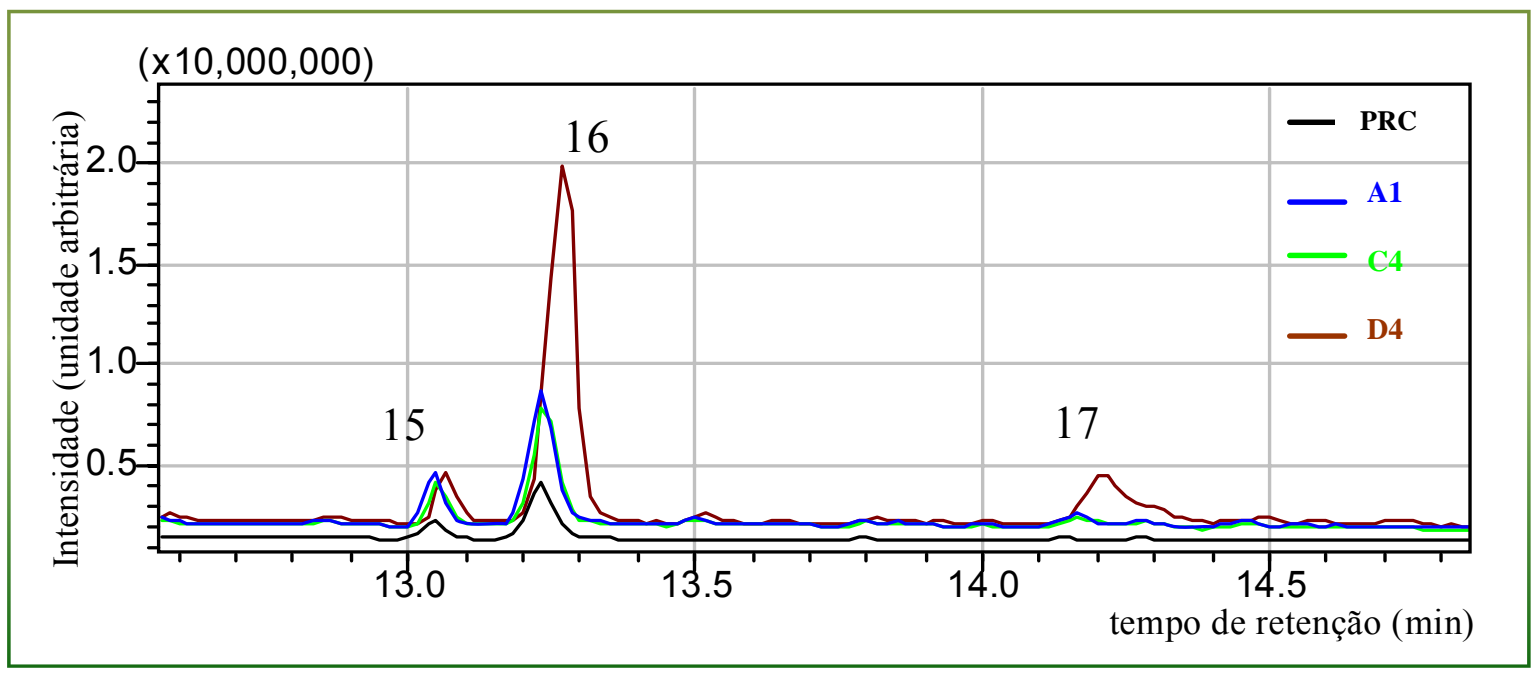

FIGURA 20 - Cromatograma GC/MS de tempo de retenção de 12,7 a 14,7 min.

Neste cromatograma é observada a formação do composto 16 (Nbutylpentamethylenediamine), o mais abundante, seguido do composto 17 (Ethylene glycol monovinyl ether), com intensidade muito menor; não oferecendo aplicações industriais, no contexto atual.

No tempo de retenção de 14,8 a $30,0 \mathrm{~min}$, predominaram os hidrocarbonetos identificados como composto: (18) eicosano $\left(\mathrm{C}_{20} \mathrm{H}_{42}\right)$, (19) 2metil, octadecano $\left(\mathrm{C}_{19} \mathrm{H}_{40}\right)$, (20) eicosano $\left(\mathrm{C}_{20} \mathrm{H}_{42}\right)$, (21) eicosano $\left(\mathrm{C}_{20} \mathrm{H}_{42}\right),(22)$ eicosano $\left(\mathrm{C}_{20} \mathrm{H}_{42}\right)$, (23) eicosano $\left(\mathrm{C}_{20} \mathrm{H}_{42}\right)$ e (24) pentatriacontano $\left(\mathrm{C}_{35} \mathrm{H}_{72}\right)$, (FIG. 21). Estes compostos são característicos de óleos minerais parafínicos, a característica principal da amostra PRC, recuperada pelo processo Tasa. 


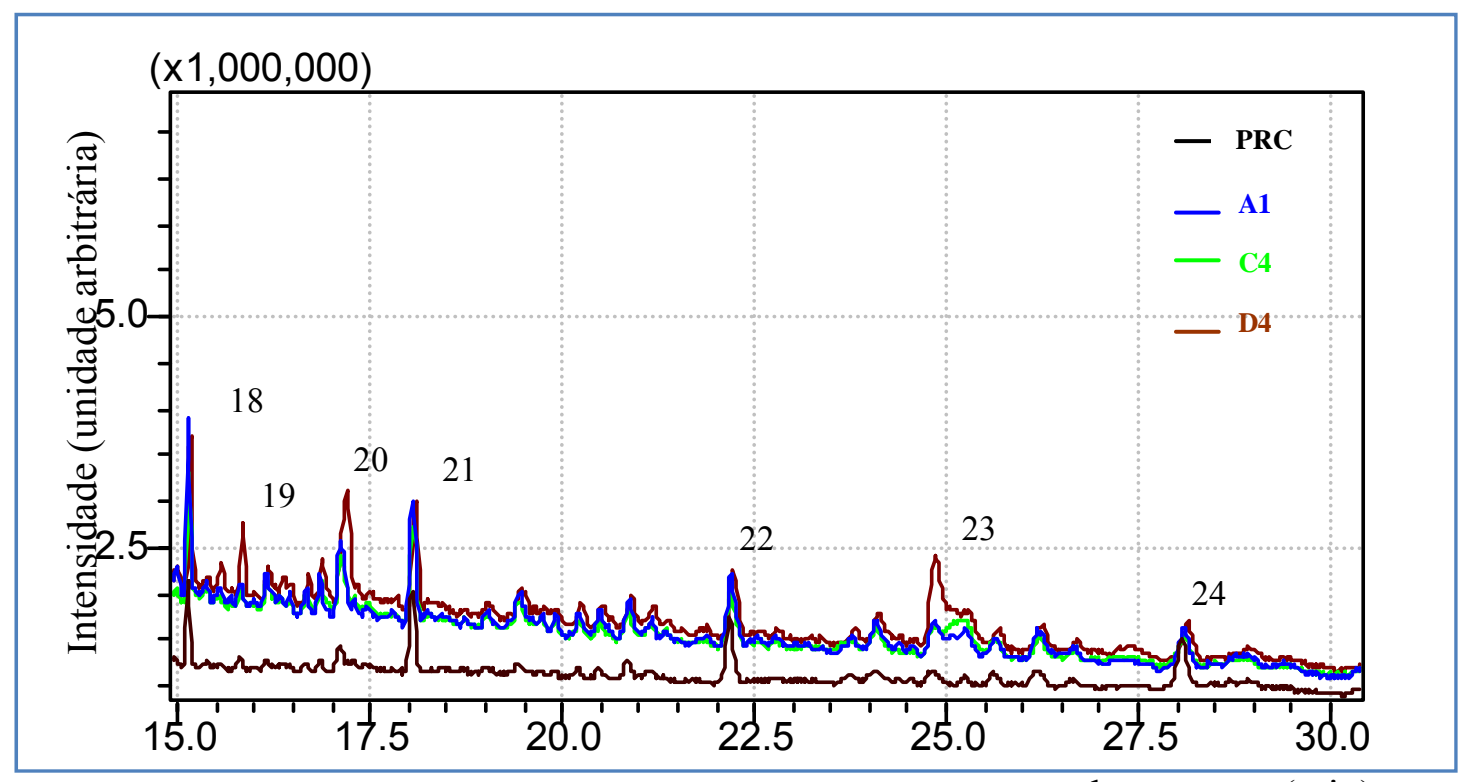

tempo de retenção $(\min )$

FIGURA 21 - Cromatograma GC/MS no intervalo de tempo de retenção 14,8 a $30,0 \mathrm{~min}$.

A contribuição inédita deste estudo foi à verificação e comprovação de que o procedimento utilizado, aplicação da radiação gama juntamente com a adição de $\mathrm{H}_{2} \mathrm{O}$ Milli-Q proporcionou a formação de vários compostos de aplicações industriais como, dietanometilamina, dietilenoglicol e etil-octanol. Estes resultados demonstram uma promissora possibilidade de reutilização de óleos usados após o tratamento para aplicações industriais, adicionando maior valia como matéria-prima, aditivo ou combustível. 


\subsubsection{Análise por GC/FID}

Com a finalidade de quantificar e comparar os produtos orgânicos formados após a irradiação e adição de água, análises por GC/FID foram realizadas para a amostra PRC, B4, C4 e D4. No APÊNDICE E são apresentados as intensidades de sinal referentes aos compostos formados (os mais abundantes) e identificados por GC/MS, a saber: $\left[\mathrm{C}_{5} \mathrm{H}_{13} \mathrm{NO}(4), \mathrm{C}_{13} \mathrm{H}_{28}\right.$ (5), $\mathrm{C}_{16} \mathrm{H}_{34}(6), \mathrm{C}_{5} \mathrm{H}_{13} \mathrm{NO}_{3}(7), \mathrm{C}_{8} \mathrm{H}_{18} \mathrm{O}_{3}$ (9) $\mathrm{C}_{10} \mathrm{H}_{22} \mathrm{~N}_{2}$ (11), $\mathrm{C}_{10} \mathrm{H}_{18} \mathrm{O}$ (12), $\mathrm{C}_{7} \mathrm{H}_{16} \mathrm{O}$ (13) e $\mathrm{C}_{9} \mathrm{H}_{22} \mathrm{~N}_{2}$ (16)]. No APÊNDICE F são apresentadas as intensidades de sinal relativa percentual, calculadas por meio do software acoplado ao CG/FID. Os valores permitiram uma avaliação estimada e são mostrados na FIG. 22.

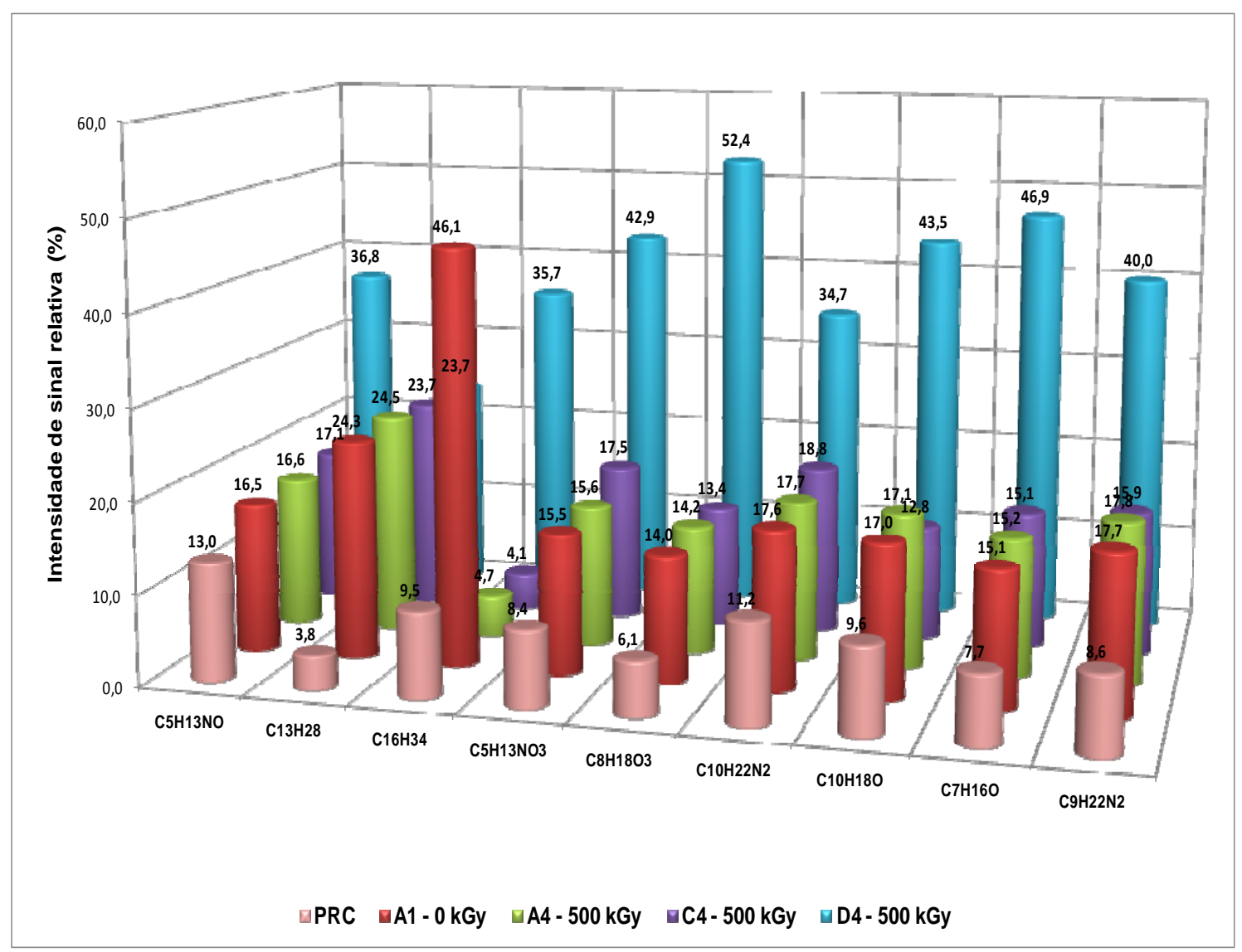

FIGURA 22 - Intensidade de sinal relativa (\%) dos compostos orgânicos determinados por GC/FID. 
$\mathrm{O}$ composto $\mathrm{C}_{8} \mathrm{H}_{18} \mathrm{O}_{3}$ (9), identificado como BUTILDIGLICOL (solvente utilizado na composição de resinas, tintas e vernizes) apresentou uma intensidade de sinal relativa de $14 \%$ para a amostra A1 e 52,4\% para a amostra D4, evidenciando a mais valia produzida no óleo lubrificante usado após a irradiação e adição de água. Os compostos $\mathrm{C}_{5} \mathrm{H}_{13} \mathrm{NO}_{3}(4), \mathrm{C}_{10} \mathrm{H}_{22} \mathrm{~N}_{2}$ (11), $\mathrm{C}_{10} \mathrm{H}_{18} \mathrm{O}$ (12), $\mathrm{C}_{7} \mathrm{H}_{16} \mathrm{O}$ (13) e $\mathrm{C}_{9} \mathrm{H}_{22} \mathrm{~N}_{2}$ (16) mostraram um aumento de 23,8 $\%, 23,5 \%, 39,2 \%$ e $31,4 \%$, respectivamente.

Os resultados mostraram que o processo de oxidação avançada apresenta-se muito promissor, demonstrando a viabilidade do reuso do óleo usado para novas aplicações industriais.

\subsection{Parâmetros físico-químicos}

Os parâmetros físico-químicos analisados foram cor, viscosidade e densidade, que serão discutidos a seguir.

\subsubsection{Cor}

Como descrito anteriormente (pg. 49) as variações de cor do óleo lubrificante permite verificar possível contaminação e indícios de oxidação, ou seja, quanto mais claro for o óleo, menor será o nível de contaminação e oxidação, assim este parâmetro também contribui para a especificação de um óleo lubrificante.

Na FIG. 23 é mostrado o espectro de absorção na região do UV próximo para a amostra PRC, A1, B4, C4 e D4. 


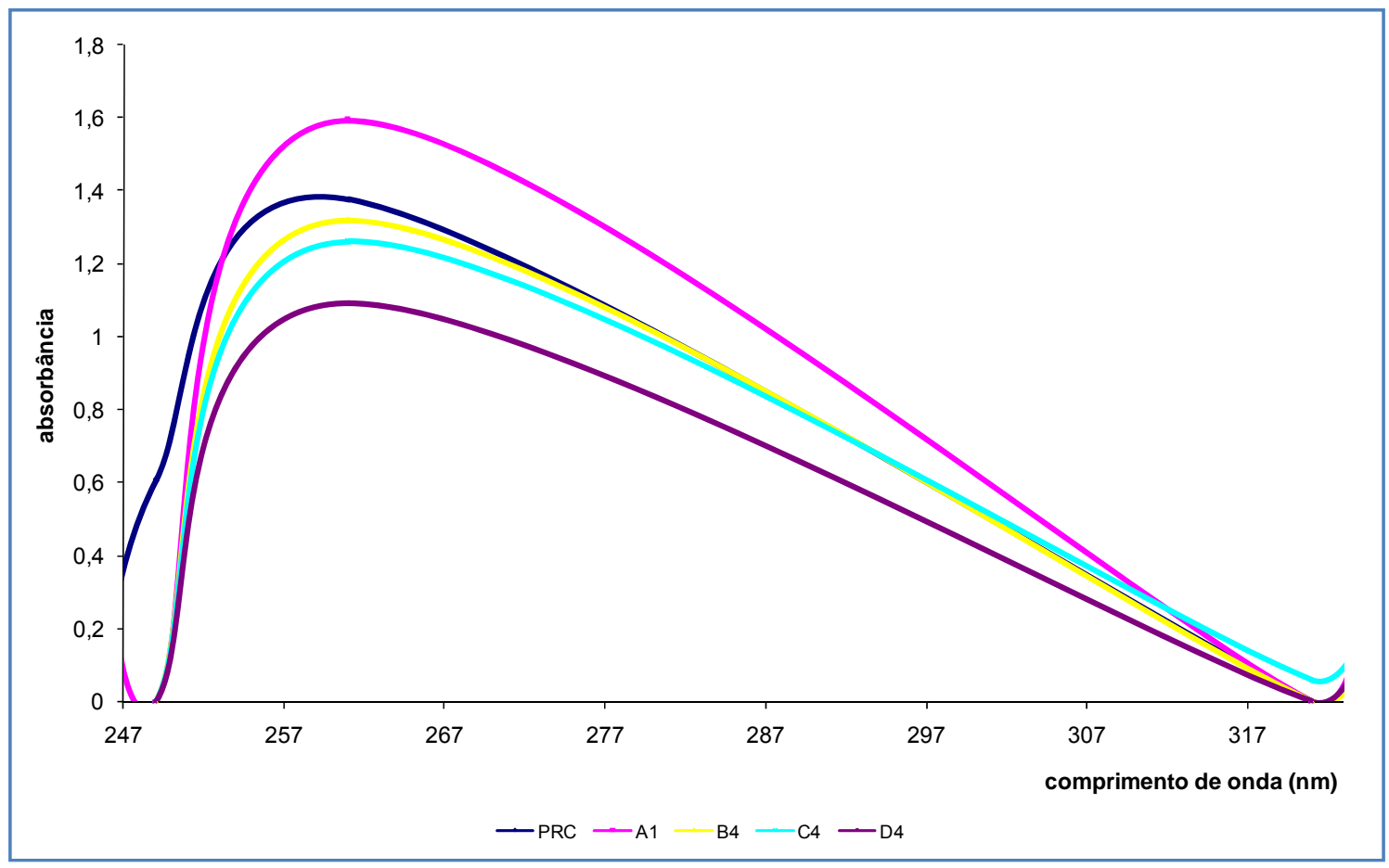

FIGURA 23 - Espectro de absorção UV próximo para as amostras PRC, A1, B4, C4 e D4.

O espectro de emissão UV mostra que os procedimentos aplicados (adição de $\mathrm{H}_{2} \mathrm{O}_{2}$ e $\mathrm{H}_{2} \mathrm{O}$ e irradiação) conduziram à clarificação da amostra $\mathrm{A} 1$, o óleo usado, A amostra A1 apresentou maior absorbância do que a amostra PRC, seguida das amostras B4, C4 e D4, demonstrado que os estudos realizados neste trabalho permitem a clarificação de óleo usado, indícios de parâmetros de descontaminação de óleo usado.

A amostra D4 apresentou o menor valor de absorbância, demonstrando que o procedimento utilizado $\left(\mathrm{H}_{2} \mathrm{O}\right.$ e dose de 500 kGy) apresenta uma grande potencialidade para o clareamento de óleo usado. Alem disto, quando comparado aos processos correntes, apresenta a vantagem de não utilizar agentes químicos, não produzindo rejeitos adicionais, permitindo classificá-lo como uma tecnologia limpa e ecologicamente correta. 


\subsubsection{Viscosidade Cinemática}

Como descrito anteriormente (pg. 50), a viscosidade cinemática é também um parâmetro que contribui para a especificação de um óleo lubrificante, pois permite avaliar a resistência ao escoamento para uma determinada temperatura.

Na FIG. 24 é mostrada a variação da viscosidade cinemática em função dos tratamentos aplicados para as mesmas amostras utilizadas para o ensaio da cor a saber: PRC, A1, B4, C4 e D4.

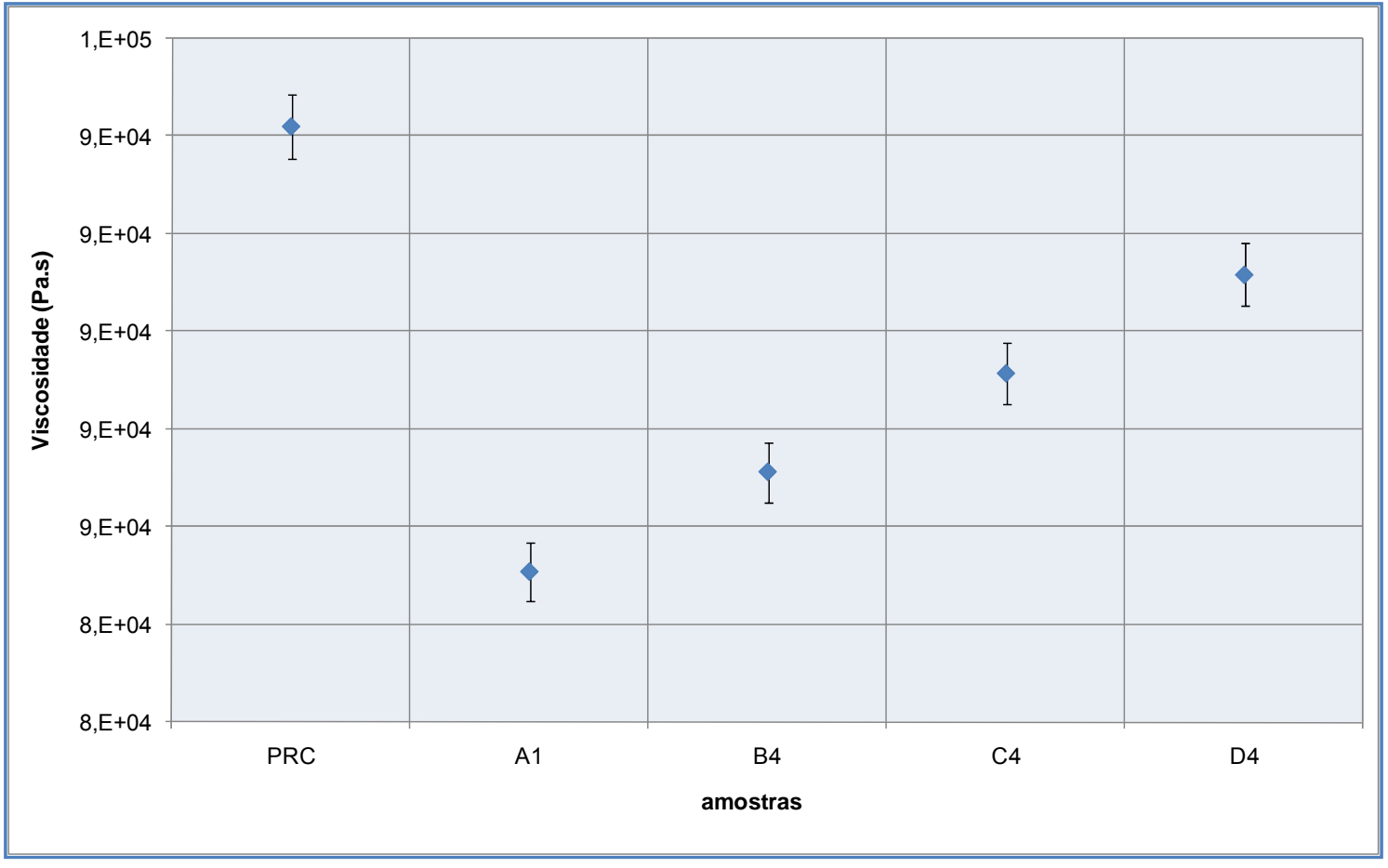

FIGURA 24 - Variação da viscosidade cinemática para as amostras PRC, A1, B4, C4 e D4 
Os tratamentos utilizados (adição de $\mathrm{H}_{2} \mathrm{O}_{2}$ e $\mathrm{H}_{2} \mathrm{O}$ e irradiação) apresentam uma relação linear crescente com a viscosidade. A amostra D4 apresentou um valor de viscosidade próximo da amostra PRC, demonstrando que o tratamento pode ser utilizado para a recuperação da viscosidade, por meio da degradação de compostos oxidativos.

\subsubsection{Densidade}

A densidade, como descrito anteriormente (pg. 50) é um parâmetro que permite avaliar prováveis níveis de contaminação e degradação de um óleo lubrificante contribuindo também para a especificação de um óleo lubrificante. Este parâmetro físico-químico foi avaliado também, para as amostras PRC, A1, B4, C4 e D4, descritos anteriormente.

Os resultados (FIG. 25) indicam uma tendência de diminuição da densidade em função dos tratamentos aplicados, comprovando a degradação dos hidrocarbonetos mais pesados e a formação dos compostos etil,octanol $\left(\mathrm{C}_{10} \mathrm{H}_{18} \mathrm{O}\right)$, dietanometilamina $\left(\mathrm{C}_{5} \mathrm{H}_{13} \mathrm{NO}_{3}\right)$, dietiletilenoglicol $\left(\mathrm{C}_{8} \mathrm{H}_{18} \mathrm{O}_{3}\right)$ e outros identificados e determinados por GC/MS e GC/FID (pg. 68 à 74). 


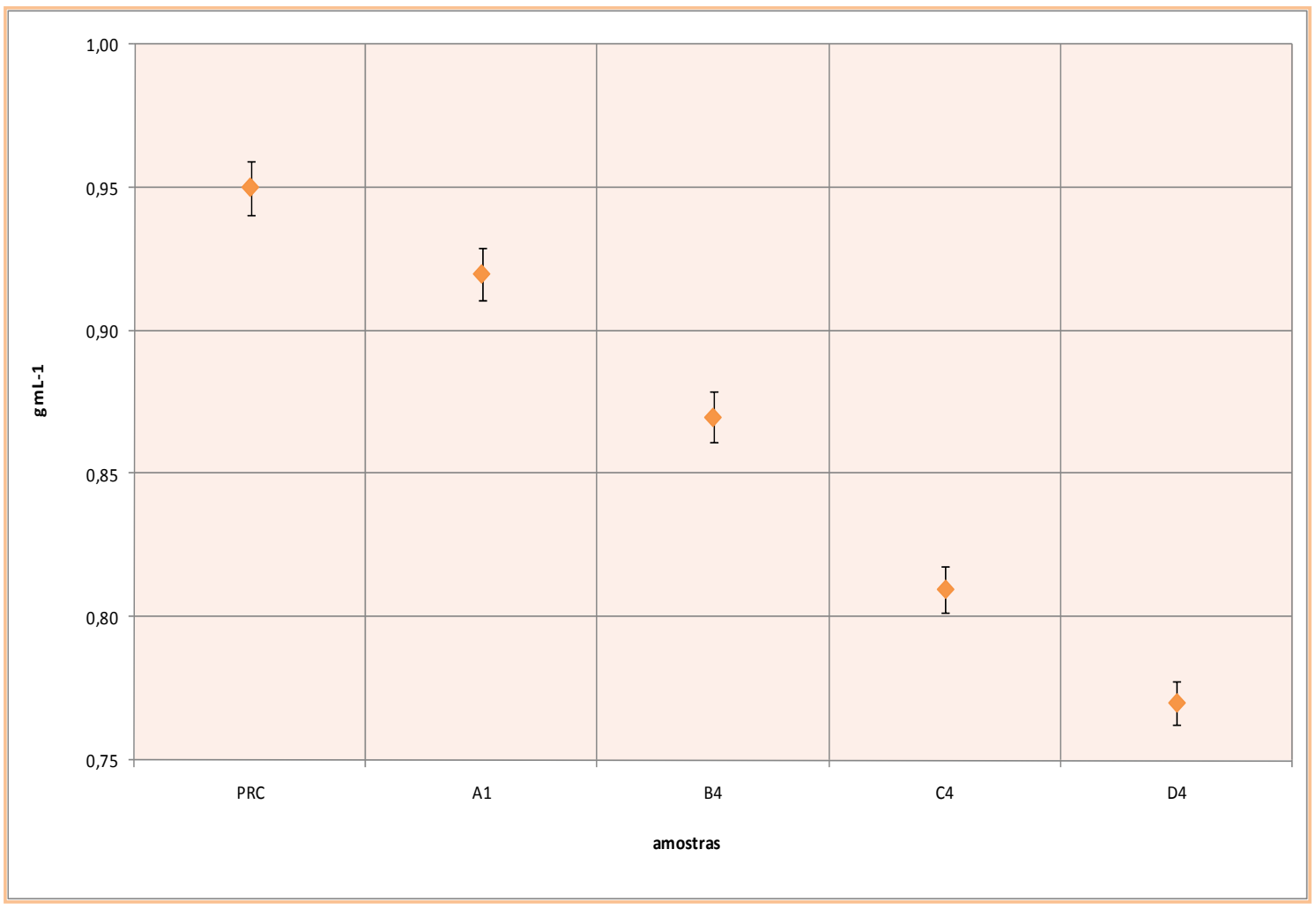

FIGURA 25 - Variação da densidade para as amostras PRC, A1, B4, C4 e D4

\subsection{Análise Multivariada}

A análise multivariada, utilizando a Análise de Cluster, foi realizada considerando-se como casos, os resultados de análises químicas e físicoquímicas e variáveis as amostras A1, B4, C4, D4 e PRC.

Na FIG. 26, é mostrado o dendograma, obtido pelo método de Ward, após os cálculos realizados pelo software STATISTICA, versão 6 . 


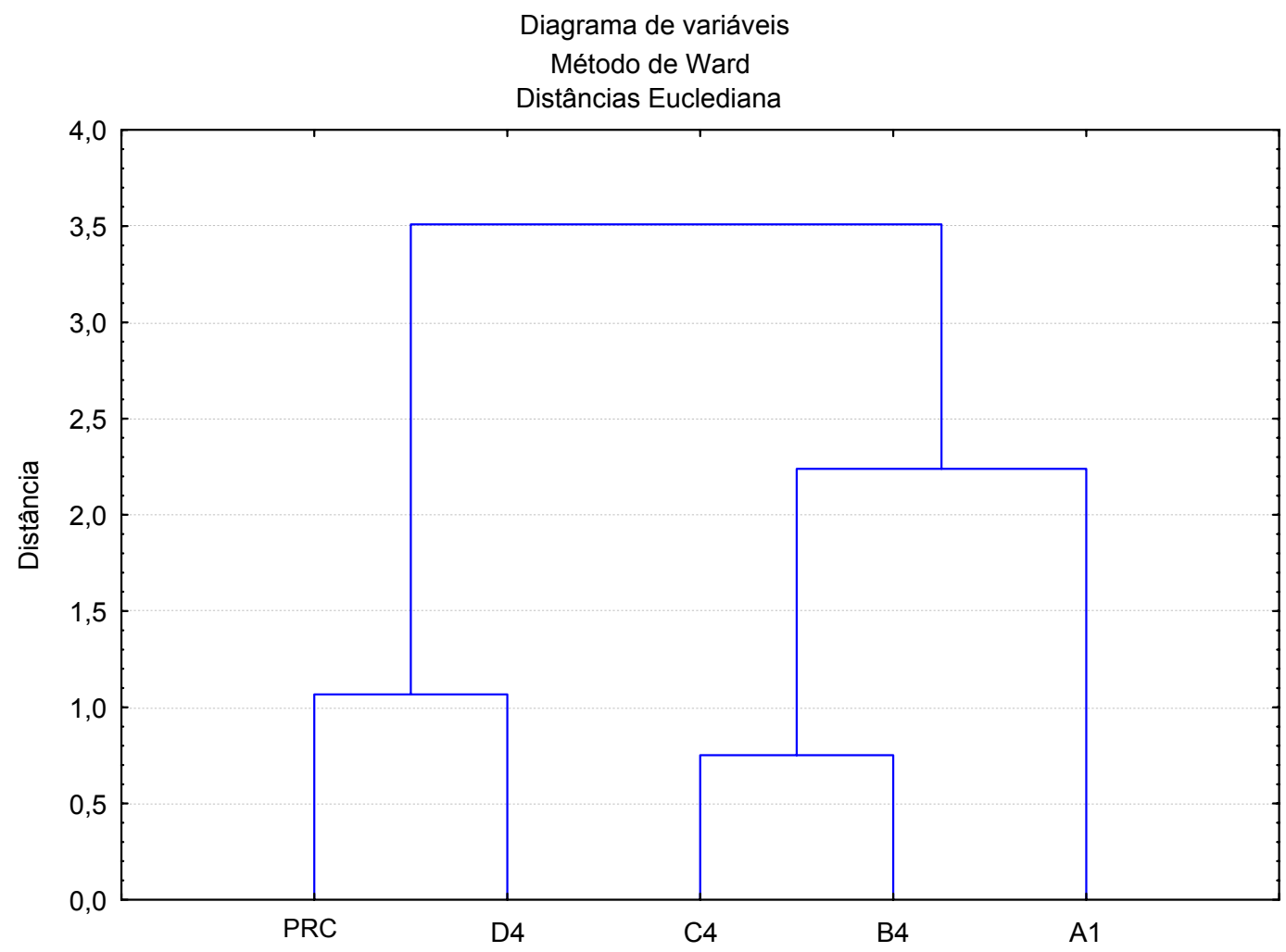

FIGURA 26 - Diagrama de variáveis, método de Ward, distância Euclidiana

Os resultados indicam a formação de 3 grupos. O primeiro apresenta a amostra $\mathrm{A} 1$, completamente isolada (amostra de óleo usado). O segundo, o agrupamento das amostras C4 com B4, demonstrando que estatisticamente entre estas amostras não ocorreu diferença significativa entre os tratamentos aplicados, isto é adição de $\mathrm{H}_{2} \mathrm{O}_{2}(25 \% \mathrm{v} / \mathrm{v})$ ou água Milli-Q $(50 \% \mathrm{v} / \mathrm{v})$ são equivalentes. $O$ terceiro grupo apresenta o agrupamento das amostras PRC com D4. Este resultado permite afirmar estatisticamente, que o tratamento utilizado produz resultados que se aproximam dos obtidos pelo processo de reciclagem TASA.

Os estudos realizados neste trabalho, independente da necessidade de otimização do processo, é um tratamento promissor e viável para a reutilização do óleo usado. 


\section{CONCLUSÕES}

Os estudos e experiências realizadas evidenciaram que:

- A metodologia utilizada para a avaliação do nível de remoção de elementos inorgânicos, presentes no óleo lubrificante automotivo usado é estatisticamente satisfatória, além disto, de baixo custo e ambientalmente correta, visto que para a preparação de amostras e realização dos ensaios não foram necessários tratamentos químicos prévios.

- O processo de oxidação avançada (POA) utilizando a radiação gama, produzida por fonte de Co-60 e a adição de $\mathrm{H}_{2} \mathrm{O}$ Milli-Q $(70 \%$, v/v) permitiu a remoção de enxofre, cálcio, ferro e níquel maior ao tratamento convencional, demonstrando que o POA, apresenta-se como um tratamento promissor para a remoção de elementos inorgânicos em óleo lubrificante usado. Além disto, o processo pode ser classificado como ambientalmente limpo e ecologicamente correto, pois o uso de reagentes químicos não se faz necessário para remoção.

- A aplicação do POA promove a formação de compostos orgânicos que são amplamente utilizados nos diversos setores industriais, demonstrando que o seu uso produz "mais valia" em óleos lubrificantes usados. A formação do composto $\mathrm{C}_{8} \mathrm{H}_{18} \mathrm{O}_{3}$ (9), (butildiglicol, solvente utilizado na composição de resinas, tintas e vernizes) e dos compostos $\mathrm{C}_{5} \mathrm{H}_{13} \mathrm{NO}_{3}$ (4), $\mathrm{C}_{10} \mathrm{H}_{22} \mathrm{~N}_{2}$ (11), $\mathrm{C}_{10} \mathrm{H}_{18} \mathrm{O}$ (12), $\mathrm{C}_{7} \mathrm{H}_{16} \mathrm{O}$ (13) e $\mathrm{C}_{9} \mathrm{H}_{22} \mathrm{~N}_{2}$ (16), após a irradiação com fonte de Co-60, sugere que o óleo usado possa ser reutilizado, principalmente como fonte de combustível alternativo. 
- Os resultados obtidos por meio da análise multivariada permitiram concluir que, independente da necessidade de otimização do processo, o POA é um promissor e viável tratamento para a recuperação de óleo lubrificante usado. 


\section{SUGESTÕES PARA TRABALHOS FUTUROS}

Dando seguimento aos estudos realizados, sugerem-se os seguintes tópicos para futuros trabalhos:

- Avaliar o recipiente mais adequado para a irradiação das amostras, ou seja, repetir os experimentos utilizando materiais inertes, como teflon, para evitar a contaminação de $\mathrm{Cl}$, Si e Ca;

- Analisar prováveis compostos gasosos formados para melhorar a compreensão do processo de degradação e parâmetros de riscos envolvidos;

- Verificar a influência da temperatura e do pH, objetivando a diminuição das doses absorvidas, visando maior economia do processo;

- Introduzir a água conjuntamente com ozônio, ácido acético e outros, objetivando a diminuição de doses absorvidas, na remoção de elementos inorgânicos. 
APÊNDICE A - Condições de medidas utilizadas para a obtenção da curva de sensibilidade (Espectrômetro WDRXF RIGAKU, RIX 3000)

\begin{tabular}{|c|c|c|c|c|c|c|c|c|c|}
\hline $\begin{array}{l}\text { Elemento/ } \\
\text { Linha de } \\
\text { emissão }\end{array}$ & $\begin{array}{c}\text { Pico } 2 \theta \\
\text { grau }\end{array}$ & $\begin{array}{c}\text { BG(1) } \\
\text { grau }\end{array}$ & $\begin{array}{l}\mathrm{BG}(2) \\
\text { grau }\end{array}$ & $\begin{array}{c}\text { Cristal } \\
\text { analisador }\end{array}$ & Colimador & Detector & $\begin{array}{l}\text { Potência } \\
\mathrm{kV} \times \mathrm{mA}\end{array}$ & PHA & Filtro \\
\hline $\mathrm{B}-\mathrm{K}_{\alpha}$ & 51.120 & 45.075 & 57.110 & $R X-70$ & $480 \mu \mathrm{m}$ & FPC & $50 \times 50$ & $100-300$ & $* * *$ \\
\hline $\mathrm{C}-\mathrm{K}_{\alpha}$ & 33.070 & 28.050 & 39.070 & $R X-70$ & $480 \mu \mathrm{m}$ & FPC & $50 \times 50$ & $100-300$ & *** \\
\hline $\mathrm{O}-\mathrm{K}_{\alpha}$ & 132.850 & 130.880 & 134.880 & TAP & $4800 \mu \mathrm{m}$ & FPC & $50 \times 50$ & $100-300$ & $* * *$ \\
\hline $\mathrm{F}-\mathrm{K}_{\alpha}$ & 90.720 & 85.720 & 92.720 & TAP & $480 \mu \mathrm{m}$ & FPC & $50 \times 50$ & $100-300$ & $* * *$ \\
\hline $\mathrm{Na}-\mathrm{K}_{\alpha}$ & 55.230 & 53.500 & 57.120 & TAP & $480 \mu \mathrm{m}$ & FPC & $50 \times 50$ & $100-300$ & $* * *$ \\
\hline $\mathrm{Mg}-\mathrm{K}_{\alpha}$ & 45.300 & 43.190 & 47.190 & TAP & $480 \mu \mathrm{m}$ & FPC & $50 \times 50$ & $100-300$ & ** * \\
\hline Al- $\mathrm{K}_{\alpha}$ & 144.700 & 139.610 & 146.810 & PET-00 1 & $480 \mu \mathrm{m}$ & FPC & $50 \times 50$ & $100-300$ & $* * *$ \\
\hline $\mathrm{Si}-\mathrm{K}_{\alpha}$ & 109.045 & 106.040 & 112.040 & PET-001 & $480 \mu \mathrm{m}$ & FPC & $50 \times 50$ & $100-300$ & $* * *$ \\
\hline $\mathrm{P}-\mathrm{K}_{\alpha}$ & 141.100 & 139.180 & 143.180 & GE & $480 \mu \mathrm{m}$ & FPC & $50 \times 50$ & $100-300$ & $* * *$ \\
\hline S-K ${ }_{\alpha}$ & 110.820 & 108.820 & 112.820 & GE & $480 \mu \mathrm{m}$ & FPC & $50 \times 50$ & $100-300$ & $* * *$ \\
\hline $\mathrm{Cl}-\mathrm{K}_{\alpha}$ & 92.870 & 91.370 & 94.870 & GE & $480 \mu \mathrm{m}$ & FPC & $50 \times 50$ & $100-300$ & *** \\
\hline $\mathrm{K}-\mathrm{K}_{\alpha}$ & 70.000 & 68.000 & 72.000 & GE & $480 \mu \mathrm{m}$ & FPC & $50 \times 50$ & $100-300$ & $* * *$ \\
\hline $\mathrm{Ca}-\mathrm{K}_{\alpha}$ & 61.980 & 59.980 & 63.980 & GE & $480 \mu \mathrm{m}$ & FPC & $50 \times 50$ & $100-300$ & $* * *$ \\
\hline $\mathrm{Ti}^{-\mathrm{K}_{\alpha}}$ & 86.110 & 85.510 & 86.710 & LiF-200 & $160 \mu \mathrm{m}$ & SC & $50 \times 50$ & $100-300$ & $* * *$ \\
\hline $\mathrm{V}-\mathrm{K}_{\alpha}$ & 76.910 & 76.310 & 77.510 & LiF-200 & $480 \mu \mathrm{m}$ & SC & $50 \times 50$ & $100-300$ & *** \\
\hline $\mathrm{Cr}-\mathrm{K}_{\alpha}$ & 69.340 & 68.730 & 69.930 & LiF-200 & $480 \mu \mathrm{m}$ & SC & $50 \times 50$ & $100-300$ & *** \\
\hline $\mathrm{Mn}-\mathrm{K}_{\alpha}$ & 62.950 & 62.350 & 63.550 & LiF-200 & $480 \mu \mathrm{m}$ & SC & $50 \times 50$ & $100-300$ & *** \\
\hline $\mathrm{Fe}-\mathrm{K}_{\alpha}$ & 57,500 & 56.900 & 58,000 & LiF-200 & $480 \mu \mathrm{m}$ & SC & $50 \times 50$ & $100-300$ & $* * *$ \\
\hline Co-K $\mathrm{K}_{\alpha}$ & 52.760 & 52.170 & 53.370 & LiF-200 & $480 \mu \mathrm{m}$ & SC & $50 \times 50$ & $100-300$ & *** \\
\hline $\mathrm{Ni}-\mathrm{K}_{\alpha}$ & 48.660 & 48.050 & 49.250 & LiF-200 & $480 \mu \mathrm{m}$ & SC & $50 \times 50$ & $100-300$ & ** * \\
\hline $\mathrm{Cu}-\mathrm{K}_{\alpha}$ & 45.020 & 44.410 & 45.610 & LiF-200 & $480 \mu \mathrm{m}$ & SC & $50 \times 50$ & $100-300$ & *** \\
\hline $\mathrm{Zn}-\mathrm{K}_{\alpha}$ & 41.780 & 41.180 & 42.380 & LiF-200 & $480 \mu \mathrm{m}$ & SC & $50 \times 50$ & $100-300$ & $* * *$ \\
\hline $\mathrm{Ga}-\mathrm{K}_{\alpha}$ & 38.900 & 38.300 & 39.500 & LiF-200 & $480 \mu \mathrm{m}$ & SC & $50 \times 50$ & $100-300$ & $* * *$ \\
\hline $\mathrm{Ge}-\mathrm{K}_{\alpha}$ & 36.310 & 35.720 & 36.910 & LiF-200 & $480 \mu \mathrm{m}$ & SC & $50 \times 50$ & $100-300$ & $* * *$ \\
\hline As- $K_{\alpha}$ & 33.980 & 33.380 & 34.580 & LiF-200 & $480 \mu \mathrm{m}$ & SC & $50 \times 50$ & $100-300$ & $* * *$ \\
\hline $\mathrm{Br}-\mathrm{K}_{\alpha}$ & 29.950 & 29.350 & 30.550 & LiF-200 & $480 \mu \mathrm{m}$ & SC & $50 \times 50$ & $100-300$ & $* * *$ \\
\hline $\mathrm{Sr}-\mathrm{K}_{\alpha}$ & 25.060 & 24.530 & 25.730 & LiF-200 & $480 \mu \mathrm{m}$ & SC & $50 \times 50$ & $100-300$ & *** \\
\hline $\mathrm{Y}-\mathrm{K}_{\alpha}$ & 23.780 & 23.180 & 24.380 & LiF-200 & $480 \mu \mathrm{m}$ & SC & $50 \times 50$ & $100-300$ & *** \\
\hline $\mathrm{Zr}-\mathrm{K}_{\alpha}$ & 22.540 & 21.940 & 23.140 & LiF-200 & $480 \mu \mathrm{m}$ & SC & $50 \times 50$ & $100-300$ & $* * *$ \\
\hline $\mathrm{Nb}-\mathrm{K}_{\alpha}$ & 21.390 & 20.790 & 21.990 & LiF-200 & $480 \mu \mathrm{m}$ & SC & $50 \times 50$ & $100-300$ & $* * *$ \\
\hline Mo-K $\alpha$ & 20.320 & 19.720 & 20.920 & LiF-200 & $480 \mu \mathrm{m}$ & SC & $50 \times 50$ & $100-300$ & $* * *$ \\
\hline Rh- $\mathrm{K}_{\alpha}$ & 17.550 & 16.950 & 18.150 & LiF-200 & $480 \mu \mathrm{m}$ & SC & $50 \times 50$ & $100-300$ & *** \\
\hline
\end{tabular}


APÊNDICE A - Condições de medidas utilizadas para a obtenção da curva de sensibilidade (Espectrômetro WDRXF RIGAKU, RIX 3000)

\begin{tabular}{|c|c|c|c|c|c|c|c|c|c|}
\hline $\begin{array}{l}\text { Elemento/ } \\
\text { Linha de } \\
\text { emissão }\end{array}$ & $\begin{array}{c}\text { Pico } 2 \theta \\
\text { grau }\end{array}$ & $\begin{array}{l}\mathrm{BG}(1) \\
\text { grau }\end{array}$ & $\begin{array}{l}\mathrm{BG}(2) \\
\text { grau }\end{array}$ & $\begin{array}{c}\text { Cristal } \\
\text { analisador }\end{array}$ & Colimador & Detector & $\begin{array}{l}\text { Potência } \\
\mathrm{kV} \times \mathrm{mA}\end{array}$ & PHA & Filtro \\
\hline $\mathrm{Pd}-\mathrm{K}_{\alpha}$ & 16.750 & 16.150 & 17.350 & LiF-200 & $480 \mu \mathrm{m}$ & SC & $50 \times 50$ & $100-300$ & $* * *$ \\
\hline $\mathrm{Ag}-\mathrm{K}_{\alpha}$ & 16.000 & 15.400 & 16.600 & LiF-200 & $480 \mu \mathrm{m}$ & SC & $50 \times 50$ & $100-300$ & *** \\
\hline $\mathrm{Cd}-\mathrm{K}_{\alpha}$ & 15.300 & 14.700 & 15.900 & LiF-200 & $480 \mu \mathrm{m}$ & SC & $50 \times 50$ & $100-300$ & $\mathrm{Zr}$ \\
\hline $\ln -\mathrm{K}_{\alpha}$ & 14.640 & 14.040 & 15.240 & LiF-200 & $480 \mu \mathrm{m}$ & SC & $50 \times 50$ & $100-300$ & $* * *$ \\
\hline $\mathrm{Sb}-\mathrm{K}_{\alpha}$ & 13.450 & 12.850 & 14.050 & LiF-200 & $480 \mu \mathrm{m}$ & SC & $50 \times 50$ & $100-300$ & $* * *$ \\
\hline $\mathrm{Te}-\mathrm{K}_{\alpha}$ & 12.900 & 12.300 & 13.500 & LiF-200 & $480 \mu \mathrm{m}$ & SC & $50 \times 50$ & $100-300$ & $* * *$ \\
\hline $\mathrm{I}-\mathrm{K}_{\alpha}$ & 12.390 & 11.790 & 12.990 & LiF-200 & $480 \mu \mathrm{m}$ & SC & $50 \times 50$ & $100-300$ & $* * *$ \\
\hline $\mathrm{Cs}-\mathrm{K}_{\alpha}$ & 11.445 & $* * *$ & $* * *$ & LiF-200 & $480 \mu \mathrm{m}$ & SC & $50 \times 50$ & $100-300$ & $* * *$ \\
\hline$B a-L_{\alpha}$ & 87.130 & 86.530 & 87.730 & LiF-200 & $480 \mu \mathrm{m}$ & SC & $50 \times 50$ & $100-300$ & $* * *$ \\
\hline La- $\mathrm{L}_{\alpha}$ & 82.880 & 82.280 & 83.480 & LiF-200 & $480 \mu \mathrm{m}$ & SC & $50 \times 50$ & $100-300$ & $* * *$ \\
\hline $\mathrm{Ce}-\mathrm{L}_{\alpha}$ & 78.980 & 78.380 & 79.580 & LiF-200 & $480 \mu \mathrm{m}$ & SC & $50 \times 50$ & $100-300$ & $* * *$ \\
\hline $\operatorname{Pr}-L_{\alpha 1}$ & 68.220 & 67.500 & 68.500 & LiF-200 & $480 \mu \mathrm{m}$ & SC & $50 \times 50$ & $100-300$ & $* * *$ \\
\hline $\mathrm{Nd}-\mathrm{L}_{\alpha}$ & 72.100 & 71.000 & $* * *$ & LiF-200 & $480 \mu \mathrm{m}$ & SC & $50 \times 50$ & $100-300$ & $* * *$ \\
\hline$S m-L_{\alpha 1}$ & 59.475 & 57.000 & 61.000 & LiF-200 & $480 \mu \mathrm{m}$ & SC & $50 \times 50$ & $100-300$ & $* * *$ \\
\hline Gd- $L_{\alpha}$ & 61.080 & $* * *$ & $* * *$ & LiF-200 & $480 \mu \mathrm{m}$ & SC & $50 \times 50$ & $100-300$ & $* * *$ \\
\hline Dy- $\mathrm{L}_{\alpha}$ & 56.570 & $* * *$ & $* * *$ & LiF-200 & $480 \mu \mathrm{m}$ & SC & $50 \times 50$ & $100-300$ & $* * *$ \\
\hline $\mathrm{Yb}-\mathrm{L}_{\alpha}$ & 49.045 & $* * *$ & $* * *$ & LiF-200 & $480 \mu \mathrm{m}$ & $\mathrm{SC}$ & $50 \times 50$ & $100-300$ & $* * *$ \\
\hline$H f-L_{\alpha}$ & 45.860 & 45.260 & 46.460 & LiF-200 & $480 \mu \mathrm{m}$ & SC & $50 \times 50$ & $100-300$ & $* * *$ \\
\hline $\mathrm{Ta}-\mathrm{L}_{\alpha}$ & 44.400 & 43.800 & 45.000 & LiF-200 & $480 \mu \mathrm{m}$ & SC & $50 \times 50$ & $100-300$ & $* * *$ \\
\hline$W-L_{\alpha}$ & 43.000 & 42.400 & 43.600 & LiF-200 & $480 \mu \mathrm{m}$ & SC & $50 \times 50$ & $100-300$ & *** \\
\hline Ir- $\mathrm{L}_{\alpha}$ & 39.200 & 37.000 & 41.000 & LiF-200 & $480_{\mu} \mathrm{m}$ & SC & $50 \times 50$ & $100-300$ & $* * *$ \\
\hline Pt- $\mathrm{L}_{\alpha}$ & 38.040 & 37.440 & 38.640 & LiF-200 & $480 \mu \mathrm{m}$ & SC & $50 \times 50$ & $100-300$ & $* * *$ \\
\hline $\mathrm{Au}-\mathrm{L}_{\alpha}$ & 36.940 & 36.340 & 37.540 & LiF-200 & $480 \mu \mathrm{m}$ & SC & $50 \times 50$ & $100-300$ & $* * *$ \\
\hline $\mathrm{Hg}-\mathrm{L}_{\alpha}$ & 35.890 & 35.290 & 36.490 & LiF-200 & $480 \mu \mathrm{m}$ & SC & $50 \times 50$ & $100-300$ & $\mathrm{Zr}$ \\
\hline $\mathrm{TI}-\mathrm{L}_{\alpha}$ & 34.880 & 34.280 & 35.480 & LiF-200 & $480 \mu \mathrm{m}$ & SC & $50 \times 50$ & $100-300$ & $* * *$ \\
\hline $\mathrm{Pb}-\mathrm{L}_{\beta 1}$ & 28.240 & 27.640 & 28.840 & LiF-200 & $480 \mu \mathrm{m}$ & $\mathrm{SC}$ & $50 \times 50$ & $100-300$ & $* * *$ \\
\hline $\mathrm{Bi}-\mathrm{L}_{\alpha}$ & 32.990 & 32.390 & 33.590 & LiF-200 & $480 \mu \mathrm{m}$ & $\mathrm{SC}$ & $50 \times 50$ & $100-300$ & $* * *$ \\
\hline Th- $\mathrm{L}_{\alpha}$ & 27.450 & 26.850 & 28.050 & LiF-200 & $480 \mu \mathrm{m}$ & SC & $50 \times 50$ & $100-300$ & $* * *$ \\
\hline $\mathrm{U}-\mathrm{L}_{\alpha}$ & 26.130 & 25.530 & 26.760 & LiF-200 & $480 \mu \mathrm{m}$ & SC & $50 \times 50$ & $100-300$ & $* * *$ \\
\hline
\end{tabular}

$\mathrm{PHA}^{*}$ (analisador de altura de pulso - Linha de Base x Abertura de Janela) 
APÊNDICE B - Materiais utilizados (MU), linhas de emissão, intensidades experimentais $\left(I E X^{*}\right)$ e teóricas $\left(I T^{* *}\right)$ e sensibilidade (S) determinada para os elementos $\mathrm{B}$ a $\mathrm{U}$ para o espectrômetro Rigaku Co.; RIX 3000.

\begin{tabular}{|c|c|c|c|c|c|c|}
\hline № Atômico & Elemento & $\mathrm{MU}$ & Linhas & $\mathrm{IEX}$ & $1 T^{* *}$ & $S$ \\
\hline 5 & $B$ & $\mathrm{H}_{3} \mathrm{BO}_{3}$ & $\mathrm{~B}-\mathrm{K} \alpha$ & 0,447 & 4,7632 & 0,09377 \\
\hline 6 & C & Interpolado & $\mathrm{C}-\mathrm{K} \alpha$ & 0,181 & 1.0000 & 0,18093 \\
\hline 7 & $\mathrm{~N}$ & Interpolado & $\mathrm{N}-\mathrm{K} \alpha$ & 0,049 & 1.0000 & 0,04874 \\
\hline 8 & O & $\mathrm{H}_{3} \mathrm{BO}_{3}$ & $\mathrm{O}-\mathrm{K} \alpha$ & 1,622 & 45,456 & 0,03567 \\
\hline 9 & $\mathrm{~F}$ & LiF & $\mathrm{F}-\mathrm{K} \alpha$ & 10,008 & 36,8348 & 0,2717 \\
\hline 11 & $\mathrm{Na}$ & $\mathrm{NaCl}$ & $\mathrm{Na}-\mathrm{K} \alpha$ & 30,131 & 19,0519 & 1,58152 \\
\hline 12 & $\mathrm{Mg}$ & Mg-metal & $\mathrm{Mg}-\mathrm{K} \alpha$ & 344,444 & 100.0000 & 3,44444 \\
\hline 13 & $\mathrm{Al}$ & Al-metal & $\mathrm{Al}-\mathrm{K} \alpha$ & 1199,888 & 100.0000 & 11,99888 \\
\hline 14 & Si & $\mathrm{SiO}_{2}$ & Si-K $\alpha$ & 410,888 & 44,1039 & 9,31637 \\
\hline 15 & $P$ & $\mathrm{CaHPO}_{4}$ & $\mathrm{P}-\mathrm{K} \alpha$ & 778,856 & 28,3864 & 27,43765 \\
\hline 16 & $S$ & $S$ & S-K $\alpha$ & 1784,476 & 100.0000 & 17,84476 \\
\hline 17 & $\mathrm{Cl}$ & $\mathrm{NaCl}$ & $\mathrm{Cl}-\mathrm{K} \alpha$ & 181,246 & 55,2654 & 3,27956 \\
\hline 19 & $\mathrm{~K}$ & $\mathrm{KBr}$ & $\mathrm{K}-\mathrm{K} \alpha$ & 577,841 & 15,1394 & 38,16795 \\
\hline 20 & $\mathrm{Ca}$ & $\mathrm{CaHPO}_{4}$ & Ca-K $\alpha$ & 1004,053 & 76,6921 & 13,092 \\
\hline 22 & $\mathrm{Ti}$ & Ti-metal & $\mathrm{Ti}-\mathrm{K} \alpha$ & 417,305 & 100.0000 & 4,17305 \\
\hline 23 & V & V-metal & $\mathrm{V}-\mathrm{K} \alpha$ & 662,237 & 100.000 & 6,62237 \\
\hline 24 & $\mathrm{Cr}$ & Cr-metal & $\mathrm{Cr}-\mathrm{K} \alpha$ & 349,257 & 36,0768 & 9,68093 \\
\hline 25 & $\mathrm{Mn}$ & Mn-metal & $M n-K \alpha$ & 267,587 & 17,6509 & 15,15992 \\
\hline 26 & $\mathrm{Fe}$ & Fe-metal & $\mathrm{Fe}-\mathrm{K} \alpha$ & 1948,836 & 100.0000 & 19,48837 \\
\hline 27 & Co & Co-metal & Co-K $\alpha$ & 2513,12 & 100.0000 & 25,1312 \\
\hline 28 & $\mathrm{Ni}$ & Ni-metal & $\mathrm{Ni}-\mathrm{K} \alpha$ & 3123,38 & 100.0000 & 31,2338 \\
\hline 29 & $\mathrm{Cu}$ & Cu-metal & $\mathrm{Cu}-\mathrm{K} \alpha$ & 3699,581 & 100.0000 & 36,99581 \\
\hline 30 & $\mathrm{Zn}$ & Zn-metal & $\mathrm{Zn}-\mathrm{K} \alpha$ & 4376,787 & 100.0000 & 43,76787 \\
\hline 31 & $\mathrm{Ga}$ & $\mathrm{Ge} / \mathrm{Ga}$ & $\mathrm{Ga}-\mathrm{K} \alpha$ & 387,36 & 7,0843 & 54,67873 \\
\hline 32 & $\mathrm{Ge}$ & $\mathrm{Ge} / \mathrm{Ga}$ & $\mathrm{Ge}-\mathrm{K} \alpha$ & 426,003 & 7,1242 & 59,79647 \\
\hline 33 & As & TTAs & As-K $\alpha$ & 1316,44 & 20,1984 & 65,17551 \\
\hline 35 & $\mathrm{Br}$ & $\mathrm{KBr}$ & $\mathrm{Br}-\mathrm{K} \alpha$ & 5029,772 & 71,868 & 69,98623 \\
\hline 38 & $\mathrm{Sr}$ & $\mathrm{GeGa}$ & $\mathrm{Sr}-\mathrm{K} \alpha$ & 1085,983 & 14,5713 & 74,52878 \\
\hline 39 & $Y$ & YBa & $\mathrm{Y}-\mathrm{K} \alpha$ & 913,067 & 12,2656 & 74,44154 \\
\hline 40 & $\mathrm{Zr}$ & Zr-metal & $\mathrm{Zr}-\mathrm{K} \alpha$ & 7428,938 & 100.0000 & 74,28938 \\
\hline
\end{tabular}


APÊNDICE B - Materiais utilizados (MU), linhas de emissão, intensidades experimentais $\left(I E X^{*}\right)$ e teóricas $\left(I T^{* *}\right)$ e sensibilidade (S) determinada para os elementos $\mathrm{B}$ a $\mathrm{U}$ para o espectrômetro Rigaku Co.; RIX 3000.

\begin{tabular}{|c|c|c|c|c|c|c|}
\hline №̂ Atômico & Elemento & MU & Linhas & $I E X^{*}$ & $1 T^{* *}$ & $S$ \\
\hline 41 & $\mathrm{Nb}$ & Nb-metal & $\mathrm{Nb}-\mathrm{K} \alpha$ & 7393,107 & 100.0000 & 73,93107 \\
\hline 42 & Mo & Mo-metal & Mo-K $\alpha$ & 7343,76 & 100.0000 & 73,4376 \\
\hline 44 & $\mathrm{Ru}$ & Interpolado & Ru-Ka & 33,235 & 1.0000 & 33,23456 \\
\hline 45 & $\mathrm{Rh}$ & Interpolado & Rh-K $\alpha$ & 25,6 & 1.0000 & 25,60005 \\
\hline 46 & $\mathrm{Pd}$ & $\mathrm{Pd} / \mathrm{lr}$ & $\mathrm{Pd}-\mathrm{K} \alpha$ & 1507,125 & 81,1354 & 18,57542 \\
\hline 47 & $\mathrm{Ag}$ & Ag-metal & $\mathrm{Ag}-\mathrm{K} \alpha$ & 1580,871 & 100.0000 & 15,80871 \\
\hline 48 & $\mathrm{Cd}$ & Cd-metal & $\mathrm{Cd}-\mathrm{K} \alpha$ & 1310,608 & 100.0000 & 13,10608 \\
\hline 49 & In & In-metal & $\ln -\mathrm{K} \alpha$ & 1120,487 & 100.0000 & 11,20487 \\
\hline 50 & Sn & Sn-metal & $\mathrm{Sn}-\mathrm{K} \alpha$ & 1118,765 & 99,115 & 11,28754 \\
\hline 51 & $\mathrm{Sb}$ & $\mathrm{Sb} / \mathrm{Ce}$ & $\mathrm{Sb}-\mathrm{K} \alpha$ & 291,925 & 33,1567 & 8,80439 \\
\hline 52 & $\mathrm{Te}$ & TTAs & $\mathrm{Te}-\mathrm{K} \alpha$ & 177,143 & 26,5875 & 6,66263 \\
\hline 53 & 1 & Interpolado & I-K $\alpha$ & 5,41 & 1.0000 & 5,41049 \\
\hline 55 & Cs & $\mathrm{Cs}_{2} \mathrm{O}$ & Cs-Ka & 71,913 & 29,1861 & 2,46394 \\
\hline 56 & $\mathrm{Ba}$ & $\mathrm{Y} / \mathrm{Ba}$ & $B a-L \alpha$ & 34,769 & 57,7888 & 0,6165 \\
\hline 57 & $\mathrm{La}$ & RLTS & La-L $\alpha$ & 24,94 & 35,2383 & 0,70777 \\
\hline 58 & $\mathrm{Ce}$ & $\mathrm{Sb} / \mathrm{Ce}$ & $\mathrm{Ce}-\mathrm{L} \alpha$ & 25,589 & 28,5914 & 0,89498 \\
\hline 59 & $\operatorname{Pr}$ & Interpolado & $\operatorname{Pr}-\mathrm{L} \alpha$ & 1,003 & 1.0000 & 1,00279 \\
\hline 60 & $\mathrm{Nd}$ & $\mathrm{NdO}_{2}$ & Nd-Laa & 48,142 & 45,8729 & 1,04946 \\
\hline 62 & $\mathrm{Sm}$ & $\mathrm{Sm} / \mathrm{Co}$ & Sm-L $\beta 1$ & 90,62 & 53,4627 & 1,69501 \\
\hline 64 & $\mathrm{Gd}$ & $\mathrm{Gd}_{2} \mathrm{O}$ & $\mathrm{Gd}-\mathrm{L} \alpha$ & 301,859 & 98,1961 & 3,07404 \\
\hline 65 & $\mathrm{~Tb}$ & Interpolado & Tb-L $\alpha$ & 3,499 & 1.0000 & 3,49894 \\
\hline 66 & Dy & $\mathrm{DyO}_{2}$ & Dy-L $\alpha$ & 386,86 & 98,442 & 3,92983 \\
\hline 70 & $\mathrm{Yb}$ & $\mathrm{Yb}_{2} \mathrm{O}$ & Yb-L $\alpha$ & 584,331 & 98,7543 & 5,91702 \\
\hline 72 & $\mathrm{Hf}$ & $\mathrm{HfO}_{2}$ & $H f-L \alpha$ & 591,723 & 100.0000 & 5,91723 \\
\hline 73 & Ta & Ta-metal & Ta-L $\alpha$ & 644,387 & 100.0000 & 6,44397 \\
\hline 74 & W & W-metal & W-L $\alpha$ & 686,377 & 100.0000 & 6,86377 \\
\hline 77 & Ir & $\mathrm{Pd} / \mathrm{lr}$ & $\operatorname{Ir}-\mathrm{L} \alpha$ & 114,789 & 13,2535 & 8,66106 \\
\hline 78 & $\mathrm{Pt}$ & $\mathrm{Pt} / \mathrm{Rh}$ & Pt-L $\alpha$ & 848,858 & 93,3191 & 9,09629 \\
\hline 79 & $\mathrm{Au}$ & Au-metal & $A u-L \alpha$ & 923,266 & 100.0000 & 9,23266 \\
\hline 80 & $\mathrm{Hg}$ & $\mathrm{HgCl}$ & $\mathrm{Hg}-\mathrm{L} \alpha$ & 946,129 & 93,8663 & 10,07953 \\
\hline 81 & $\mathrm{TI}$ & TTAs & Ta-L $\alpha$ & 500,243 & 45,3326 & 11,03495 \\
\hline
\end{tabular}


APÊNDICE B - Materiais utilizados (MU), linhas de emissão, intensidades experimentais $\left(I E X^{*}\right)$ e teóricas $\left(I T^{* *}\right)$ e sensibilidade (S) determinada para os elementos $B$ a $U$ para o espectrômetro Rigaku Co.; RIX 3000.

\begin{tabular}{ccccccc} 
№ Atômico & Elemento & $\mathrm{MU}$ & Linhas & $\mathrm{I} \mathrm{EX}^{*}$ & $\mathrm{I} \mathrm{T}^{* *}$ & $\mathrm{~S}$ \\
\hline 82 & $\mathrm{~Pb}$ & $\mathrm{~Pb}-$ metal & $\mathrm{Pb}-\mathrm{L} \beta 1$ & 1151,912 & 100.0000 & 11,51912 \\
83 & $\mathrm{Bi}$ & $\mathrm{Bi}$ & $\mathrm{Bi}-\mathrm{L} \alpha$ & 490,635 & 42,6366 & 11,50737 \\
90 & $\mathrm{Th}$ & $\mathrm{ThO}_{2}$ & $\mathrm{Th}-\mathrm{L} \alpha$ & 990,813 & 83,4076 & 11,87917 \\
92 & $\mathrm{U}$ & $\mathrm{U}_{3} \mathrm{O}_{8}$ & $\mathrm{U}-\mathrm{L} \alpha$ & 1218,081 & 97,5802 & 12,48287 \\
\hline
\end{tabular}

$\mathrm{I} E X^{\star}=$ Intensidade Experimental (kcps)

I T $T^{* *}=$ Intensidade calculada - Método de Parâmetros Fundamentais (kcps) 
APÊNDICE C - Curva de sensibilidade instrumental para as linhas de emissão $\mathrm{K}$ e $\mathrm{L}$ do espectrômetro de fluorescência de raios $\mathrm{X}$, WDRXF RIGAKU Co., RIX 3000.

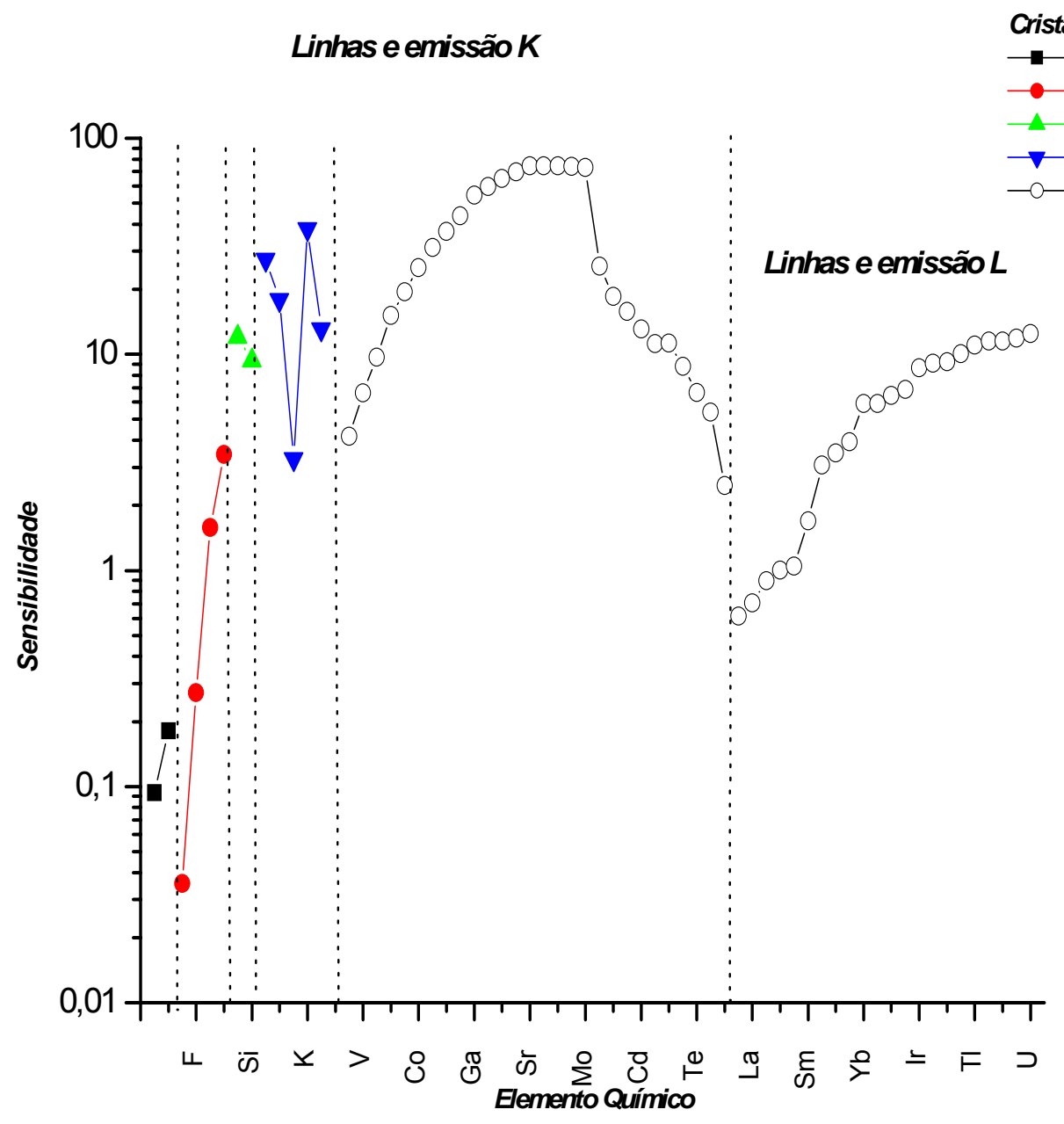


APÊNDICE D - Valores calculados de Limites Quantificação dos elementos O à U utilizando as amostras MU, do APÊNDICE B.

\begin{tabular}{|c|c|c|c|}
\hline Elemento & $\mathrm{LQ}\left(\mu \mathrm{g} \mathrm{g}^{-1}\right)$ & Elemento & $\mathrm{LQ}\left(\left(\mu \mathrm{g} \mathrm{g} \mathrm{g}^{-1}\right)\right.$ \\
\hline 0 & 5 & $\mathrm{Sn}$ & 28 \\
\hline $\mathrm{F}$ & 5 & $\mathrm{Sb}$ & 31 \\
\hline $\mathrm{Na}$ & 5 & $\mathrm{Te}$ & 31 \\
\hline $\mathrm{Mg}$ & 5 & 1 & 32 \\
\hline $\mathrm{Al}$ & 5 & Cs & 42 \\
\hline $\mathrm{Si}$ & 5 & $\mathrm{Ba}$ & 10 \\
\hline$P$ & 5 & La & 11 \\
\hline$S$ & 5 & $\mathrm{Ce}$ & 10 \\
\hline $\mathrm{Cl}$ & 7 & $\operatorname{Pr}$ & 11 \\
\hline $\mathrm{K}$ & 5 & $\mathrm{Nd}$ & 10 \\
\hline $\mathrm{Ca}$ & 6 & $\mathrm{Sm}$ & 9 \\
\hline $\mathrm{Ti}$ & 15 & $\mathrm{Gd}$ & 6 \\
\hline V & 10 & $\mathrm{~Tb}$ & 5 \\
\hline $\mathrm{Cr}$ & 7 & Dy & 6 \\
\hline $\mathrm{Mn}$ & 7 & $\mathrm{Yb}$ & 6 \\
\hline $\mathrm{Fe}$ & 7 & $\mathrm{Hf}$ & 7 \\
\hline Co & 7 & $\mathrm{Ta}$ & 8 \\
\hline $\mathrm{Ni}$ & 8 & W & 8 \\
\hline $\mathrm{Cu}$ & 9 & Ir & 8 \\
\hline $\mathrm{Zn}$ & 13 & $\mathrm{Pt}$ & 10 \\
\hline $\mathrm{Ga}$ & 9 & $\mathrm{Au}$ & 10 \\
\hline $\mathrm{Ge}$ & 9 & $\mathrm{Hg}$ & 10 \\
\hline As & 10 & $\mathrm{TI}$ & 8 \\
\hline $\mathrm{Br}$ & 15 & $\mathrm{~Pb}$ & 12 \\
\hline $\mathrm{Sr}$ & 15 & $\mathrm{Bi}$ & 10 \\
\hline$Y$ & 15 & Th & 15 \\
\hline $\mathrm{Zr}$ & 16 & $U$ & 17 \\
\hline $\mathrm{Nb}$ & 19 & & \\
\hline Mo & 21 & & \\
\hline $\mathrm{Pd}$ & 36 & & \\
\hline $\mathrm{Ag}$ & 37 & & \\
\hline $\mathrm{Cd}$ & 32 & & \\
\hline In & 32 & & \\
\hline
\end{tabular}


APÊNDICE E - Intensidades de sinal (unidade arbitrária) para os compostos orgânicos identificados por GC/MS

\begin{tabular}{lccccc}
\hline Compostos & \multicolumn{5}{c}{ Amostras } \\
\cline { 3 - 6 } & PRC & A1 & B4 & C4 & D4 \\
$\mathrm{C}_{5} \mathrm{H}_{13} \mathrm{NO}$ & 2560242 & 3234199 & 3266540 & 3353132 & 7238292 \\
$\mathrm{C}_{13} \mathrm{H}_{28}$ & 3024479 & 19358007 & 19551587 & 18898131 & 18898131 \\
$\mathrm{C}_{16} \mathrm{H}_{34}$ & 2909510 & 14144757 & 1428205 & 1246257 & 10975841 \\
$\mathrm{C}_{5} \mathrm{H}_{13} \mathrm{NO}_{3}$ & 9391383 & 17313673 & 17486810 & 19618339 & 47994541 \\
$\mathrm{C}_{8} \mathrm{H}_{18} \mathrm{O}_{3}$ & 3521810 & 8131142 & 8212453 & 7771038 & 30385574 \\
$\mathrm{C}_{10} \mathrm{H}_{22} \mathrm{~N}_{2}$ & 2554936 & 3995353 & 4035307 & 4283436 & 7884477 \\
$\mathrm{C}_{10} \mathrm{H}_{18} \mathrm{O}$ & 10261164 & 18111443 & 18292557 & 13646142 & 46487635 \\
$\mathrm{C}_{716} \mathrm{O}$ & 1489705 & 2930122 & 2959423 & 2930122 & 9123912 \\
$\mathrm{C}_{9} \mathrm{H}_{22} \mathrm{~N}_{2}$ & 4226496 & 8691787 & 8778705 & 7827537 & 19688240 \\
\hline
\end{tabular}


APÊNDICE F - Intensidades de sinal relativas (\%) dos compostos orgânicos determinados por GC/FID.

\begin{tabular}{lccccc}
\hline Compostos & \multicolumn{5}{c}{ Amostras } \\
\hline & $\mathrm{PRC}$ & $\mathrm{A} 1$ & $\mathrm{~B} 4$ & $\mathrm{C} 4$ & $\mathrm{D} 4$ \\
& $(\%)$ & $(\%)$ & $(\%)$ & $(\%)$ & $(\%)$ \\
\hline $\mathrm{C}_{5} \mathrm{H}_{13} \mathrm{NO}$ & 13,0 & 16,5 & 16,6 & 17,1 & 36,8 \\
$\mathrm{C}_{13} \mathrm{H}_{28}$ & 3,8 & 24,3 & 24,5 & 23,7 & 23,7 \\
$\mathrm{C}_{16} \mathrm{H}_{34}$ & 9,5 & 46,1 & 4,7 & 4,1 & 35,7 \\
$\mathrm{C}_{5} \mathrm{H}_{13} \mathrm{NO} \mathrm{N}_{3}$ & 8,4 & 15,5 & 15,6 & 17,5 & 42,9 \\
$\mathrm{C}_{8} \mathrm{H}_{18} \mathrm{O}_{3}$ & 6,1 & 14,0 & 14,2 & 13,4 & 52,4 \\
$\mathrm{C}_{10} \mathrm{H}_{22} \mathrm{~N}_{2}$ & 11,2 & 17,6 & 17,7 & 18,8 & 34,7 \\
$\mathrm{C}_{10} \mathrm{H}_{18} \mathrm{O}$ & 9,6 & 17,0 & 17,1 & 12,8 & 43,5 \\
$\mathrm{C}_{716} \mathrm{O}$ & 7,7 & 15,1 & 15,2 & 15,1 & 46,9 \\
$\mathrm{C}_{9} \mathrm{H}_{22} \mathrm{~N}_{2}$ & 8,6 & 17,7 & 17,8 & 15,9 & 40,0 \\
\hline
\end{tabular}


APÊNDICE G - Matriz casos \& variáveis, amostras controle (A1), irradiadas com dose absorvida de 500 kGy, após adição de $\mathrm{H}_{2} \mathrm{O}_{2}$ (B4) e água Miili-Q (50 e 70\% v/v), (C4 e D4) e amostra reciclada por processo convencional (PRC).

\begin{tabular}{lccccc}
\hline Casos & \multicolumn{5}{c}{ Variáveis } \\
\hline $\mathrm{S}$ & $\mathbf{A 1}$ & $\mathbf{B 4}$ & $\mathbf{C 4}$ & $\mathbf{D 4}$ & PRC \\
$\mathrm{P}$ & 11896 & 7479 & 6890 & 3809 & 4990 \\
$\mathrm{Cl}$ & 571 & 426 & 332 & 306 & 13 \\
$\mathrm{Si}$ & 571 & 332 & 306 & 283 & $<10$ \\
$\mathrm{Ca}$ & 221 & 122 & 116 & 97 & $<10$ \\
$\mathrm{Zn}$ & 84 & 49 & 45 & 42 & 67 \\
$\mathrm{Ni}$ & 55 & 23 & 22 & 19 & 10 \\
$\mathrm{Cor}$ & 18 & 11 & 10 & $<10$ & $<10$ \\
$\mathrm{Viscosidade}$ & 1,59 & 1,09 & 1,26 & 1,31 & 1,37 \\
$\mathrm{Densidade}$ & 85092 & 87118 & 89144 & 91170 & 94209 \\
$\mathrm{C}_{5} \mathrm{H}_{13} \mathrm{NO}$ & 0,92 & 0,92 & 0,87 & 0,81 & 0,95 \\
$\mathrm{C}_{1} \mathrm{H}_{28}$ & 16,45 & 16,62 & 17,06 & 36,83 & 13,02 \\
$\mathrm{C}_{16} \mathrm{H}_{34}$ & 24,27 & 24,52 & 23,70 & 23,70 & 3,79 \\
$\mathrm{C}_{5} \mathrm{H}_{13} \mathrm{NO} \mathrm{N}_{3}$ & 46,06 & 4,65 & 4,05 & 35,74 & 9,47 \\
$\mathrm{C}_{8} \mathrm{H}_{18} \mathrm{O}_{3}$ & 15,48 & 15,64 & 17,54 & 42,92 & 8,39 \\
$\mathrm{C}_{10} \mathrm{H}_{22} \mathrm{~N}_{2}$ & 14,01 & 14,15 & 13,39 & 52,36 & 6,06 \\
$\mathrm{C}_{10} \mathrm{H}_{18} \mathrm{O}$ & 17,55 & 17,73 & 18,82 & 34,65 & 11,22 \\
$\mathrm{C}_{7} \mathrm{H}_{16} \mathrm{O}$ & 16,95 & 17,12 & 12,77 & 43,52 & 9,60 \\
$\mathrm{C}_{9} \mathrm{H}_{22} \mathrm{~N}_{2}$ & 15,07 & 15,22 & 15,07 & 46,94 & 7,66 \\
\hline & 17,66 & 17,83 & 15,90 & 40,00 & 8,58 \\
\hline
\end{tabular}


APÊNDICE H - Matriz caso \& variáveis, valores normalizados por meio do Método Ward, utilizando o software Statisitca,versão 6.

\begin{tabular}{lccccc}
\hline Casos & \multicolumn{7}{c}{ Variáveis } & & \\
\hline $\mathrm{S}$ & $\mathbf{A 1}$ & $\mathbf{B} 4$ & $\mathbf{C 4}$ & $\mathbf{D 4}$ & $\mathbf{P R C}$ \\
$\mathrm{P}$ & $-0,715$ & $-0,650$ & $-0,646$ & $-0,671$ & $-0,679$ \\
$\mathrm{Cl}$ & $-0,717$ & $-0,651$ & $-0,647$ & $-0,671$ & $-0,681$ \\
$\mathrm{Si}$ & $-0,717$ & $-0,651$ & $-0,647$ & $-0,671$ & $-0,681$ \\
$\mathrm{Ca}$ & $-0,717$ & $-0,651$ & $-0,647$ & $-0,671$ & $-0,681$ \\
$\mathrm{Zn}$ & $-0,717$ & $-0,651$ & $-0,647$ & $-0,671$ & $-0,681$ \\
$\mathrm{Ni}$ & $-0,717$ & $-0,651$ & $-0,647$ & $-0,671$ & $-0,681$ \\
$\mathrm{Cor}$ & $-0,717$ & $-0,651$ & $-0,647$ & $-0,671$ & $-0,681$ \\
$\mathrm{Viscosidade}$ & $-0,717$ & $-0,651$ & $-0,647$ & $-0,671$ & $-0,681$ \\
$\mathrm{Densidade}$ & $-0,705$ & $-0,638$ & $-0,633$ & $-0,665$ & $-0,651$ \\
$\mathrm{C}_{5} \mathrm{H}_{13} \mathrm{NO}$ & $-0,717$ & $-0,651$ & $-0,647$ & $-0,671$ & $-0,681$ \\
$\mathrm{C}_{1} \mathrm{H}_{28}$ & $-0,258$ & $-0,171$ & $-0,130$ & $-0,207$ & 0,146 \\
$\mathrm{C}_{16} \mathrm{H}_{34}$ & 2,030 & 2,224 & 2,270 & 0,541 & 0,296 \\
$\mathrm{C}_{5} \mathrm{H}_{13} \mathrm{NO} \mathrm{NO}_{3}$ & 1,290 & $-0,441$ & $-0,455$ & 0,033 & 0,259 \\
$\mathrm{C}_{8} \mathrm{H}_{18} \mathrm{O}_{3}$ & 1,740 & 1,920 & 2,381 & 2,408 & 2,354 \\
$\mathrm{C}_{10} \mathrm{H}_{22} \mathrm{~N}_{2}$ & 0,437 & 0,557 & 0,552 & 1,278 & 0,457 \\
$\mathrm{C}_{10} \mathrm{H}_{18} \mathrm{O}$ & $-0,150$ & $-0,058$ & 0,014 & $-0,165$ & 0,145 \\
$\mathrm{C}_{7} \mathrm{H}_{16} \mathrm{O}$ & 1,853 & 2,039 & 1,459 & 2,312 & 2,635 \\
$\mathrm{C}_{9} \mathrm{H}_{22} \mathrm{~N}_{2}$ & $-0,301$ & $-0,216$ & $-0,195$ & $-0,086$ & $-0,200$ \\
\hline & 0,516 & 0,640 & 0,561 & 0,592 & 0,685 \\
\hline
\end{tabular}


ANEXO A - Coeficientes de Chauvenet

\begin{tabular}{cccc}
\hline $\begin{array}{c}\text { Número de } \\
\text { leituras }(n)\end{array}$ & $k_{(\mathrm{n})}$ & $\begin{array}{c}\text { Número de } \\
\text { leituras }(n)\end{array}$ & $k_{(\mathrm{n})}$ \\
\hline 3 & 1,38 & 25 & 2,33 \\
4 & 1,54 & 50 & 2,57 \\
5 & 1,65 & 100 & 2,81 \\
6 & 1,73 & 300 & 3,14 \\
7 & 1,80 & 500 & 3,29 \\
10 & 1,96 & 1000 & 3,48 \\
15 & 2,13 & $* * *$ & $* * *$ \\
\hline
\end{tabular}

FONTE - SCAPIN, M. A. Aplicação da Difração e Fluorescência de Raios X (WDXRF): Ensaios em Argilominerais. Dissertação (Mestrado) - Instituto de Pesquisas Energéticas e Nucleares, São Paulo, 2003. p. 50 
ANEXO B - Algoritmos de Parâmetros Fundamentais

Equação para o cálculo da intensidade teórica:

$$
I_{i}=I_{P i}+I_{S i}
$$

Na qual:

$I_{i} \equiv$ intensidade teórica;

$I_{P i} \equiv$ excitação primária e

$I_{\text {Si }} \equiv$ excitação secundária.

Equações para os cálculos das intensidades de excitação primária e secundária

$$
\begin{gathered}
I_{P i}=\frac{K\left(\lambda_{l}\right)}{\operatorname{sen} \psi_{2}} \int_{\lambda \min }^{\lambda_{e}^{i}} \frac{Q_{i}(\lambda)}{X} I_{0}(\lambda) d \lambda \\
I_{S i}=\frac{K\left(\lambda_{i}\right)}{2 \operatorname{sen} \psi_{2}} \sum_{j} \int_{\lambda \min }^{\lambda_{e}^{j}} \frac{Q_{j}(\lambda) Q\left(\lambda_{j}\right)}{X} I_{0}(\lambda) . Y . d \lambda
\end{gathered}
$$

Equações para a obtenção dos algoritmos Q, X e Y

$$
\begin{gathered}
Q_{i}(\lambda)=\tau_{i}(\lambda) W_{i}\left(1-\frac{1}{j_{i}}\right) \omega_{i} R_{p}^{i} \\
X=\frac{\mu(\lambda)}{\operatorname{sen} \psi_{1}}+\frac{\mu\left(\lambda_{i}\right)}{\operatorname{sen} \psi_{2}} \\
Y=\frac{\operatorname{sen} \psi_{1}}{\mu(\lambda)} \ln \left[1+\frac{\mu(\lambda)}{\mu\left(\lambda_{j}\right) \operatorname{sen} \psi_{1}}\right]+\frac{\operatorname{sen} \psi_{2}}{\mu\left(\lambda_{i}\right)} \ln \left[1+\frac{\mu\left(\lambda_{i}\right)}{\mu\left(\lambda_{j}\right) \operatorname{sen} \psi_{2}}\right]
\end{gathered}
$$

FONTE - SCAPIN, M. A. Aplicação da Difração e Fluorescência de Raios X (WDXRF): Ensaios em Argilominerais. Dissertação (Mestrado) - Instituto de Pesquisas Energéticas e Nucleares, São Paulo, 2003. p. 6, 7 e 8. 
ANEXO B - Algoritmos de Parâmetros Fundamentais

Abreviações utilizadas nas equações para os cálculos da intensidade teórica

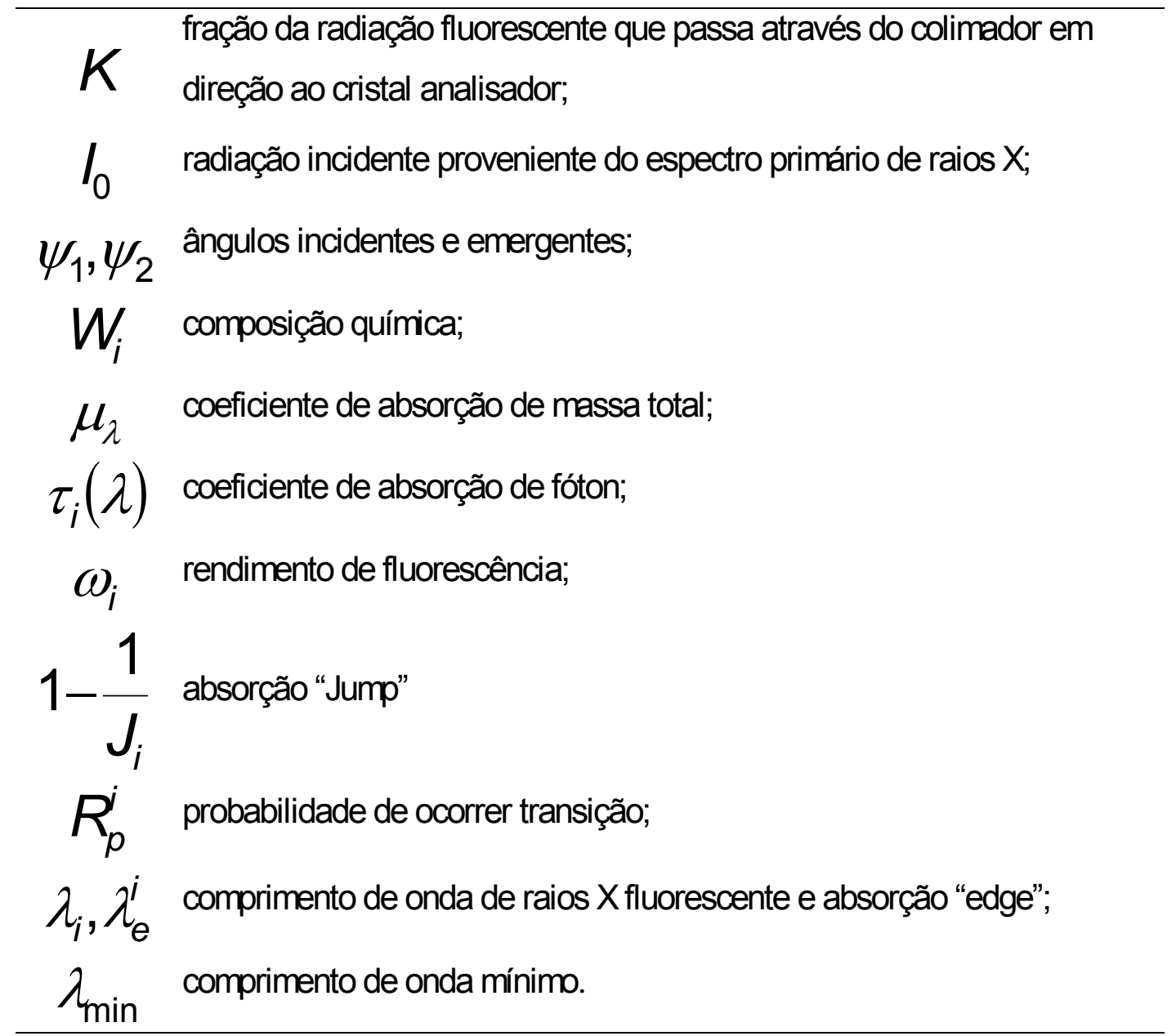

FONTE - SCAPIN, M. A. Aplicação da Difração e Fluorescência de Raios X (WDXRF): Ensaios em Argilominerais. Dissertação (Mestrado) - Instituto de Pesquisas Energéticas e Nucleares, São Paulo, 2003. p. 9 


\section{REFERÊNCIAS BIBLIOGRÁFICAS}

1. ABNT - Associação Brasileira de Normas Técnicas. Classificação de Resíduos Sólidos, NBR10004, Rio de Janeiro, 1987.

2. ALMEIDA, M.R., SATO, I. M., DUARTE, C. L., SAMPA, M. H. O., SALVADOR, V. L. R and SCAPIN, M. A. Application of the electron-beam treatment for $\mathrm{Ca}, \mathrm{Si}, \mathrm{P}, \mathrm{Al}, \mathrm{Fe}, \mathrm{Cr}, \mathrm{Zn}, \mathrm{Co}, \mathrm{As}$, Se, $\mathrm{Cd}$ and $\mathrm{Hg}$ removal in the simulated and actual industrial effluents, Radiation Physics and Chemistry, v 71, p. 425-428, 2004.

3. ALMEIDA, KCS; OIKAWA, H; OLIVEIRA, J, et al. Degradation of petroleum hydrocarbons in seawater by ionizing radiation. Journal of Radioanalytical and Nuclear Chemistry. v 270, p. 93-97, 2006.

4. ALMEIDA, K. C. S. Avaliação da contaminação da água do mar por benzeno, tolueno e xileno na região de Ubatuba, litoral norte (SP) e estudo da degradação destes compostos por radiação ionizante. 2006. Dissertação (Mestrado) - Instituto de Pesquisa Energéticas e Nucleares, São Paulo.

5. ANP - Agência Nacional do Petróleo. Portaria $\mathbf{N}^{\circ} 129$, de julho de 1999. Disponível em:

< http://www.anp.gov.br/doc/petroleo/P12999.doc>. Acesso em: 10 nov. 2007.

6. AZEVEDO, P. U.E. Revisión y análisis de lãs experiências de Argentina, Brasil, Colombia, Ecuador y México respecto a los cinco elementos claves para El manejo ambiental de lubrificantes usados. Reporte final analítico, REPAMAR, Buenos Aires, argentina, Junho de 2002.

7. BORGES, S.S., KORN, M. Geração sonoquímica de oxidantes em solução aquosa saturada de tetracloreto de carbono. Quim. Nova, v. 25, n. 4, p. 558-562, 2002.

8. BORRELY, S. I., SAMPA, M. H. O., PEDROSO, C. B., OIKAWA, H., SILVEIRA, C. G., CHERBAKIAN, E. H. and SANTOS, M. C. F. Radiation processing of wastewater evaluated by toxicity assays. Radiation Physics and Chemistry, v. 57, p. 507-511, 2000. 
9. CASTANHO, A.. D. A. A determinação quantitativa de fontes de material particulado na atmosfera da cidade de São Paulo. Dissertação (Mestrado) - Universidade de São Paulo,Instituto de Física, São Paulo, 1999.

10. CEMPRE - Compromisso empresarial para reciclagem. Óleos lubrificantes usados. Disponível em:

$<$ http://www.cempre.org.br/fichas tecnicas.php?lnk=ft oleo usado.php>.

Acesso em: 11 de nov. 2007.

11. CETESB - Companhia de Tecnologia de Saneamento Ambiental.

Reciclagem de óleos de corte, hidráulicos e lubrificantes na indústria metalúrgica. Produção mais limpa. Disponível em:

<http://www.cetesb.sp.gov.br/Tecnologia/producao limpa/casos/caso25.pdf>.

Acesso em: 11 de nov. 2007.

12. $\mathrm{CCl}-$ Centro centífico independente. Disponível em:

$\leq$ http://paginas.fe.up.pt/ jotace/temaspolemicos/oleosusados.html>.

Acesso em: 29 de nov. 2005.

13. CIORA R J; LIU P K T. Purification of used lubricating oils for removal of ash, color and/or odor, by using a combination of membranebased and adsorption-based processes. Pat. US6024880-A, 2000.

14. CHITOSE, N.; UETA, S.; SEINO, S.; YAMAMOTO, T. A. Radiolysis of aqueous phenol solutions with nanoparticles. Phenol degradations and toc removal in uv, $\gamma$ ray and electron beans. Chemosfere. 50(8): 1007-1013, 2003.

15. CLOUGH, R.L. \& SHALABY, W.S. Radiation Effects on Polymers. Amer.Chem. Soc., Washington, DC, 1991.

16. CONAMA - Conselho Nacional do Meio Ambiente. Resolução $\mathbf{N}^{\circ} \mathbf{3 6 2}$, de 23 de Junho de 2005. Disponível em:

<http://www.mma.gov.br/port/conama/res/res93/res0993.htmL>.

Acesso em: 18 de jun. 2007.

17. CONSELHO EM REVISTA. Conselho Regional de engenharia, arquitetura e agronomia do Rio Grande do Sul. Mais rigor no controle de lubrificante. Ano II, v. 13, p. 11-13, 2005. 
18. COOPER, W.J.; NICKELSEN, M. G.; LIN, K., SUTNICK, M.; MAK, F.T.; KURUCZ, C. N.; WAITE, T. D. E-Beam treatment of aqueous based toxic organic wastes. In: PROCEEDINGS ON RADIATIUON CURING CONFERENCE EXPOSITION HELD: Proceedings..., Boston, 1992. p. 509513.

19. CRAINGHILL, A.; POWELL, J., Lifecycle assessment and economic evaluation of recycling: a case study. Resources, Conservation and Recycling. n. 17, p. 75-96, 1996.

20. DEP, Departament of enviromental protection, Recycle used motor oil. Disponível em:

<http://www.dep.state.pa.us/cgi apps/oil/>. Acesso em: 29 de nov. 2005.

21. DEUTSCH R. Separation and recovery of synthetic oils from used motor sump oils, comprising mixture of mineral and synthetic oils, comprises use of cryogenic method. Pat. EP1028158-A; EP1028158-A1; FR2789692-A1, 2001.

22. DUARTE, C. L. Aplicação do processo avançado de oxidação por feixe de elétrons na degradação de compostos orgânicos presentes em efluentes industriais. 1999. Tese (Doutorado) - Instituto de Pesquisa Energéticas e Nucleares, São Paulo.

23. DUARTE, C. L., GERALDO, L. L., JUNIOR, P. O. A., BORRELY, S. I., SATO, I. M. SAMPA, M. H. O. Treatment of effluents from petroleum production by electron beam irradiation. Radiation Physics and Chemistry, v.71,n.1, p. 443-447, 2004.

24. EKAVALL, T.; Key methodological issues for life cycle inventory analysis of paper recycling. Journal of Cleaner Production. v.7, p. 281-294, 1999.

25. EUROCHEM/CITAC GUIDE, 4715-92, Quantifying Uncertainty in Analytical Measurement, second edition, 2000.

26. FAKHRI N. Treatment of waste oil comprises dehydrating waste oil, supplying dehydrated waste oil to fractionated distillation column, and withdrawing bottom product, side streams, and overhead product. Pat. WO2004011579-A1; CA2396206-A1; AU2003249818-A1, 2004. 
27. FARHATAZIZ, I \& RODGERS, M.A.J. Radiation Chemistry: Principles and Applications. VCH. Publishers, Inc New York , 1987.

28. GETOFF, N. Factors influencing the efficiency of radiation-induced degradation of water pollutants. Radiation Physics and Chemistry, v. 65, n. 4, p. 437-446, 2002.

29. HAMAD, A; AL-ZUBAIDY, E; FAYED, ME. Used lubricating oil recycling using hydrocarbon solvents. Journal of Environmental Management, v. 74, $\mathrm{n}$. 2, p. 153-159, 2005.

30. HAIR, J.F.JR. et al. Análise multivariada de dados. 5 ed. Porto Alegre: bookman, p. 593, 2005.

31. INMETRO. Guia para a expressão da incerteza de medição. 2ed. Rio de Janeiro: ABNT; INMETRO; SBM, 1998. 121p.

32. INMETRO. Orientações sobre validação de métodos de ensaios químicos. DOQ-CGCRE-008, São Paulo, mar. 2003. Disponível em:< http://www.inmetro.gov.br/Sidoq/Arquivos/CGCRE/DOQ/DOQ-CGCRE-

8 02.pdf>. Acesso em: 12 dez. 2007.

33. INSTITUTO MEXICANO DEL PETRÓLEO. Regeneration of spent lubricating oils by supercritical solvents comprises filtration for selective extraction of hydrocarbons and re-use of solvents. Pat. MX2005007587-A1, 2007.

34. KING COUTRY - Enviromental Purchasing Program. Environmentally Preferable Lubricants. Disponível em:

$<$ http://www.metroc.gov/procedure/green/oil.htm>.

Acesso em: 29 de nov. 2005.

35. LACHANCE. G. R., CLAISSE, F., Quantitative X-ray fluorescence analysis - Theory and Application. Wiley, London, 1995.

36. LANGE, L. C., ALVES, J. F., AMARAL, M. C. S., MELO JUNIOR, W. R., Tratamento de lixiviado de aterro sanitário por processo oxidativo avançado empregando reagente de fenton. Eng. Sanit. Ambient., vol.11 n.2, 2006. 
37. LIN, K.; COOPER, W. J.; NICKELSEN, M. G.; KURUCUZ, C. N.; WAITE, T. D. Decomposition of aqueous solutions of phenol using energy electron beam irradiation - a large scale study. Applied Radiation and Isotopes, v. 46, n. 12, p. 1307-1316, 1995.

38. LWART PROASFAR. Disponível em: <http://www.Iwart.com.br/proasfar.asp>. Acesso em: 27 de nov. 2007.

39. LWART. Disponível em: <http://www.Iwart.com.br>. Acesso em: 27 de nov. 2005.

40. MAGALHÃES, J. M.; DONOSO, F. F.; MELO, P. L .R. Re-refino no Brasil: A reciclagem de óleos usados. .Net, Universidade do Vale do Rio do Sinos. Disponível em:

<http://www.ead.fea.usp.br/semead/10semead/sistema/resultado/trabalhosPDF 1584.pdf>. Acesso em: 30 de nov. 2007.

41. MEDINA, H., GOMES, D. Gestão ambiental na indústria automobilística, ENEGEP, 2001.

42. MINCHER, B.; LIEKHUS, K.; ARBON, R. E. Pcb radiolysis in isooctane in the presence of ozone. Appl. Radiat. , 47 (8), p. 713-715, 1996.

43. MINISTÉRIO DO MEIO AMBIENTE. Disponível em:

<http://www.mma.gov.br/port/conama/res/res93/res0993.html>. Acesso em: 27 de nov. 2007.

44. MIRKIN, G.; ZAYKINA, R. F.; ZAYKIN, YU. A. Radiation methods for upgrading and refining of feedstock for oil chemistry. Radiation Physics and Chemistry, v. 67, p. 311-314, 2003.

45. MORI, M. N. Descontaminação de embalagens descartadas clorpirifós utilizando o processo de oxidação avançada por radiação ionizante. Dissertação (Mestrado) - Instituto de Pesquisas Energéticas e Nucleares, São Paulo, 2006.

46. MORRISON, D. F. Multivariate statistical methods. 4 ed. New York: Duxbury Press, p. 415, 2003 
47. NAGATA, N., BUENO, M. I. M. S. Métodos matemáticos para correção de interferências espectrais e efeitos interelementos na análise quantitativa por fluorescência de raios-X, Quim. Nova, Vol. 24, N 4, 531-539, 2001.

48. NICKELSEN, M. G.; COOPER, W.J. Removal of benzene and selected alkyl-substituted benzenes from aqueous solution utilizing continuous highenergy electron irradiation. Environmental science technology, v. 26, p. 144152, 1992.

49. NOGUEIRA, R. F. P.; GUIMARÃES, J. R. Processos oxidativos avançados: uma alternative para o tratamento de efluentes. Engenharia Sanitária e Ambiental. 3(3), p. 97-100, 1998.

50. PETROQUIMICA DO SUL. Disponível em:

<http://www.petroquimicasul.com.br>. Acesso em: 29 de nov. 2005.

51. PIKAEV, A. K.; SHUBIN, V. N.. Radiation treatment of liquid waste. Radiation Physics and Chemistry. 24(1), p. 77-97, 1984.

52. PIKAEV, A. K. Current state of radiation processing. Russian Chemical Reviews, v. 64 , n.6 p. 569-598, 1995. Disponível em:

<http://www.turpion.org/php/paper.phtml?journal id=rc\&paper id=165>, Acesso em: 15 de nov. 2007.

53. PODZOROVA, E. A. New developments in radiation-chemical technology of sewage treatment. Radiation Physics and Chemistry, v. 46, p. 1129-1132, 1995.

54. POPOV, P.; GETOFF, N. New Radiation-induced degradation of aqueous fluoranthene. Radiation Physics and Chemistry, v. 72 (1), p. 19-24, 2005.

55. QU, Z; YAN, NQ; ZHAO, YF, et al.. Removal of dibenzothiophene from the simulated petroleum by gamma-irradiation induced reaction. Applied Catalysis B-Environmental, v. 71, p. 108-115, 2007.

56. QU, Z; YAN, NQ; JIA, JP, et al. Removal of dibenzothiophene from simulated petroleum by integrated gamma-irradiation and Zr/alumina catalyst. Energy \& Fuels, v. 20, p. 142-147, 2006. 
57. ROSA 1 CO LTD. Cherednichenko $O A$; Cherednichenko $R \quad O$; Cherednichenko S O, et al. Lubricating oil regeneration. Pat. RU2266316-C1; WO2006028408-A2; EP1795583-A2.

58. ROSS, S.; EVANS, D. The environmental effect of reusing and recycling a plastic-based packaging system. Journal of cleaner production, v. 11, $p$. 737-751, 2003.

59. ROUSSEAU, R., Detection limit and estimate of uncertainty of analytical XRF results, The Rigaku Journal, vol. 18, n. 2, 2001.

60. SAKAMOTO, A.; MYIATA, T. Treatment of waste water by a combined technique of radiation and conventional method. Radiation Physics and Chemistry, v. 24(1), p. 99-115, 1984.

61. SATO, I. M. Determinação dos produtos de fissão em rejeito líquido de atividade alta por fluorescência de raios $X$.Correção da interferência espectral pela razão das intensidades. 1988. Tese (Doutorado) - Instituto de Pesquisa Energéticas e Nucleares, São Paulo.

62. SCAPIN, M.A., SALVADOR, V.L.R., and SATO, I.M., Determination of $\mathrm{Na}, \mathrm{Al}, \mathrm{Si}, \mathrm{P}, \mathrm{K}, \mathrm{Ca}, \mathrm{Fe}, \mathrm{Co}, \mathrm{Ni}, \mathrm{Cu}$ and $\mathrm{Zn}$ by WD-XRF Spectrometry in Industrial Effluents After an Electron-beam Treatment. Avances in Analísis por Técnicas de Rayos X, ISSN 1515-1565 XI, p. 87-91, 2002.

63. SCAPIN, M. A. Aplicação da Difração e Fluorescência de Raios X (WDXRF): Ensaios em Argilominerais. Dissertação (Mestrado) - Instituto de Pesquisas Energéticas e Nucleares, São Paulo, 2003.

64. SCAPIN, M. A.; DUARTE, C. L; SATO, I. M. Multi-element analysis of lubrificant oil by WDXRF technique. In: X SEMINÁRIO LATINOAMETRICANO DE ANÁLISIS POR TÉCNICAS DE RAYOS X, 20-24, Noviembre, 2006, Arica. Resumos...Chile.

65. SCAPIN ${ }^{\mathrm{a}}$, M. A.; DUARTE, C. L.; SAMPA, M. H. O. and SATO, I. M. Recycling of the used automotive lubricating oil by ionizing radiation process. Radiation Physics and Chemistry, v. 76, p. 1899-1902, 2007. 
66. SCAPIN ${ }^{\mathbf{b}}$, M. A.; DUARTE, C. L.; SATO, I. M. Sulphur removal from used automotive lubricating oil by ionizing radiation. In: INTERNATIONAL NUCLEAR ATLANTIC CONFERENCE, INAC 2007, Sept.29-Oct. 5, 2007, Santos, SP, Brazil. Proceedings... Santos: INAC, 2007. CD-ROM.

67. SCAPIN, M. A.; DUARTE, C. L; BUSTILLOS, J. O. W. V.; SATO, I. M. Assessment of gamma radiolytic degradation on waste lubricating oil by GC/MS and UVIVIS. In: INTERNATIONAL MEETING ON RADIATION PROCESSING (IMRP), Sept. 21-28, 2008, London. Resumos...UK. Disponível em: <www.imrp2008.com>.

68. SOC TUNISIENE LUBRIFIAN SOTULUB. Merchaoui M H; Khalef N; Jaafar $A$, et al. Rejuvenating contaminated metal working lubricants|by treatment with strong base at elevated tem . Pat. WO9421761-A; EP690903A; ES2124879-T, 1994.

69. SOLPAN, D.; GÜVEN, O. Discoloration and degradation of some textile dyes by gamma irradiation. Radiation Physics and Chemistry, v. 65, p. 549558, 2002.

70. SPINKS, J. W. T.; WOODS, R.J., An introduction to radiation chemistry.Jonh Wiley \& Sons, $3^{\text {th }}$ ed, 1990.

71. SINDIRREFINO - Sindicato Nacional da Indústria do Rerrefino de Óleos Minerais. Disponível em: <http://www.sindirrefino.org.br/>. Acesso em 30 out. 2007.

72. SYCHRA, V.; LANG, I.;SEBOR G. Analysis of petroleum and petroleum products by atomic absorption spectroscopy and related techniques.In: Program Analytical Atomic Spectroscopy, v. 4, p. 341-426, 1981.

73. TAIXING, W.; CRUZ, V.; MEZYK, S. COOPER, W. J.; O'SHEA, E. Gamma radiolysis of methyl t-butyl ether: a study of hydroxyl radical mediated reaction pathways. Radiation Physics and Chemistry, v. 65, p. 335-341, 2002.

74. TIBURTIUS, ERL; PERALTA-ZAMORA, P; EMMEL, A. Treatment of gasoline-contaminated waters by advanced oxidation processes. Journal of Hazardous Materials, v. 126, p. 86-90, 2005. 
75. TOTAL FINA ELF FRANCE SA. Beaupied P. Treatment of spent lubricating oils involves preparing a oil-containing fraction by decantation, followed by preheating and centrifugal separation stages. Pat. FR2845689-A1; WO2004033608-A1; AU2003300481-A1, 2004.

76. VISCOLUBE ITAL SPA. Minana J A G; Schieppati R; Dalla Giovanna F, et al. Processing used mineral oils comprises pretreatment of used oils with basic reagent and then to pre-flash treatment to eliminate water and volatile fractions. Pat. WO9407798-A; EP618959-A; WO9407798-A1, 1994.

77. VIVEIROS, M. Cerca de 28 mil litros de óleo poluem SP por ano. Folha de São Paulo. Disponível em:

<http://www1.folha.uol.com.br/folha/cotidiano/ult95u6713.shl/>. Acesso em 27 nov. 2005.

78. WASIEWICZ, M.; CHMIELEWSKI, A. G.; GETOFF, N. Radiation-induced degradation of aqueous 2,3-dihydroxynaphthalene. Radiation Physics and Chemistry, v. 75, p. 201-209, 2006.

79. ZAYKINA, RF; ZAYKIN, YA; MIRKIN, G, et al. Prospects for irradiation processing in the petroleum industry. Radiation Physics and Chemistry.v. 63, p. 3-6, 2002.

80. ZHANG, S. J.; YU, H. Q. Radiation-induced degradation of polyvinyl alcohol in aqueous solutions. Water Research. 38(2), p. 309-316, 2004. 